\title{
ẢNH HƯởNG CỦA GIỚI TÍNH TỚI Ý ĐỊNH KHỞI NGHIỆP CỦA SINH VIÊN HÀ NộI
}

\author{
Lê Duy Thắng \\ Khoa Kinh tế và Kinh doanh Quốc tế, Đại học Ngoại Thương \\ E-mail: thangld.ftu@gmail.com
}

Nguyễn Thị Kiều Trang

Khoa Kinh tế và Kinh doanh Quốc tế, Đại học Ngoại Thương

E-mail: trangntk.ftu@gmail.com

Tạ Thị Lâm Nhi

Khoa Kinh tế và Kinh doanh Quốc tế, Đại học Ngoại Thương

E-mail: nhita.ftu@gmail.com

\section{ĐỀ TÀI NGHIÊN CỨU KHOA HỌC SINH VIÊN NĂM 2019 - ĐẠI HỌC NGOẠI THƯƠNG}

Giảng viên hướng dẫn: Thạc sỹ Lê Minh Trâm

Hà Nội, 03-06-2019

Bản hiệu chỉnh 
Tên đề tài: ẢNH HƯởNG CỦA GIỚI TÍNH TỚI Ý ĐỊNH KHỞI NGHIỆP CỦA SINH VIÊN HÀ NộI

Giảng viên hướng dẫn chính: Thạc sỹ Lê Minh Trâm

\begin{tabular}{|l|l|l|c|}
\hline Sinh viên thực hiện & \multicolumn{1}{|c|}{ Lớp, khoa, khóa } & Ngành học & \multicolumn{1}{c|}{ Email } \\
\hline Lê Duy Thắng & $\begin{array}{l}\text { Anh 2 - Kinh tế và kinh } \\
\text { doanh quốc tế - K55 }\end{array}$ & $\begin{array}{l}\text { CLC Kinh } \\
\text { tế đối ngoại }\end{array}$ & Thangld.ftu@ gmail.com \\
\hline $\begin{array}{l}\text { Nguyễn Thị Kiều } \\
\text { Trang }\end{array}$ & $\begin{array}{l}\text { Anh 10 - Kinh tế và } \\
\text { kinh doanh quốc tế - } \\
\text { K55 }\end{array}$ & $\begin{array}{l}\text { Kinh tế đối } \\
\text { ngoại }\end{array}$ & trangntk.ftu @ gmail.com \\
\hline Tạ Thị Lâm Nhi & $\begin{array}{l}\text { Anh 3 - Kinh tế và kinh } \\
\text { doanh quốc tế - K55 }\end{array}$ & $\begin{array}{l}\text { Kinh tế đối } \\
\text { ngoại }\end{array}$ & nhita.ftu @ gmail.com \\
\hline
\end{tabular}




\section{MỤC LỤC}

DANH MỤC BẢNG BIỂU

DANH MỤC SƠ ĐỒ



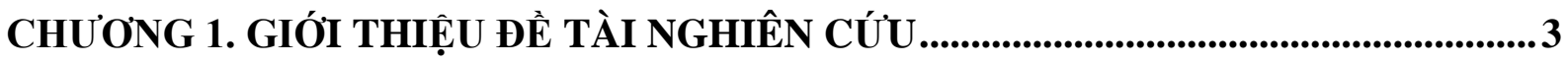



1.2. Mục tiêu nghiên cứu ......................................................................................... 4

1.3. Đối tượng nghiên cứu, phạm vi nghiên cứu .............................................................. 4

1.4. Tổng quan tình hình nghiên cứu ....................................................................... 5

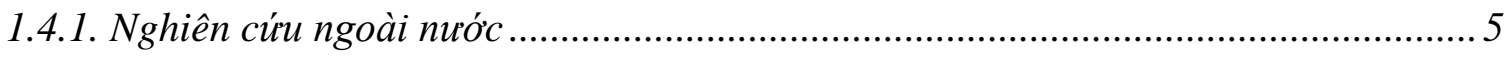



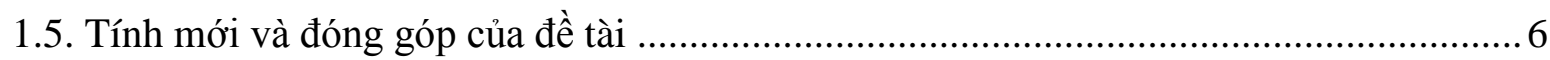

1.6. Kết cấu đề tài .................................................................................................... 7

CHƯƠNG 2. CƠ SỞ LÝ LUẬN VỀ Ý ĐỊNH KHỞI NGHIỆP ........................................8

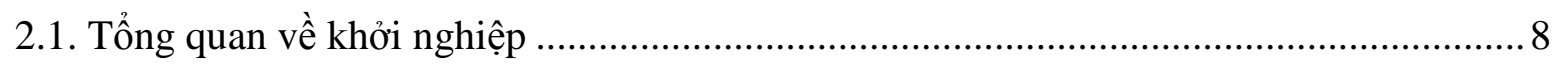

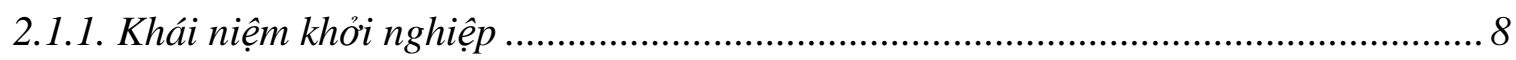



2.1.3. Vai trò của khởi nghiệp đối với sự phát triển kinh tế............................................... 9

2.1.4. Thực trạng khởi nghiệp của sinh viên Hà Nội ....................................................... 11

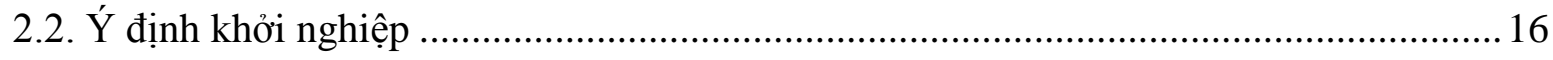

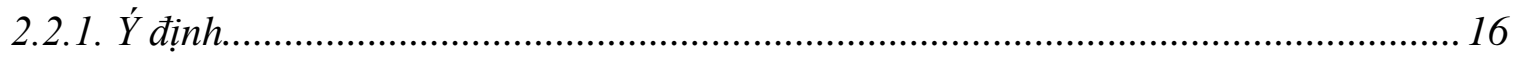

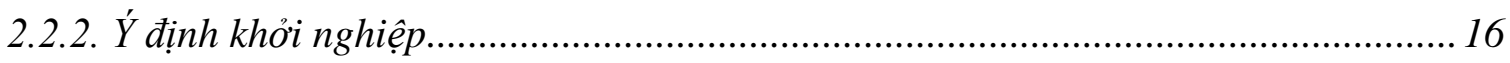

2.3. Các nhân tố ảnh hưởng đến ý định khởi nghiệp ....................................................... 17

2.3.1. Nhóm yếu tố nhân khẩu học (Demographic factors) ............................................ 17

2.3.2. Nhóm yếu tố năng lục cá nhân (Personal Characteristics) .................................... 18

2.3.3. Nhóm yếu tố đặc điểm tính cách (Personality traits)........................................... 19

2.3.4. Nhóm các yếu tố xã hội (Social factors) ….......................................................... 19

2.3.5. Nhóm các yếu tố văn hóa (Cultural factors) ......................................................... 19 
2.3.6. Nhóm các yếu tố môi trương (Environmental factors)............................................ 20

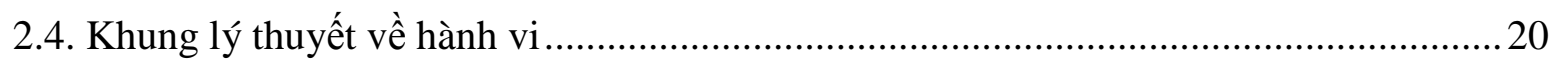

2.4.1. Lý thuyết hành động hợp lý (Theory of Reasoned Action) ..................................... 20

2.4.2. Lý thuyết hành vi có kế hoạch - Theory of planned behaviour (TPB).................... 21

CHƯƠNG 3. MÔ HİNH ĐỀ XUẤT VÀ PHƯƠNG PHÁP NGHIÊN CÚU .....................25

3.1. Quy trình thực hiện nghiên cứu ......................................................................... 25

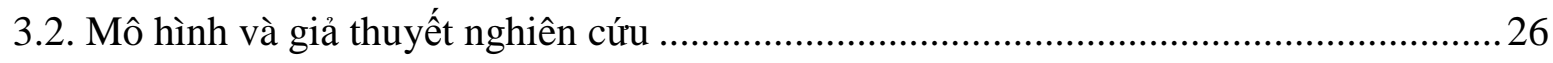

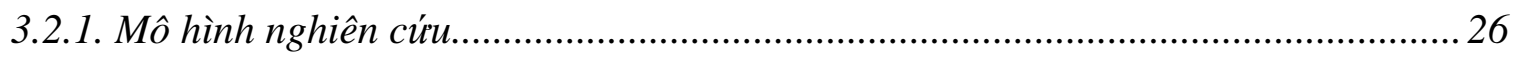

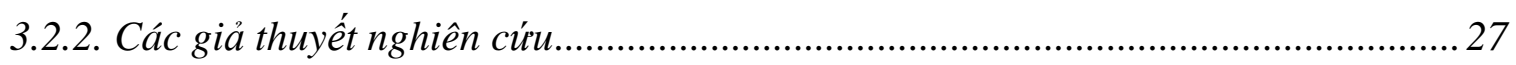

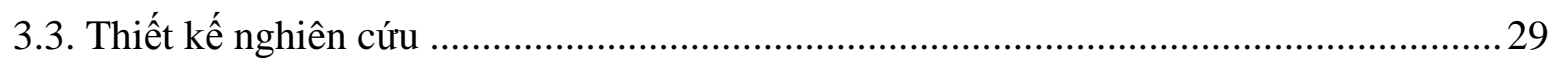

3.3.1. Phát triển bảng hỏi và lựa chọn thang đo nghiên cứu...........................................29

3.3.2. Tổng thể, mẫu nghiên cưu và phương pháp thu thập dũ liệu................................... 32



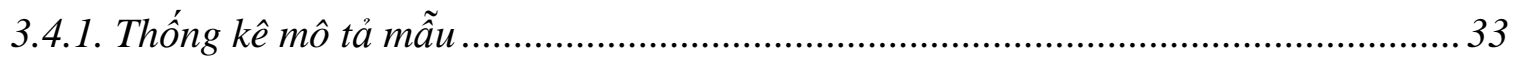



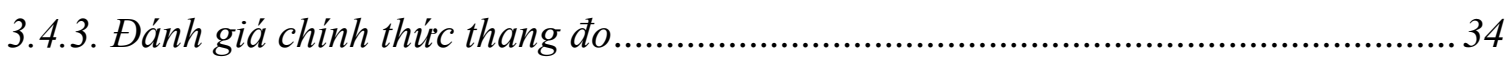

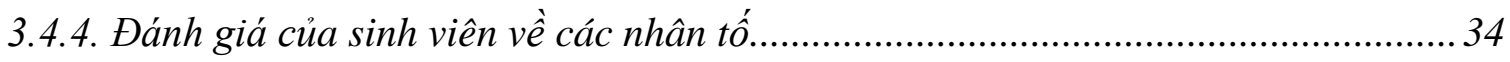

3.4.5. Đánh giá sụ khác biệt giũ̃a các biến phân loại với ý định chuyển đổi ..................... 34

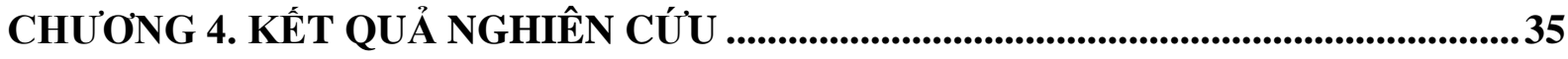

4.1. Kết quả thống kê mô tả mẫu ................................................................................... 35

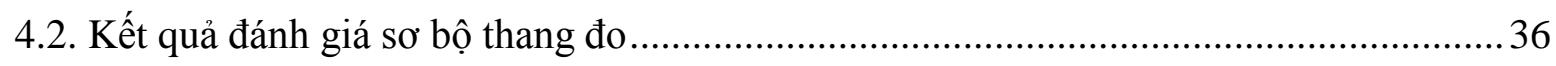

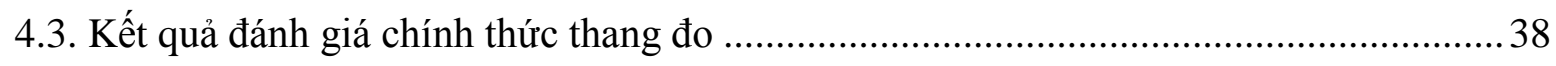

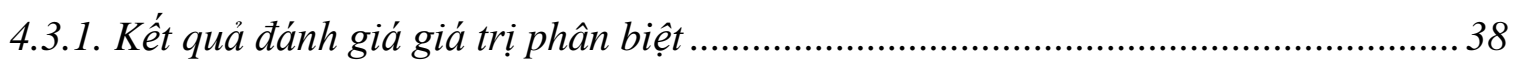

4.3.2. Kết quả phân tích bằng hồi quy đa biến và kiểm định giả thuyết nghiên cứu ......... 39

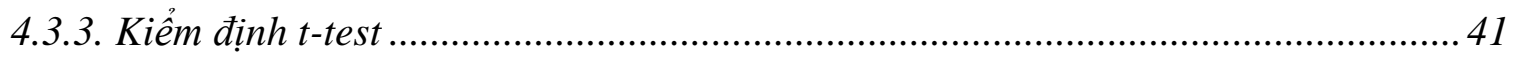

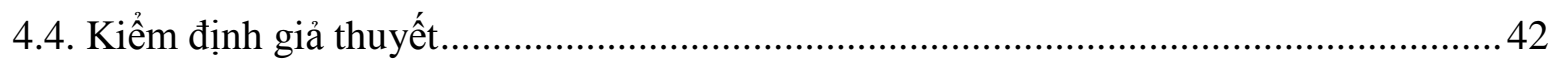

CHƯƠNG 5. THẢO LUẬN VÀ ĐỀ XUẤT GIẢI PHÁP ............................................45

5.1. Thảo luận kết quả nghiên cứu ........................................................................... 45 


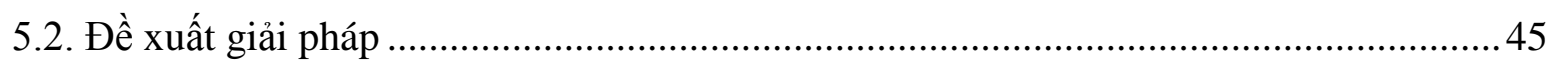

5.2.1. Nhóm giải pháp tù hoạt động giáo dục của nhà trường ......................................... 46

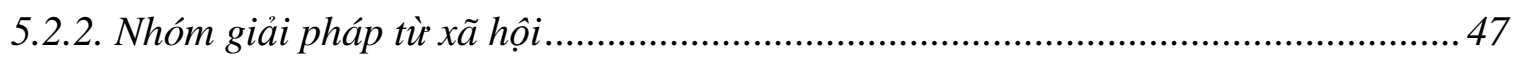



TÀI LIỆU THAM KHẢO......................................................Error! Bookmark not defined.

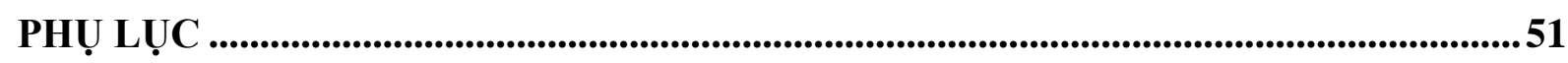




\section{DANH MỤC BẢNG BIỂU}

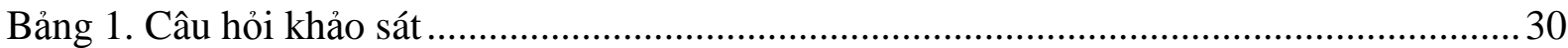



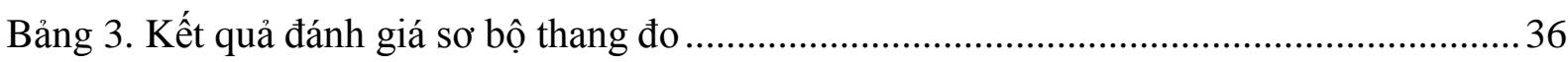

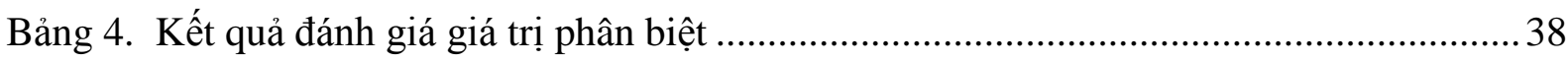

Bảng 5. Mô hình thể hiện mối quan giữa giới tính và các nhân tố ảnh hưởng đến ý định khởi

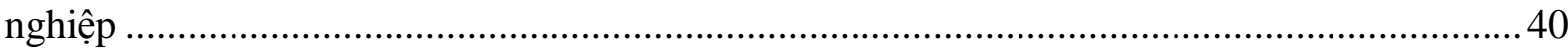

Bảng 6. Kết quả kiểm định T-test ảnh hưởng của giới tính tới ý định khởi nghiệp ................. 41

Bảng 7. Ảnh hưởng của giới tính tới yếu tố cấu thành kỳ vọng về khởi nghiệp và năng lực bản thân cảm nhận (thông qua hệ số Beta chuẩn hóa)

\section{DANH MỤC SƠ ĐỒ}

Sơ đồ 1. Cơ hội và tiềm năng kinh doanh theo độ tuổi năm 2015 ở Việt Nam........................ 15

Sơ đồ 2. Mô hình thuyết hành động hợp lý ........................................................................... 20

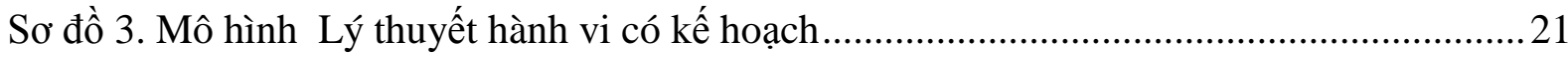

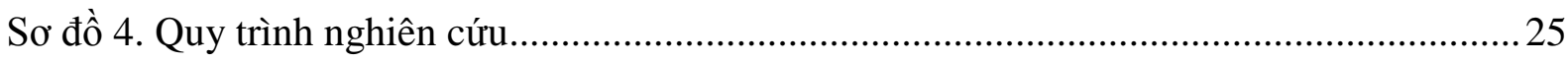

Sơ đồ 5 . Mô hình thể hiện mối quan giữa giới tính và các nhân tố ảnh hưởng đến ý định khởi

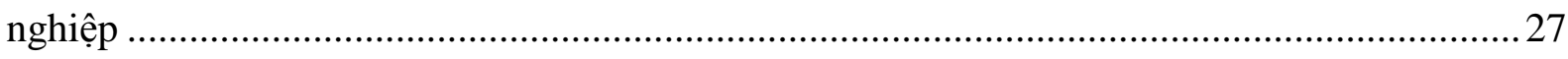

Sơ đồ 6. Mô hình ước lượng với hệ số chuẩn hóa Beta .......................................................... 41 
DANH MỤC TỪ VIẾT TẮT

Tiếng Việt

\begin{tabular}{|c|c|c|}
\hline STT & Từ viết tắt & Nội dung \\
\hline 1 & DNNVV & Doanh nghiệp vừa và nhỏ \\
\hline 2 & ĐH & Đại học \\
\hline 3 & KSDN & Khởi sự doanh nghiệp \\
\hline
\end{tabular}

\section{Tiếng Anh}

\begin{tabular}{|c|c|c|c|}
\hline STT & Từ viết tắt & Nội dung & Nghĩa \\
\hline 1 & VCCI & $\begin{array}{l}\text { Vietnam Chamber of Commerce and } \\
\text { Industry }\end{array}$ & $\begin{array}{c}\text { Phòng Công nghiệp và Thương } \\
\text { mại Việt Nam }\end{array}$ \\
\hline 2 & $R \& D$ & Research \& Develop & Nghiên cứu và phát triển \\
\hline 3 & GDP & Gross Domestic Product & Tổng sản phẩm quốc dân \\
\hline 4 & TPB & The theory of Planned Behavior & Lý thuyết hành vi có kế hoạch \\
\hline 5 & TRA & The theory of Reasoned Action & Lý thuyết hành động hợp lý \\
\hline 6 & CEO & Chief Executive Officer & Giám đốc điều hành \\
\hline 7 & AEC & ASIAN Economic Community & Cộng đồng kinh tế ASIAN \\
\hline 8 & WTO & World Trade Organization & Tổ chức kinh tế thế giới \\
\hline 9 & СТ-TPP & $\begin{array}{l}\text { Comprehensive and Progressive Agreement } \\
\text { for Trans-Pacific Partnership). }\end{array}$ & $\begin{array}{l}\text { Hiệp định Đối tác Toàn diện và } \\
\text { Tiến bộ xuyên Thái Bình Dương }\end{array}$ \\
\hline 10 & ASEAN & Association of South East Asian Nations & $\begin{array}{c}\text { Hiệp hội các Quốc gia Đông } \\
\text { Nam Á }\end{array}$ \\
\hline
\end{tabular}




\section{CHƯƠNG 1. GIỚI THIỆU ĐỀ TÀI NGHIÊN CỨU}

\subsection{Tính cấp thiết của đề tài}

Những năm gần đây, xu hướng khởi nghiệp đang phát triển mạnh mẽ tại Việt Nam, đặc biệt trong cộng đồng sinh viên các trường cao đẳng, đại học. Cùng với đó, đề án "Hỗ trợ học sinh, sinh viên khởi nghiệp đến năm 2025" do Thủ tướng Chính phủ phê duyệt ngày 30/11/2017 góp phần thúc đẩy xu hướng khởi nghiệp của giới trẻ. Sinh viên sẽ được Nhà nước và các trường đại học tạo điều kiện ra sao, nguồn kinh phí để khuyến khích khởi nghiệp được tạo ra từ những nguồn nào? Các trường nên làm gì để khơi gợi và làm bùng cháy khát khao khởi nghiệp trong sinh viên và đáp ứng được yêu cầu đặt ra? Đây đang là một vấn đề mà giới trẻ hiện nay hết sức quan tâm. Người khởi nghiệp cần trang bị cho mình không chỉ kiến thức, mà cần rèn luyện cả ý chí kiên định và khát khao thành công. Thời sinh viên là giai đoạn tốt nhất để tiếp thu những kiến thức, kỹ năng đó và trọng trách của trường ĐH là tối quan trọng.

Đối với mỗi quốc gia, khởi nghiệp có vai trò quan trọng đối với hoạt động sáng tạo, phát triển kinh tế và tạo công ăn việc làm cho người lao động (Hoang \& Dung, 2009; Phạm \& Vương, 2009; Vương, 2007). Tại Việt Nam, đóng góp của các doanh nghiệp mới, phần lớn là các doanh nghiệp vừa và nhỏ từ khu vực tư nhân chiếm $45 \%$ GDP và thu hút khoảng $52 \%$ lao động mới (VCCI, 2016b). Do vậy, thúc đẩy phong trào khởi nghiệp là một trong những giải pháp chiến lược giúp giải quyết việc làm, làm tăng tính năng động của nền kinh tế và làm giảm tỉ lệ thất nghiệp.

Trong những năm gần đây, mức độ thất nghiệp của sinh viên đại học ra trường ngày càng trở nên trầm trọng. Theo công bố của Bộ Lao động Thương binh và Xã hội trong quý 4/2018 có khoảng 127 nghìn cử nhân và thạc sĩ thất nghiệp (Xuân, 2018). Điều này cho thấy công tác thúc đẩy và tạo điều kiện mạnh cho hoạt động khởi nghiệp của sinh viên là rất quan trọng. Tuy vậy, hành trình khởi nghiệp không chỉ đơn giản là việc thành lập doanh nghiệp mới mà cần được chuẩn bị theo một quá trình từ ý định đến hành động (Hisrich, Peters, \& Shepherd, 2013). Hoạt động khởi nghiệp là hoạt động có dự định và kế hoạch (Krueger Reilly, \& Carsrud, 2000; Hisrich et al., 2013). Ý định khởi nghiệp là giai đoạn đầu tiên của hoạt động khởi nghiệp và chịu ảnh hưởng của các nhân tố ngoại sinh (Jack \& Anderson, 2002). Ý định thể hiện mức độ sẵn sàng của cá nhân để thực hiện hành vi và là tiền đề trực tiếp của hành vi (Fishbein \& Ajzen, 2011). Nghiên cứu của Armitage \& Corner (2001), Kibler, Kautone, \& Fink (2014), cho thấy ý định dự báo được khoảng 50\% hành vị trong thực tế. 
Tuy nhiên, ý định khởi nghiệp của sinh viên có sự khác nhau lớn giữa nam và nữ (Maes, Leroy, \& Sels 2014). Như vậy, việc thúc đẩy và cân bằng ý định khởi nghiệp giữa hai giới có ý nghĩa quan trọng với cả cá nhân sinh viên và xã hội. Tuy nhiên, chưa có các nghiên cứu sâu về ý định khởi nghiệp trong sinh viên trong nước còn chưa nhiều, đặc biệt là các mô hình nghiên cứu sự tác động của giới tính đến ý định khởi nghiệp của sinh viên.

Với những lý do nêu trên, nhóm tác giả tiến hành thực hiện đề tài “Ảnh hưởng của giới tính tới ý định khởi nghiệp của sinh viên Hà Nội” và tin rằng đề tài này thật sự cần thiết đối với sinh viên Hà Nội hiện nay nhằm mục đích phân tích, tìm ra các nhân tố thực sự ảnh hưởng đến ý định khởi nghiệp và từ đó đề xuất các giải pháp có cơ sở nhằm mục đích nâng cao ý định khởi nghiệp của trong cộng đồng sinh viên Hà Nội.

\subsection{Mục tiêu nghiên cứu}

Nghiên cứu nhằm giải thích ảnh hưởng của giới tính dẫn đến sự khác biệt trong ý định khởi nghiệp của sinh viên. Bên cạnh đó, nhóm nghiên cứu đưa ra những số liệu và đánh giá về thực trạng tác động của giới tính và các yếu tố ảnh hưởng đến ý định khởi nghiệp của sinh viên. Cuối cùng, nhóm đề xuất những giải pháp thiết thực, hợp lý để thúc đẩy hoạt động khởi nghiệp của sinh viên cũng như tạo những cơ hội công bằng trong khởi nghiệp cho nam giới và nữ giới.

\section{3. Đối tượng nghiên cứu, phạm vi nghiên cứu}

- Đối tượng nghiên cứu: độ nhận biết về hoạt động khởi nghiệp của sinh viên tại thành phố Hà Nội

- Đối tượng khảo sát: Sinh viên tại thành phố Hà Nội

- Phạm vi:

Không gian: trên địa bàn thành phố Hà Nội

Thời gian: Dữ liệu trong nghiên cứu thu thập từ 2012 đến nay bao gồm nguồn dữ liệu thứ cấp nhờ các quyết định của Thủ tướng Chính phủ, Bộ Lao động và Xã hội ... và nguồn dữ liệu sơ cấp là 300 bảng hỏi sinh viên Hà Nội được thực hiện từ tháng 3/2019 đến đầu tháng 5/2019, được thiết kế phù hợp với mục đích nghiên cứu. 


\subsection{Tổng quan tình hình nghiên cứu}

\subsubsection{Nghiên cứu ngoài nước}

Ý định khởi nghiệp là một thuật ngữ được sử dụng khá phổ biến hiện nay và đang được các nhà làm chính sách, nhà nghiên cứu kinh tế rất quan tâm. Vì thế, đã có một số đề tài liên quan đến vấn đề này.

Các đề tài nghiên cứu của tác giả nước ngoài có thể kể đến mô hình Lý thuyết hành vi kế hoạch của Ajzen (1991) là một trong những mô hình được sử dụng phổ biến nhất để giải thích ý định khởi nghiệp của một cá nhân. Lý thuyết hành vi kế hoạch của Ajzen (1991) cho rằng ý định thực hiện một hành vi chịu tác động của 3 yếu tố: thái độ của cá nhân, quy chuẩn chủ quan và nhận thức kiểm soát hành vi. Thái độ của cá nhân đối với một hành vi là việc cá nhân đó cảm thấy như thế nào khi thực hiện hành vi, thái độ này có thể là tích cực hoặc tiêu cực. Quy chuẩn chủ quan lại liên quan đến việc người khác (gia đình, bạn bè, giáo viên...) cảm thấy như thế nào khi cá nhân thực hiện hành vi đó. Nhận thức kiểm soát hành vi đề cập đến cảm nhận về sự dễ dàng hay khó khăn khi thực hiện hành vi, thể hiện cảm nhận của cá nhân là bản thân có khả năng và đủ nguồn lực để thực hiện hành vi hay không.

Nghiên cứu của Armitage và Conner (2001) với 185 nghiên cứu thực nghiệm, đã kết luận rằng lý thuyết hành vi kế hoạch có hiệu quả trong việc tiên lượng cả ý định và hành vi. Tuy nhiên, những nghiên cứu về ý định KSDN dựa trên lý thuyết hành vi kế hoạch cho thấy thái độ đối với hành vi, quy chuẩn chủ quan và nhận thức kiểm soát hành vi thường chỉ giải thích được từ $30 \%$ đến $50 \%$ sự khác biệt trong ý định. Khả năng giải thích này còn tùy thuộc vào ngữ cảnh và tình huống.

Một phát hiện nhất quán trong nghiên cứu về các yếu tố ảnh hưởng đến ý định khởi nghiệp là phụ nữ có ý định kinh doanh thấp hơn nam giới (Crant, 1996; Kolvereid, 1996; Veciana Aponte, \& Urbano, 2005; Raijman, 2001; Davidsson, 1995; Wilson, Kickul, \& Marlino, 2007). Mặc dù hầu hết các nghiên cứu coi giới tính như một biến độc lập nhưng chúng lại không được thiết kế đặc biệt để nghiên cứu sự khác biệt về giới trong ý định khởi nghiệp. Những nghiên cứu này báo cáo kết quả thực nghiệm mà không đề cập đến bất kỳ lý thuyết cụ thể nào để giải thích sự khác biệt giới tính.

Veciana et al. (2005) so sánh thái độ của sinh viên đại học đối với ý định kinh doanh ở Catalonia và Puerto Rico. Họ thấy sinh viên nam có nhiều khả năng có ý định nghiêm túc để tạo ra một công ty mới hơn sinh viên nữ khi lấy mẫu trường đại học Catalan Routamaa và cộng sự (2003) báo cáo rằng đàn ông thể hiện ý định kinh doanh cao hơn và đang nỗ lực nhiều hơn 
để bắt đầu kinh doanh. Kourilsky và Walstad (1998) cho rằng nữ sinh trung học thường ít muốn bắt đầu kinh doanh và có ít kiến thức về tinh thần kinh doanh hơn nam sinh viên.

Tuy nhiên, một số nghiên cứu giới thiệu các biến kiểm soát khác và báo cáo rằng hiệu ứng giới tính được trung gian giải thích bởi thái độ, chuẩn mực chủ quan và kiểm soát hành vi nhận thức (Kolvereid, 1996) và xử lý rủi ro (Raijman, 2001).

Một nhóm nghiên cứu cho thấy rằng phụ nữ tiếp tục thể hiện ý định khởi nghiệp thấp hơn do ảnh hưởng của giáo dục, cha mẹ và tính cách chủ động (Crant, 1996), lý lịch cá nhân, thái độ và tình trạng việc làm hiện tại (Davidsson, 1995), kinh nghiệm, tình trạng gia đình, động lực làm việc (Kolvereid \& Moen, 1997). Wang và Wong (2004) thấy rằng ảnh hưởng của giới đến ý định khởi nghiệp được giải thích trung gian một phần bởi sự thiếu kiến thức kinh doanh.

\subsubsection{Nghiên cúu trong nưóc}

Trong các nghiên cứu trong nước, tuy chưa có bài nghiên cứu cụ thể về ảnh hưởng của giới tính đối với ý định khởi nghiệp của giới trẻ. Tuy nhiên, có một số nghiên cứu cho thấy giới tính là một trong các yếu tố ảnh hưởng trực tiếp trong việc hình thành ý định khởi nghiệp.

Nghiên cứu của Duy, Lin, Duyên và Hiền (2011) xem xét ảnh hưởng của đặc điểm giới tính trong mối quan hệ với thái độ, quy chuẩn chủ quan, nhận thức kiểm soát hành vi và nguồn vốn đối với ý định khởi nghiệp trong khi có kiểm soát các biến số khác trong mô hình (dân tộc, kết quả học tập, kinh nghiệm kinh doanh và hình mẫu doanh nhân.

\subsection{Tính mới và đóng góp của đề tài}

Từ việc tổng quan tình hình nghiên cứu trong và ngoài nước, nhóm tác giả nhận thấy đề tài có những đóng góp sau:

Thứ nhất, đề tài là nghiên cứu đầu tiên tại Việt Nam sử dụng mô hình từ lý thuyết hành vi có kế hoạch (TPB) nghiên cứu ảnh hưởng của giới tính đối với ý định khởi nghiệp của sinh viên, cụ thể là trên địa bàn Hà Nội;

Thứ hai, với mô hình kết hợp thêm các chỉ số do TPB đề xuất, nhóm nghiên cứu tìm cách chứng minh rằng một số phát hiện trong nghiên cứu trước đây về ý định khởi nghiệp quyết định bởi giới tính (Ahl, 2006). Điều này sẽ giải thích rõ nguồn gốc của sự khác biệt giới tính trong ý định khởi nghiệp của sinh viên;

Thứ ba, đề tài xem xét các nhân tố bằng cách tổng hợp các biến từ các nghiên cứu thực nghiệm trên thế giới và chọn lọc thành mô hình của đề tài theo điều kiện tại Việt Nam. Kết quả 
nghiên cứu cho thấy 5 nhân tố có tác động mạnh đến ý định khởi nghiệp của sinh viên trong đó có 4 nhân tố là đại diện cho các biến liên quan đến sự đánh giá chủ quan của người được khảo sát;

Thứ tư, đề tài là sự kết hợp giữa lý thuyết và thực nghiệm, được kiểm định về độ tin cậy và góp phần bổ sung và phát triển phương pháp luận cho các nghiên cứu về sau cũng như đề xuất các giải pháp mang tính thực tiễn;

\subsection{Kết cấu đề tài}

Ngoài phần danh mục từ viết tắt, danh mục bảng và biểu đồ, danh mục tài liệu tham khảo, phụ lục và kết luận, đề tài được kết cấu thành 5 mục như sau:

Chương 1: Giới thiệu đề tài nghiên cứu

Chương 2: Cơ sở lý luận về ý định khởi nghiệp

Chương 3: Phương pháp nghiên cứu

Chương 4: Kết quả nghiên cứu

Chương 5: Thảo luận và đề xuất. 


\section{CHƯƠNG 2. CƠ SỞ LÝ LUẬN VỀ Ý ĐỊNH KHỞI NGHIỆP}

\subsection{Tổng quan về khởi nghiệp}

\subsubsection{Khái niệm khởi nghiệp}

Hiện nay trên thế giới có nhiều quan điểm khác nhau về khởi nghiệp như sau:

Định nghĩa khởi nghiệp theo từ điển tiếng Việt được giải nghĩa là bắt đầu sự nghiệp. Định nghĩa khởi nghiệp cũng thay đổi qua thời gian với các nhà nghiên cứu khác nhau. Đến đầu thế kỷ 20, định nghĩa khởi nghiệp đã được hoàn thiện và được diễn đạt là quá trình tạo dựng một tổ chức kinh doanh và người khởi nghiệp là người sáng lập nên doanh nghiệp đó. Tuy nhiên, không phải bất cứ ai cũng có tiềm năng để mở một doanh nghiệp riêng. Một người khởi nghiệp tiềm năng là người ñón lấy cơ hội ñể thành lập công ty riêng mình ngay khi cơ hội xuất hiện (Shapero, 1981). Sự khởi nghiệp là một quá trình bắt đầu từ việc nhận biết cơ hội, từ đó phát triển ý tưởng để theo đuổi cơ hội qua việc thành lập công ty mới. Theo tổ chức Global Entrepreneurship Monitor thì một doanh nghiệp khi vừa thành lập sẽ trải qua 3 giai đoạn từ hình thành, phát triển ý tưởng ñến thành lập doanh nghiệp và cuối cùng là duy trì và phát triển doanh nghiệp.

Với Neil Blumenthal - đồng sáng lập và là CEO của Warby Parker thì "Mọi doanh nghiệp khởi nghiệp là một công ty đang hoạt động để giải quyết một vấn đề khi mà điều đó còn chưa rõ ràng và thành công thì không được đảm bảo". Khởi nghiệp với Adora là "Khi nhiều người cùng tham gia trong công ty của bạn và theo đuổi những quyết định mạo hiểm và từ bỏ sự ổn định, để đổi lại những lời hứa về sự tăng trưởng trong tương lai và sự phấn khích trong công việc". Trong American Heritage Dictionary, ta cũng có thể tìm thấy định nghĩa tương tự như vậy “khởi nghiệp là một doanh nghiệp đang bắt tay vào hoạt động”.

Từ trước tới nay có 2 cách tiếp cận:

- Từ góc độ lựa chọn nghề nghiệp

"Khởi nghiệp là một sự lựa chọn nghề nghiệp của cá nhân giữa việc đi làm thuê hoặc tự tạo việc làm cho mình" hoặc "Khởi nghiệp là lựa chọn nghề nghiệp của những người không sợ rủi ro tự làm chủ công việc kinh doanh của chính mình và thuê người khác làm công cho họ”.

- Từ góc độ tạo dựng doanh nghiệp mới

Wortman định nghĩa "Khởi nghiệp là việc một cá nhân chấp nhận rủi ro để tạo lập một doanh nghiệp mới và tự làm chủ nhằm mục đích làm giàu", hoặc "Khởi nghiệp là việc bắt đầu 
tạo lập một công việc kinh doanh mới bằng đầu tư vốn kinh doanh, hay mở cửa hàng kinh doanh".

Tuy có sự khác biệt nhưng khởi sự kinh doanh đều đề cập tới việc một cá nhân (một mình hoặc cùng người khác) tạo dựng một công việc kinh doanh mới.

Trong nghiên cứu này, nhóm nghiên cứu tiếp cận và nhìn nhận khởi nghiệp dưới quan điểm của Phạm (2015), “khởi nghiệp kinh doanh có thể là thành lập một doanh nghiệp mới hoặc có thể là kinh doanh trong một doanh nghiệp đang hoạt động (đổi mới, sáng tạo), nhằm theo đuổi những quyết định mạo hiểm và từ bỏ sự ổn định, để đổi lại những lời hứa về sự tăng trưởng trong tương lai và sự phấn khích trong công việc".

\subsubsection{Doanh nhân}

\section{Khái niệm:}

Khái niệm doanh nhân có thể được hiểu theo nhiều cách tiếp cận khác nhau. Doanh nhân cũng có thể hiểu là "người làm kinh doanh, là chủ thể lãnh đạo, chịu trách nhiệm trước xã hội và pháp luật. Doanh nhân có thể là chủ một doanh nghiệp, là người sở hữu và điều hành, chủ tịch công ty, giám đốc công ty hoặc cả hai”’

Trong nghiên cứu này, nhóm tác giả sử dụng cách hiểu khái niệm doanh nhân theo nghĩa rộng. Doanh nhân là người trong tổ chức quản lý doanh nghiệp, người kết hợp sử dụng nguồn vốn (con người, tài chính, nguồn lực vật chất) nhằm làm cho doanh nghiệp hoạt động hiệu quả, mang lại lợi nhuận cho doanh nghiệp.

\section{Đặc điểm:}

Thứ nhất, doanh nhân là những người dám mạo hiểm trong hoạt động kinh doanh.

Thứ hai, doanh nhân là những người có năng khiếu, khả năng kinh doanh, quản lý hoạt động kinh doanh và đặc điểm cuối cùng của doanh nhân là có tư duy đổi mới và sáng tạo.

\subsubsection{Vai trò của khởi nghiệp đối với sụ phát triển kinh tế}

Vai trò của khởi nghiệp không đồng nhất trong các nền kinh tế khác nhau tùy thuộc vào nguồn lực tài nguyên, điều kiện kinh doanh và chính sách hỗ trợ của Chính phủ. Sự đóng góp của khởi nghiệp được thể hiện rõ hơn ở những nền kinh tế có nhiều điều kiện cơ hội thuận lợi hơn trong các nền kinh tế tương đối ít thuận lợi điều kiện cơ hội. 
Trong những năm đầu thế kỉ XX, vai trò quan trọng của khởi nghiệp trong sự phát triển kinh tế của các nước phương Tây đã làm người dân của các nước kém phát triển ý thức hơn về tầm quan trọng của tinh thần kinh doanh đố phát triển kinh tế. Cho đến hiện nay, người dân, đặc biệt là giới trẻ, đều nhận ra rằng để đạt được mục tiêu phát triển kinh tế, cần tăng tinh thần kinh doanh cả về chất và lượng. Hoạt động khởi nghiệp chỉ mang lại hiệu quả khi các doanh nhân nhận thức đầy đủ tiềm năng của các nguồn lực sẵn có của đất nước - lao động, công nghệ và vốn.

Schumpeter (1934) cho rằng người khởi nghiệp là nhân vật chủ chốt trong phát triển kinh tế vì về vai trò của ông trong việc giới thiệu phương pháp kinh doanh đổi mới đối với nền kinh tế. Parson và Smelser (1956) mô tả tinh thần kinh doanh là một trong hai điều kiện cần thiết cho kinh tế phát triển.

Harbison (1965) cho rằng doanh nhân à một trong số động lực chính của đổi mới, và Sayigh (1962) đơn giản mô tả tinh thần kinh doanh là cần thiết lực động cho sự phát triển. Về cơ bản, doanh nhân luôn tìm kiếm sự thay đổi, cơ hội kinh doanh và sau đó tập hợp lại nhân lực, vật chất và vốn cần có đáp ứng cơ hội đó.

Cụ thể, khởi nghiệp tác động đến sự phát triển kinh tế theo những cách thức như sau (Dhaliwal, 2016):

- Thúc đẩy hình thành nguồn vốn

Doanh nhân thúc đẩy hình thành vốn bằng cách huy động các khoản tiết kiệm nhàn rỗi của công chúng. Họ có thể sử dụng nguồn vốn riêng cũng như vay mượn vốn của người khác để thiết lập doanh nghiệp. Do vậy, hoạt động khởi nghiệp tạo ra giá trị gia tăng và của cải, điều rất cần thiết cho công nghiệp và kinh tế sự phát triển của mỗi quốc gia.

- Tạo cơ hội việc làm quy mô lớn

Hoạt động khởi nghiệp cung cấp việc làm quy mô lớn, một phần giải quyết vấn đề thất nghiệp, một vấn đề nan giải của các quốc gia kém phát triển. Với việc hình thành ngày càng nhiều đơn vị kinh doanh cả trên quy mô nhỏ và quy mô lớn, giới trẻ có thể dễ dàng tìm được cơ hội việc làm cho mình. Theo cách này, khởi nghiệp đóng một vai trò hiệu quả trong việc giảm vấn đề thất nghiệp trong nước, mở ra hướng phát triển mới cho nền kinh tế của quốc gia. Trong đó, doanh nhân góp phần tạo ra việc làm trực tiếp và gián tiếp. Họ vừa trực tiếp làm việc như một doanh nhân vừa gián tiếp tạo ra cơ hội việc làm cho hàng triệu công nhân khác.

- Thúc đẩy phát triển cân bằng giữa các khu vực 
Việc hình thành các doanh nghiệp mới giúp xóa bỏ chênh lệch giữa các khu vực thông qua thiết lập các ngành công nghiệp mới tại các vùng kém phát triển và lạc hậu. Sự tăng trưởng của ngành công nghiệp và kinh doanh ở những khu vực này đồng thời mang lại những lợi ích công cộng như nâng cấp vận tải đường bộ, y tế, giáo dục, giải trí ...

- Tăng tổng sản phẩm quốc gia (GDP) và thu nhập bình quân đầu người

Doanh nhân luôn luôn tìm kiếm cơ hội, khám phá và khai thác cơ hội kinh doanh mới, khuyến khích huy động nguồn lực hiệu quả vốn và kỹ năng, mang lại sản phẩm và dịch vụ mới cho của nền kinh tế. Theo cách này, họ giúp tăng tổng sản phẩm quốc gia cũng như thu nhập bình quân đầu người của người dân mỗi nước.

\subsubsection{Thực trạng khởi nghiệp của sinh viên Hà Nội}

\section{Cơ sở chính sách và pháp lý:}

Cùng với sự phát triển hội nhập sâu rộng, Việt Nam đã và đang nhận được nhiều sự quan tâm của các nhà đầu tư quốc tế, các mô hình khởi nghiệp phát triển mạnh mẽ, thu hút sự chú ý của nhiều nhà đầu tư. Từ đó, việc xây dựng hệ sinh thái khởi nghiệp càng được quan tâm, hướng tới mục tiêu quốc gia khởi nghiệp và khởi nghiệp là trung tâm sáng tạo. Ngày 18/5/2016, Thủ tướng Chính phủ đã phê duyệt Đề án "Hỗ trợ hệ sinh thái khởi nghiệp đổi mới sáng tạo quốc gia đến năm 2025”. Đề án hướng tới mục tiêu tạo dựng hình ảnh quốc gia khởi nghiệp trong bối cảnh hội nhập kinh tế quốc tế ngày càng sâu, rộng.

Nhằm thúc đẩy mạnh mẽ các loại hình khởi nghiệp, tạo lập môi trường pháp lý, Nhà nước đã cải thiện văn bản pháp luật và ban hành một số văn bản hỗ trợ như: Nghị định 90/2001/NĐCP về trợ giúp phát triển DNNVV, quy định chính sách hỗ trợ DNNVV ở từ Trung ương tới địa phương; Ngày 30/6/2009, Chính phủ ban hành Nghị định 56/2009/NĐ-CP về trợ giúp phát triển DNNVV (thay thế Nghị định 90/2001/NĐ-CP) quy định 8 nhóm hỗ trợ phát triển DNNVV; Quyết định 1231/QĐ-TTg, đề ra một số giải pháp, chương trình hỗ trợ DNNVV

Tuy vậy, hành lang pháp lý và chính sách, tồn tại nhiều xung đột, thiếu tính đồng bộ, Hoạt động trợ giúp đối với các DNNVV đến nay vẫn chưa phát huy được tác dụng, còn chồng chéo và phân tán, chưa có trọng tâm, trọng điểm. Tỷ lệ DNNVV tiếp cận được nguồn vốn tín dụng thấp, Quỹ bảo lãnh tín dụng cho DNNVV kém hiệu quả, khó khăn trong tiếp cận đất đai...

\section{Điều kiện thị truò̀ng:}


Việt Nam trở thành thành viên của tổ chức Thương mại thế giới WTO từ năm 2007, Hiệp định đối tác và toàn diện xuyên Thái Bình Dương CP-TTP và Cộng đồng Kinh tế ASEAN (AEC) năm 2018. Nhiều tập đoàn và doanh nghiệp nước ngoài đã đổ bộ vào thị trường Việt Nam với giá cả và chất lượng mang tính cạnh tranh cao chứng tỏ thị trường Việt Nam rất hấp dẫn với 90 triệu dân, dân thành thị chiếm 1/3 dân số, lực lượng dân số trẻ chiếm hơn một nửa. Trước tình hình đó, những doanh nghiệp Việt Nam tận dụng nguồn nhân công rẻ và tài nguyên khoáng sản để sản xuất hàng hóa và xuất khẩu, thậm chí xuất khẩu thô chiếm tỷ trọng rất lớn, giao phó thị trường trong nước cho các doanh nghiệp nước ngoài hoặc các sản phẩm, dịch vụ thương hiệu ngoại khiến người tiêu dùng ngày càng tin dùng và thích sử dụng các sản phẩm ngoại, tạo nên thế khó khi các doanh nghiệp muốn quay lại khai thác thị trường nội địa. Việc cạnh tranh với các thương hiệu ngoại sẽ giúp nâng cao chất lượng hàng hóa, dịch vụ của thương hiệu trong nước. Tuy nhiên, vẫn cần có những chính sách, chương trình tạo lòng tin của người tiêu dùng Việt Nam với hàng hóa, dịch vụ nội địa trước cơn bão đổ bộ các thương hiệu nước ngoài. Việc hội nhập quốc tế cũng đã tạo nhiều cơ hội cho người trẻ khởi nghiệp, đặc biệt trong các lĩnh vực: kinh doanh, công nghệ, nông nghiệp ... Trong những năm gần đây, làn sóng khởi nghiệp đã phát triển mạnh mẽ trong cộng đồng doanh nghiệp và giới trẻ Việt Nam, tạo nhiều cơ hội kinh doanh tại thị trường nội địa, hấp dẫn giới trẻ.

\section{Vốn:}

Việc tiếp cận vốn vay của sinh viên Hà Nội tương đối dễ dàng, thường huy động từ các nguồn vay như: tích luỹ vốn cá nhân, vay mượn người thân, bạn bè, các công ty tài chính ... Các công ty tài chính và ngân hàng hiện nay đã có nhiều chính sách và chương trình hỗ trợ cho khối doanh nghiệp, tuy nhiên thủ tục, giấy tờ còn nhiều bất cập như chứng minh thu nhập, thế chấp tài sản ...

Tại các trường đại học như Đại học Ngoại Thương, Đại học Kinh tế quốc dân ... đã và đang hình thành nhiều Trung tâm hỗ trợ sinh viên khởi nghiệp, Trung tâm hỗ trợ thanh niên khởi nghiệp sYs đã đóng góp lớn trong việc hình thành hệ sinh thái khởi nghiệp, cung cấp nguồn vốn cho các dự án khởi nghiệp của sinh viên. Các quỹ đầu tư này tạo khả năng vay vốn cho các dự án khởi nghiệp khả thi và có số vốn đầu tư dưới 100 triệu, tuy nhiên đây cũng chính là nhược điểm dành cho các dự án cần có số vốn đầu tư nhiều hơn với thời hạn tối đa nhiều hơn. Một trở ngại phổ biến khác của những người khởi nghiệp trẻ tại các nước đang phát triển như Việt Nam là việc thiếu kiến thức và thông tin về thị trường vốn nói chung, vay vốn nói riêng. 


\section{Nghiên cúu - phát triển và Công nghệ:}

Thực hiện chủ trương của Đảng và Nhà nước "Các trường đại học vừa là cơ sở đào tạo vừa là cơ sở nghiên cứu ứng dụng khoa học và công nghệ", trong những năm qua các trường đại học đã đẩy mạnh hoạt động nghiên cứu khoa học, triển khai ứng dụng kết quả nghiên cứu giáo dục, đào tạo, thực tế sản xuất, đời sống. Đây là công việc cần thiết trong quá trình phát triển kinh tế, đời sống của người dân Việt Nam trong thời đại Công nghiệp 4.0 và Khởi nghiệp điện toán (Vuong, 2019). Công tác chuyển giao công nghệ, sản xuất kinh doanh, sử dụng chi phí khoa học hợp lý trong các trường đại học là công tác rất quan trọng cần đẩy mạnh hơn nữa trong thời gian tới (Vuong, 2018).

Tình trạng vi phạm pháp luật sở hữu trí tuệ và xâm phạm quyền sở hữu trí tuệ đang ngày càng gia tăng đã ảnh hưởng lớn đến tinh thần khởi nghiệp của người trẻ, đem đến những tác động tiêu cực cho tâm lý của người khởi nghiệp. Ví dụ, lĩnh vực nghệ thuật Việt Nam hiện nay tràn ngập tranh giả và chưa có hướng giải quyết cụ thể (Vuong, Ho, Nguyen, Vuong, Tran \& Ho, 2018). Việt Nam là thành viên chính thức của WTO thì hoạt động đẩy lùi vi phạm quyền sở hữu này trở nên sôi động với tất cả các dạng tài sản trí tuệ được bảo hộ, bao gồm: bản quyền tác giả và các sáng chế, kiểu dáng công nghiệp, nhãn hiệu hàng hóa, tên gọi xuất xứ và chỉ dẫn địa lý, giống cây trồng mới... Việt Nam đã có nhiều nỗ lực trong việc xây dựng các văn bản pháp luật về sở hữu trí tuệ nhưng vấn đề thực thi là một điểm yếu cần phải khắc phục.

Về công nghệ, khâu đầu tư ngân sách cho khoa học, công nghệ chưa tương xứng với sự quan tâm của Nhà nước. Tổng hợp dự toán chi ngân sách nhà nước cho khoa học, công nghệ qua các năm cho thấy, chưa năm nào đạt mức $2 \%$ tổng chi ngân sách nhà nước theo quy định. Thậm chí tỷ lệ này đang có xu hướng giảm qua các năm: năm 2011 đạt 1,6\%, 2012 là 1,46\%, năm 2013 là 1,42\% và năm 2014 dự báo chỉ đạt mức 38 chi 1,36\% (theo Bộ Khoa học và Công nghệ). Chưa kể, cơ chế quản lý, xác định các nhiệm vụ khoa học và công nghệ để làm cơ sở phân bổ ngân sách cũng còn những bất cập...

\section{Khả năng của ngưòi khởi nghiệp:}

Theo Báo cáo chỉ số khởi nghiệp Việt Nam GEM 2015 (VCCI, 2016a), ở Việt Nam, sự tự tin về năng lực kinh doanh thường tỷ lệ thuận với độ tuổi. Tỷ lệ thanh niên (18 - 34 tuổi) nhận thức có khả năng kinh doanh ở Việt Nam là 55\% trong khi tỷ lệ này ở trung niên (35 - 64 tuổi) là $68,6 \%$. Trong khi đó, dường như thanh niên lại là nhóm nhanh nhạy và nhìn nhận cơ hội kinh doanh tốt hơn, khi mà 58,7\% thanh niên nhận thấy có cơ hội kinh doanh, trong khi tỷ lệ này ở nhóm người lứa tuổi trung niên là $54,9 \%$. Đây là điểm khác biệt đầu tiên so với kết quả 
khảo sát năm 2014 của VCCI khi mà không có sự khác biệt về nhận thức cơ hội kinh doanh giữa thanh niên và trung niên. Điểm khác biệt thứ hai là về tỷ lệ người lo sợ thất bại trong kinh doanh (VCCI, 2014). Nếu năm 2014, tỷ lệ thanh niên lo sợ thất bại trong kinh doanh cao hơn so với người trung niên thì năm 2015 lại hoàn toàn ngược lại. Tỷ lệ thanh niên nhận thấy lo sợ thất bại trong kinh doanh là 43,8\% thấp hơn mức 47,4\% của những người trung niên. 
Sơ đồ 1. Cơ hội và tiềm năng kinh doanh theo độ tuổi năm 2015 ở Việt Nam

Đo'n vị: \%



Nguồn: Báo cáo chỉ số khởi nghiệp Việt Nam GEM 2015 (VCCI, 2016a)

Hiện ở Việt Nam có các tổ chức đào tạo kỹ năng khởi nghiệp như Topica Institute, Hatch! Program, Yup! Institutess..., trường doanh nhân PACE, Del Carnegie, PTI... tập trung chủ yếu ở các thành phố lớn như thành phố Hồ Chí Minh và Hà Nội. Ở Hà Nội có nhiều cuộc thi khởi nghiệp sinh viên như: Techfest, Khởi nghiệp cùng Kawai, Business Challenge, VietChallenge... Các cuộc thi đã mang đến cho sinh viên các kĩ năng cá nhân, những kiến thức, trải nghiệm về hoạt động khởi nghiệp, từ đó thúc đẩy ý định và làn sóng khởi nghiệp trong sinh viên.

Kỹ năng kinh doanh và khởi nghiệp gồm các kỹ năng mềm như lòng kiên trì, tạo lập các mối quan hệ, tự tin và những kỹ năng cứng đòi hỏi cần có như kiến thức khởi nghiệp, kỹ năng thiết lập một kế hoạch kinh doanh, quản trị tài chính, kỹ năng quản lý công việc. Chính sách giáo dục khởi nghiệp hiệu quả tập trung vào phát triển năng lực và kỹ năng cho những nhà khởi nghiệp. Mục đích không chỉ dừng lại ở việc cải thiện năng lực, tạo ra khát khao làm chủ doanh nghiệp mà còn phát triển văn hóa khởi nghiệp trong xã hội, đòi hỏi sự kết hợp giữa Bộ giáo dục, văn hóa truyền thông, kinh tế, nghiên cứu và phát triển, khoa học công nghệ

\section{Văn hoá:}

Các chuẩn mực văn hoá của Việt Nam không phải lúc nào cũng ủng hộ tích cực đến khởi nghiệp. Một trong những rào cản chính của văn hoá Việt Nam là hệ tư tưởng Nho giáo (Hoang \& Dung, 2009; Vuong et al., 2018), coi trọng tôn ti trật tự. Nhân viên ở các doanh nghiệp Việt 
Nam thường không dám chất vấn cấp trên và các dự án khởi nghiệp chỉ sao chép những gì đã thử nghiệm trước đó. Sự khác biệt giữa văn hoá khởi nghiệp cũ và hiện đại cũng mang lại rào cản cho sinh viên khởi nghiệp.

\section{2. Ý định khởi nghiệp}

\subsection{1. Ý định}

Ý định là kế hoạch hay mong muốn làm một việc gì đó.

Theo Bird (1988), định nghĩa ý định là một trạng thái tâm lý hướng sự chú ý của cá nhân tới một đối tượng, mục tiêu, hành trình cụ thể để đạt được một kết quả có ý nghĩa với cá nhân đó.

Trong lĩnh vực văn học tâm lý, ý định được giả định để nắm bắt các yếu tố tạo động lực ảnh hưởng đến hành vi, thể hiện và thúc đẩy sự cố gắng, nỗ lực của cá nhân để có thể thực hiện được hành vi như mong muốn trong tương lai.

Ý định là một tình huống tư duy bao gồm kinh nghiệm và hành vi cá nhân cho một mục đích cụ thể hoặc một hành vi nhất định (Gerbing \& Anderson, 1988). Lý thuyết Hành vi dự định cho rằng ý định khởi nghiệp là kết quả của dự định, hành động của các cá nhân dũng cảm được các nhà nghiên cứu mô tả là những anh hùng thời hiện đại (Ajzen, 1987). Quyết định thành lập doanh nghiệp mới ẩn chứa nguy cơ về tương lai và đòi hỏi doanh nhân phải có một kỹ năng, kiến thức và động cơ nhất định.

Hầu hết các nghiên cứu đều đưa ra rằng ý định là một chỉ số thể hiện nỗ lực mà một cá nhân thực hiện để đạt một mục tiêu cụ thể. Nghiên cứu của Ajzen phát biểu ý định đóng vai trò là một chỉ báo tốt về hành vi quy hoạch trong mô hình của Ajzen, đặc biệt nếu hành vi này là khó thực hiện và yêu cầu một số lượng lớn các nguồn lực. Đơn giản nhất, ý định có thể dự đoán hành động, và thái độ sẽ dự đoán ý định. Như vậy, tìm hiểu về ý định là cách tốt nhất để đánh giá khả năng xảy ra hành động đó.

Nhóm nghiên cứu xin phép được định nghĩa ý định là yếu tố động lực ảnh hưởng tới việc thực hiện hành vi. Ý định càng cao thì xác suất thực hiện hành vi càng lớn.

\subsection{2. Ý định khởi nghiệp}

Ý định khởi nghiệp là các yếu tố động lực ảnh hưởng đến sự khởi nghiệp trong tương lai. 
Ý định khởi nghiệp có thể định nghĩa là sự liên quan ý định của một cá nhân để bắt đầu kinh doanh (Souitaris, 2017); là một quá trình định hướng việc lập kế hoạch và triển khai một kế hoạch tạo lập doanh nghiệp (Gupta \& Bhawe, 2017).

Xuất phát từ định nghĩa của Bird, Krueger et al. (2000). định nghĩa ý định khởi nghiệp là sự cam kết thành lập và làm chủ một doanh nghiệp mới. Ý định khởi nghiệp được coi là một nhân tố quan trọng có ảnh hưởng đến hành vi lập nghiệp trong tương lai. Bird (1988) cũng khẳng định rằng ý định khởi nghiệp tạo nền tảng cơ bản cho hành vi xây dựng doanh nghiệp mới trong tương lai.

Như vậy, các nghiên cứu trên thế giới đã thống nhất rằng khởi nghiệp là một hành vi có kế hoạch và nó đòi hỏi sự nỗ lực của mỗi cá nhân để đạt được hành vi đó. Do vậy ý định khởi nghiệp đóng vai trò hết sức quan trọng trong việc hình thành hành vi khởi nghiệp, đặc biệt trong trường hợp sinh viên các trường đại học bởi họ là lực lượng quan trong trong tương lai của đất nước.

\subsection{Các nhân tố ảnh hưởng đến ý định khởi nghiệp}

Quá trình hình thành ý định khởi nghiệp là một quá trình dài, luôn có điểm khởi đầu là hình thành hành vi khởi nghiệp, phản ánh qua mức độ quan tâm của một cá nhân tới một hành vi. Do đó, việc phân tích, tìm hiểu và đánh giá các yếu tố ảnh hưởng đến ý định khởi nghiệp là vô cùng quan trọng trong việc giải thích sự hình ý định khởi nghiệp, từ đó, có thể thiết lập các hành động, can thiệp để tác động, xây dựng và hình thành ý định khởi nghiệp, đặc biệt trong sinh viên. Các nghiên cứu trước đã chứng minh có rất nhiều yếu tố tác động đến ý định khởi nghiệp, trong bài nghiên cứu, các nhân tố được chia thành 6 nhóm nhân tố chính bao gồm: nhóm yếu tố nhân khẩu học, nhóm yếu tố về năng lực cá nhân, nhóm yếu tố đặc điểm tính cách, nhóm các yếu tố xã hội, nhóm các yếu tố văn hóa và nhóm các yếu tố môi trường.

\subsubsection{Nhóm yếu tố nhân khẩu học (Demographic factors)}

Yếu tố nhân khẩu học bao gồm tuổi, giới tính, tôn giáo, quốc tịch, truyền thống kinh doanh của gia đình. Bài nghiên cứu sẽ đi sâu vào ảnh hưởng của yếu tố giới tính tới ý định khởi nghiệp.

Giới tính là mối quan hệ tương quan giữa nam với nữ trong một bối cảnh cụ thể, nói lên vai trò, trách nhiệm, quyền lợi xã hội của nam với nữ. Do được quy định bởi bản chất xã hội, nên hoàn cảnh xã hội khác nhau, bối cảnh khác nhau dẫn đến mối quan hệ giới tính khác nhau. 
Nghiên cứu của nhóm Sullivan \& Meek, (2012), Zhang et al. (2009) cho thấy khi so sánh với nam, nữ sẽ có mức ảnh hưởng cao hơn trong ý định khởi nghiệp. Nicolaou \& Shane (2010) kết luận rằng không có sự khác nhau giữa ý định khởi nghiệp của nam và nữ. Maes et al. (2014) chứng minh thái độ cá nhân giải thích ý định khởi nghiệp của nữ yếu hơn của nam; sự kiểm soát hành vi giải thích ý định khởi nghiệp của nữ yếu hơn của nam; vì phụ nữ khởi nghiệp mong muốn cân bằng các giá trị xã hội hơn nam (dành thời gian nhiều hơn cho gia đình, con cái...) nên phụ nữ trong khởi nghiệp ít thành tựu hơn nam. Như vậy, có sự mâu thuẫn rõ ràng trong kết quả của các nghiên cứu về giới tính ảnh hưởng đến ý định khởi nghiệp. Nghiên cứu này đề xuất nên xem xét vai trò của giới tính ảnh hưởng đến ý định khởi nghiệp của sinh viên nam và nữ Việt Nam cần được nghiên cứu thêm.

\subsubsection{Nhóm yếu tố năng lục cá nhân (Personal Characteristics)}

Yếu tố năng lực cá nhân bao gồm trình độ chuyên môn, kỹ thuật, năng lực kinh doanh, năng lực quản lý, kiến thức kĩ năng, kinh nghiệm...

Kinh nghiệm của những người khởi nghiệp có thể tích lũy từ nhiều nguồn khác nhau, nhưng có một điểm chung là xuất phát từ trải nghiệm cá nhân của chính họ. Họ có thể tích lũy kinh nghiệm từ những bài học kinh doanh trong cuộc sống, hoặc trải nghiệm kinh doanh của mình.

Kiến thức giáo dục nền tảng đóng vai trò quan trọng trong việc định hình những ý định ban đầu về khởi nghiệp, kiến thức bao gồm trong các lĩnh vực như marketing, tài chính, chính trị, quản trị... Những kiến thức này có thể được cung cấp và đạo tạo trong trường lớp, tài liệu, kiến thức online... Các kĩ năng bao gồm kĩ năng cứng và kĩ năng mềm. Hiện nay, các trường đại học đều đã chú trọng hơn trong việc đào tạo kĩ năng mềm cho sinh viên thông qua các hoạt động ngoại khóa, kết hợp thực hành các kĩ năng mềm trong các môn học. Kỹ năng giao tiếp, xây dựng các mối quan hệ là nền tảng cho khởi nghiệp thành công, các mối quan hệ là những nguồn hỗ trợ hiệu quả cho những doanh nhân tiềm năng. Đồng thời, giáo dục khởi nghiệp đã trở thành một nhân tố quan trọng trong nỗ lực của nhiều nước nhằm tác động đến tư duy của con người, khiến họ có tinh thần khởi nghiệp hơn. Hình thức giáo dục này không nhằm dạy một kỹ năng cụ thể liên quan đến khởi nghiệp mà hướng đến việc giới thiệu quan niệm về khởi nghiệp, tầm quan trọng của nó trong xã hội, và một vài năng lực quan trọng của một người kinh doanh ví dụ như tiên phong thực hiện.

Đặc biệt, việc tham gia các chương trình đào tạo khởi nghiệp nói riêng sẽ đóng góp rất lớn trong việc hình thành và phát triển ý định khởi nghiệp cho sinh viên. Nhiều bài nghiên cứu đã khẳng định mối quan hệ giữa học vấn và khởi nghiệp, Kwong, Evans \& Brooksbank (2006) 
khẳng định cá nhân có bằng tốt nghiệp đại học thường tham gia vào những giai đoạn đầu của hoạt động khởi nghiệp hơn so với những người không có bằng cấp và trở thành chủ của các công ty có mức tăng trưởng cao.

\subsubsection{Nhóm yếu tố đặc điểm tính cách (Personality traits)}

Theo Meredith và các cộng sự đã tóm tắt 5 đặc điểm tính cách cá nhân mà mỗi nhà khởi nghiệp doanh nghiệp đều có, bao gồm: sự tự tin, sự năng động nhạy bén, có hoài bão, sự tự chủ cao, và sự sẵn sàng chấp nhận rủi ro.

Sự sẵn sàng và chấp nhận rủi ro là quan niệm và thái độ của mỗi người trước những rủi ro và mạo hiểm trong cuộc sống, có người ưa thích rủi ro, có người ghét rủi ro và có người trung lập với rủi ro. Chính vì vậy, thái độ của mỗi người với rủi ro ảnh hưởng đến ý định và quyết định hành động của mình. Nhiều người tránh rủi ro bằng cách chọn cho mình một công việc với mức lương ổn định, luôn nghĩ rằng khởi nghiệp đi liền với rủi ro. Chi phí thất bại với rủi ro được cân nhắc cẩn thận.

\subsubsection{Nhóm các yếu tố xã hội (Social factors)}

Xã hội là yếu tố ảnh hưởng lớn đến ý định khởi nghiệp, bao gồm các yếu tố: vai trò, tầm ảnh hưởng của nhà khởi nghiệp kinh doanh trong xã hội; hỗ trợ từ phía xã hội; hỗ trợ từ phía gia đình. Nhiều người nhận định khởi nghiệp là một lựa chọn nghề nghiệp đúng đắn hoặc đáng ngưỡng mộ, trong khi đó số khác rất xem trọng khởi nghiệp, điều này đến từ thực tế những người khởi nghiệp thành công có địa vị khá cao và được tôn trọng. Ngược lại, một bộ phận xã hội xem khởi nghiệp nói chung và những người chọn con đường khởi nghiệp nói riêng là không khôn ngoan vì chứa đựng quá nhiều sự không chắc chắn. Ngày nay nhiều nước đã có những giải thưởng riêng nhằm vinh danh những nhà khởi nghiệp hoặc tạo nên các chiến dịch về khởi nghiệp. Thái độ của xã hội đến khởi nghiệp ảnh hưởng đến nhận thức về khởi nghiệp và ý định khởi nghiệp, định hướng thái độ của cá nhân đối với ý định khởi nghiệp.

\subsubsection{Nhóm các yếu tố văn hóa (Cultural factors)}

Văn hóa thể hiện sự tác động mạnh mẽ đến ý định khởi nghiệp, sự tồn tại của văn hóa khởi nghiệp là một minh chứng. Ví dụ điển hình nhất cho sự tác động của văn hóa, là trường hợp các quốc gia thu nhập cao ở Châu Âu. Mặc dù số liệu điều tra từ Global Entrepreneurship Monitor qua các năm 2007, 2008, 2009, 2010 cho thấy người dân có nhận định rất tốt về khởi nghiệp nhưng phần lớn lại không có ý định khởi nghiệp bởi một trong những lý do chính là 
không hề tồn tại văn hoá khởi nghiệp ở các quốc gia này (Bosma, Jones, Autio, \& Levie, 2007; Bosma, Acs, Autio, Coduras, \& Levie, 2008; Bosma \& Levie, 2009; Kelly, Bosma, \& Amóros, 2010). Điều đó lý giải vì sao sinh viên ở đây thích đi làm công cho các doanh nghiệp hơn là tìm kiếm cơ hội khởi nghiệp.

Các yếu tố văn hóa có thể được hiểu là chủ nghĩa cá nhân, chủ nghĩa tập thể, văn hóa ở đây không chấp nhận sự bất ổn định. Các yếu tố này mang tính

\subsubsection{Nhóm các yếu tố môi trương (Environmental factors)}

Môi trường là một yếu tố khách quan tác động đến ý định của cá nhân, bao gồm: nguồn lực kinh tế, cơ hội việc làm, thể chế chính trị. Hệ sinh thái khởi nghiệp bao gồm thể chế chính trị - văn hóa - xã hội liên quan đến khởi nghiệp tác động mạnh mẽ tới mỗi cá nhân tồn tại trong môi trường đó, đến sự hình thành và nâng cao ý định khởi nghiệp. Các cơ hội kinh doanh có xu hướng cao hơn ở các nước có thị trường tự do, ít rào cản, tình hình chính trị ổn định. Ngược lại, cơ chế chính sách bất ổn sẽ tác động tiêu cực đến ý định kinh doanh, khởi nghiệp của các cá nhân.

\subsection{Khung lý thuyết về hành vi}

\subsubsection{Lý thuyết hành động hợp lý (Theory of Reasoned Action)}

Mô hình hành động hợp lý của Ajzen và Fishbein (2011) cho thấy hành vi được quyết định bởi ý định thực hiện hành vi đó. Với hai yếu tố chính và thái độ cá nhân và chuẩn chủ quan. Trong đó, thái độ cá nhân được thể hiện bởi sự niềm tin với sự đánh giá kết quả của hành vi đó. Chuẩn chủ quan được hiểu là nhận thức của người ảnh hưởng sẽ nghĩ rằng cá nhân đó có nên hay không nên thực hiện hành vi đó.

Sơ đồ 2. Mô hình thuyết hành động hợp lý

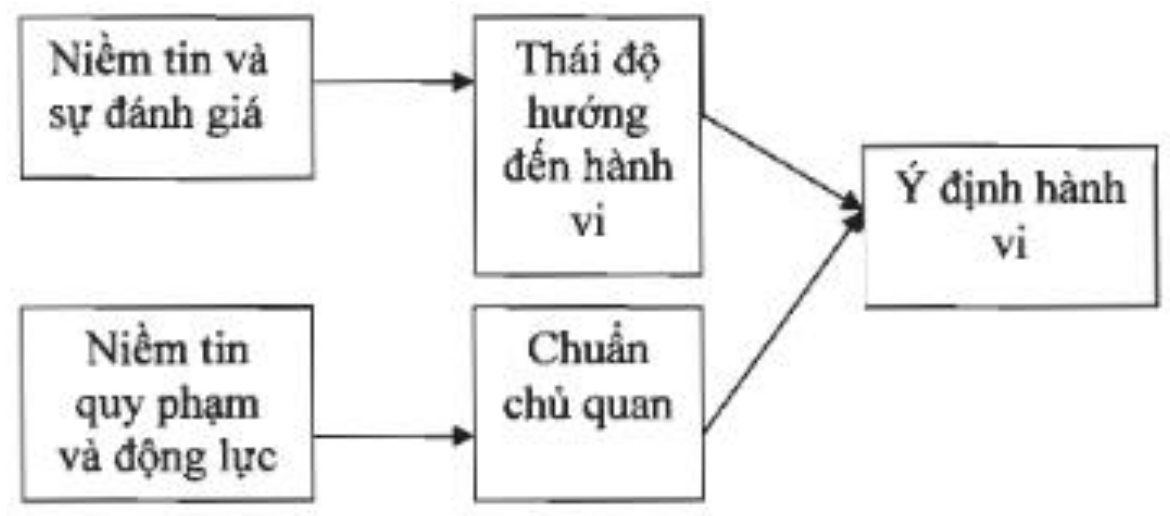


Tóm lại lý thuyết hành động hợp lý nhằm lý giải gián tiếp quá trình tác động của động cơ lên những hành vi thực sự, và những hành vi này thì không xuất phát từ ý chí và sự kiểm soát của cá nhân. Đây cũng là một điểm hạn chế của lý thuyết TRA. Lý thuyết này đã giải thích việc hình thành ý định khởi nghiệp của cá nhân bắt đầu từ những niềm tin tốt đẹp với kinh doanh, mong muốn trở thành doanh nhân, và những tác động từ phía những người quan trọng, ... Từ đó, niềm tin hay sự quan tâm của người xung quanh có thể truyền sang cá nhân chủ thể tiếp nhận, từ đó hình thành ý định kinh doanh khởi nghiệp.

\subsubsection{Lý thuyết hành vi có kế hoạch - Theory of planned behaviour (TPB)}

Năm 1991, Ajzen hoàn thiện Lý thuyết hành vi kế hoạch (TPB) trên cơ sở mô hình Hành động hợp lý (TRA), theo đó hành vi thực sự của một người được quyết định bởi ý định thực hiện hành vi đó. Ý định hành vi lại là một hàm của ba yếu tố. Thứ nhất, các thái độ được khái niệm như là đánh giá tích cực hay tiêu cực về hành vi thực hiện, nó chịu ảnh hưởng của niềm tin của cá nhân đó đối với kết quả hành động và việc cá nhân đó đánh giá kết quả hành động ra sao. Yếu tố thứ hai là ảnh hưởng xã hội mà đề cập đến sức ép xã hội được cảm nhận để thực hiện hay không thực hiện hành vi đó, nó chịu ảnh hưởng của niềm tin mà những người xung quanh có ảnh hưởng tới và sự thúc đẩy làm theo ý muốn những người ảnh hưởng. Yếu tố thứ ba là thành phần kiểm soát hành vi cảm nhận phản ánh việc dễ dàng hay khó khăn khi thực hiện hành vi; điều này phụ thuộc vào sự sẵn có của các nguồn lực và các cơ hội để thực hiện hành vi, Nó được dựa trên việc cá nhân biết làm thế nào và kinh nghiệm của họ hoặc quan niệm của họ về những trở ngại có thể xảy ra để thực hiện hành vi.

Sơ đồ 3. Mô hình Lý thuyết hành vi có kế hoạch

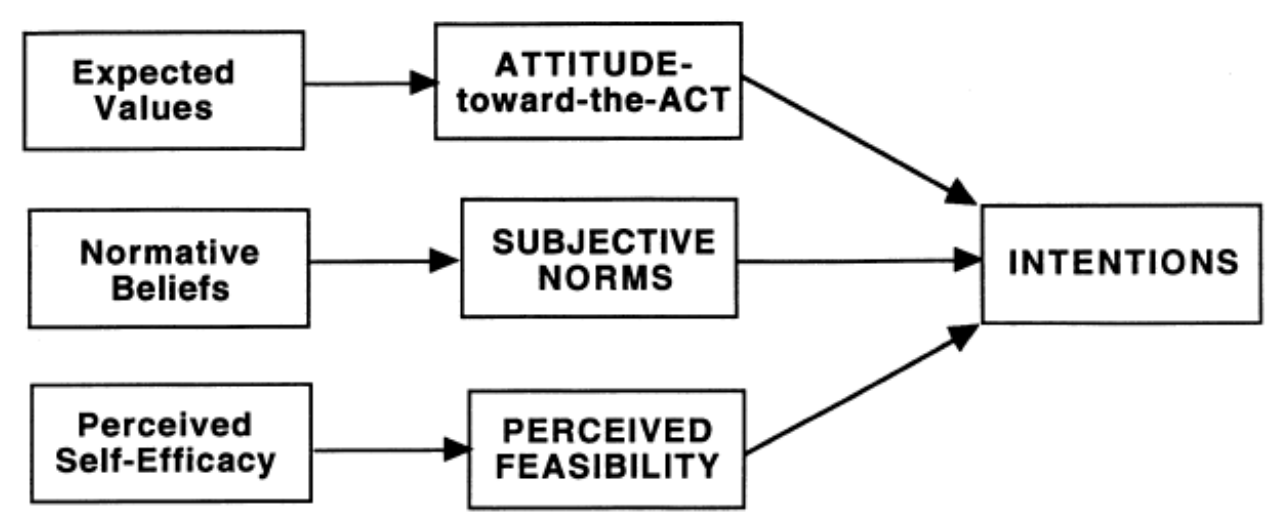

Nguồn: (Ajzen, 1991) 
Thái độ của cá nhân đối với một hành vi (Attitude toward the Act) là việc cá nhân đó cảm thấy như thế nào (tích cực hay tiêu cực) về tính mong muốn thực hiện hành vi. Khi kiểm tra sự ảnh hưởng của nó, nhận thấy rằng, thái độ này phụ thuộc vào giá trị kì vọng và niềm tin về các tác động của kết quả hành vi, bao gồm các yếu tố sau: sự giàu có, sự chủ động và lợi ích cộng đồng.

Chuẩn chủ quan (Perceived social norms) lại liên quan đến nhận thức của cá nhân về việc người khác (gia đình, bạn bè...) cảm thấy như thế nào khi cá nhân thực hiện hành vi đó. Chuẩn chủ quan ảnh hưởng bởi niềm tin về các chuẩn mực xã hội ở cá nhân. Gia đình mong muốn bạn trở thành bác sĩ, luật sư hay doanh nhân, những kỳ vọng của gia đình sẽ trở thành một động cơ để tuân thủ. Để phân tích được yếu tố này, cần xác định những ảnh hưởng quan trọng của xã hội, có thể kể đến như cha mẹ, những người đáng kính hơn, bạn bè.

Nhận thức kiểm soát hành vi (Perceived behavioral control) đề cập đến nhận thức về sự dễ dàng hay khó khi thực hiện hành vi, thể hiện nhận thức của cá nhân là bản thân có khả năng và đủ nguồn lực để thực hiện hành vi hay không. Năng lực kiểm soát hành vi chịu sự chi phối của nhận thức về năng lực ở mỗi cá nhân. Vậy nhận thức kiểm soát hành vi bao gồm năng lực bản thân và khả năng nhận thức để thực hiện hành vi mục tiêu.

\section{Năng lục cá nhân và hành vi quản lý}

Năng lực cá nhân đã được liên kết về mặt lý thuyết và thực tế với nhiều người quản lý và doanh nhân. Quan trọng nhất, nhận thức về năng lực thúc đẩy các lựa chọn liên quan đến nghề nghiệp, bao gồm tự làm chủ như một doanh nhân. Ví dụ, sự khác biệt về giới tính và dân tộc trong sở thích nghề nghiệp dường như được giải thích một cách đầy đủ bởi sự khác biệt về năng lực bản thân (Hackett, Betz, Casas, \& Rocha-Singh, 1992). Mối tương quan giữa năng lực bản thân và ý định nghề nghiệp nằm trong khoảng từ 0,3 đến 0,6 (Bandura 1986; Lent et al. 1994). Mối tương quan này tốt hơn hầu hết các dự đoán được sử dụng trong nghiên cứu khởi nghiệp, chẳng hạn như quỹ kiểm soát (Brockhaus \& Horwitz, 1986)

\section{Năng lục cá nhân và hành vi khởi nghiệp}

Năng lực bản thân được hiểu là sự bắt đầu và sự kiên trì với hành vi dù không chắc chắn, để thiết lập được mục tiêu cao hơn, giảm các rủi ro và tăng sự tự chủ. Điều này rất quan trọng, vì khả năng nhận biết cơ hội phụ thuộc vào sự nhận thức và kiểm soát tình huống. Nhận thức năng lực cá nhân là mấu chốt cho sự tự chủ trong hành động, nắm bắt cơ hội khởi nghiệp. Ngoài ra, năng lực bản thân có liên quan đến nhận thức cơ hội và chấp nhận rủi ro. Vậy mô hìn ảnh hưởng đến ý định kinh doanh chỉ khi chúng ảnh hưởng đến hiệu quả bản thân. 
Như vậy, khung lý thuyết do Ajzen phát triển cho biết ý định chịu sự tác động trực tiếp của ba yếu tố: Thái độ hay quan điểm của cá nhân, Nhận thức kiểm soát hành vi và Chuẩn chủ quan. Nét mới của TPB so với các mô hình còn lại là vai trò của quan điểm không chính thức trong xã hội được đề cập trong TPB dưới tiền tố chuẩn chủ quan và đây được xem là biến độc lập ảnh hưởng tới ý định khởi nghiệp nhiều hơn so với khái niệm về văn hoá chung chung ở các nghiên cứu khác. Trong khi hầu hết các tác giả đều tập trung đều tập trung vào yếu tố cá nhân trước khi tiến hành hoạt động khởi nghiệp, chỉ riêng học giả Ajzen xây dựng Lý thuyết hành vi có kế hoạch. TPB đã xem xét cả các yếu tố nhận thức cá nhân kết hợp với yếu tố nhận thức xã hội nhằm dự đoán ý định và hành vi của con người trước các quyết định quan trọng như khởi nghiệp. Ở TPB, quan điểm cá nhân, chuẩn chủ quan, nhận thức kiểm soát hành vi và ý định hành động kết hợp một cách hoàn hảo để dự đoán hành vi. Do đó, TPB được đánh giá là mô hình hoàn chỉnh nhất và được xem là công cụ hữu ích để để lý giải hay dự đoán ý định khởi nghiệp.

Tuy nhiên TPB cũng có hạn chế trong việc dự đoán hành vi. Theo quan điểm của nhà nghiên cứu Werner, hạn chế của TPB là yếu tố quyết định ý định không giới hạn thái độ, chuẩn chủ quan, kiểm soát hành vi cảm nhận. Có thể có các yếu tố khác ảnh hưởng đến hành vi. Dựa trên kinh nghiệm nghiên cứu cho thấy rằng chỉ có $30 \%-50 \%$ sự biến động của hành vi có thể được giải thích bằng cách sử dụng $\mathrm{TPB}$. Do vậy mặc dù $\mathrm{TPB}$ được đánh giá là là mô hình hiệu quả để nghiên cứu ý định khởi nghiệp, các nhà nghiên đương đại vẫn có thể đưa thêm một số biến tác động vào mô hình nghiên cứu. Đơn cử như nghiên cứu khẳng định việc đưa thêm các biến khả dĩ khác vào mô hình có thể đem lại tính chính xác cao hơn trong việc dự đoán ý định bởi xu hướng hành động không chỉ phụ thuộc duy nhất vào các yếu tố cảm nhận của cá nhân với hành vi khởi nghiệp hay ý kiến của những người xung quanh. Ngay cả cha đẻ của TPB cũng khuyên các nhà nghiên cứu nên xem xét đưa thêm các biến khả thi vào mô hình nghiên cứu. Do đó, luận án lựa chọn các yếu tố tác động mang tính nhận thức cá nhân trong TPB làm mô hình gốc, đồng thời xem xét bổ sung thêm một số biến tác động thuộc môi trường bên ngoài vào mô hình nghiên cứu.

Với nhóm mô hình nghiên cứu khác, ý định khởi nghiệp chịu sự tác động của các nhóm yếu tố bên ngoài cá nhân như bối cảnh kinh tế, chính trị, văn hóa, xã hội hay các đặc trưng nhân khẩu học của mỗi các nhân (mô hình của Bird), cảm nhận của cá nhận về điều kiện thị trường tài chính, về môi trường giáo dục đại học. Đây cũng được xem là các nhóm yếu tố hết sức quan trọng và việc bổ sung các nhóm yếu tố này vào mô hình nghiên cứu mang ý nghĩa quan trọng bởi một cá nhân không chỉ tồn tại một cách độc lập mà luôn có mối quan hệ chặt chẽ với môi 
trường xung quanh. Do vậy mặc dù có nhiều yếu tố ảnh hưởng đén ý định khởi nghiệp nhưng bài nghiên cứu đã xem xét lựa chọn nhân tố giới tính và phân tịch theo lý thuyết TPB của Ajzen. 


\section{CHƯƠNG 3. MÔ HÌNH ĐỀ XUÁT VÀ PHƯƠNG PHÁP NGHIÊN CÚU}

\subsection{Quy trình thực hiện nghiên cứu}

Sơ đồ 4. Quy trình nghiên cứu

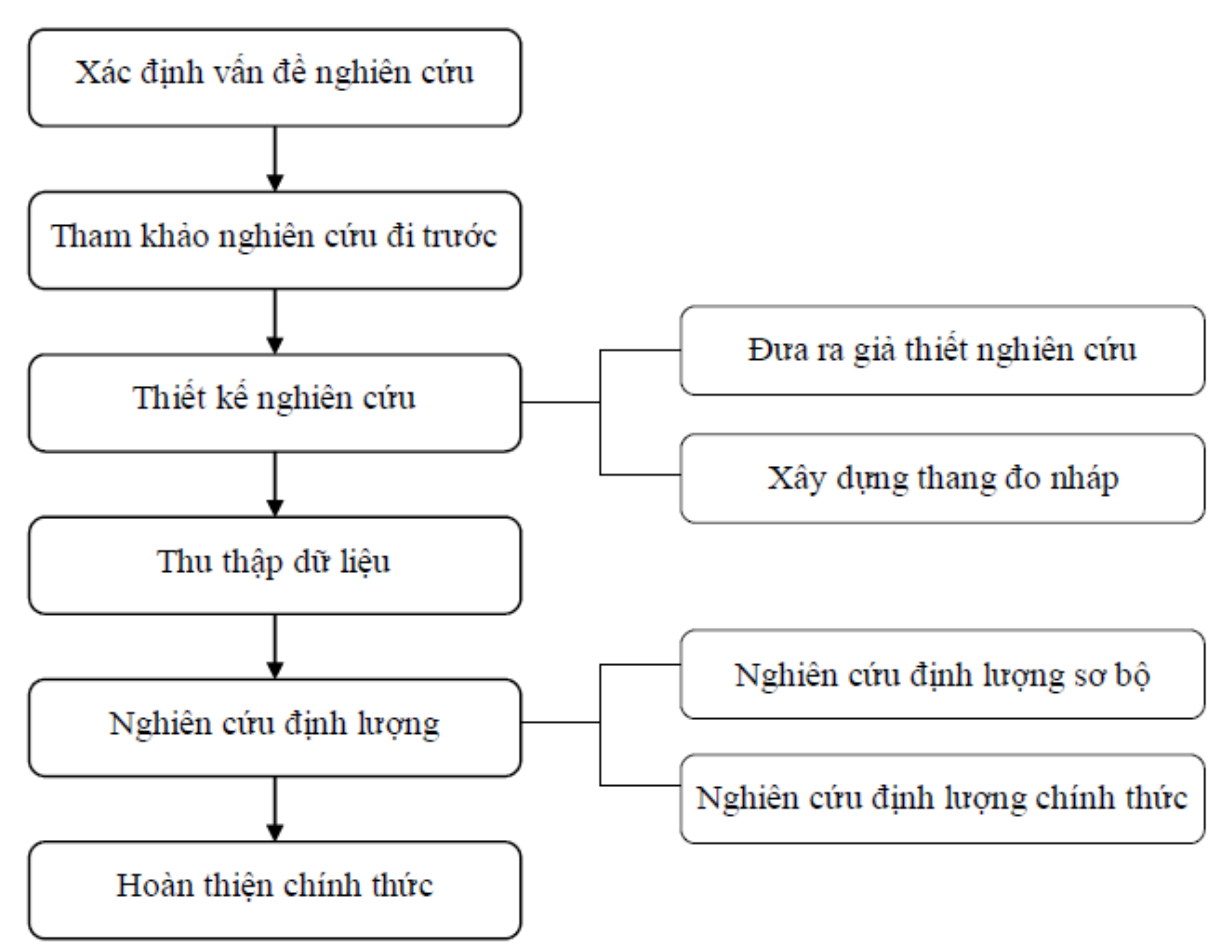

\section{Nguồn: Nhóm nghiên cứu tụ tổng hợp}

Bước 1: Xác định vấn đề nghiên cứu: Đầu tiên, nhóm tác giả cần xác định vấn đề nghiên cứu, cụ thể ở đây là ảnh hưởng của giới tính tới các nhân tố ảnh hưởng đến ý định khởi nghiệp. Tiếp theo, sau khi xác định vấn đề nghiên cứu, nhóm tác giả xác định từng mục tiêu nghiên cứu cụ thể.

Bước 2: Tham khảo các nghiên cứu đi trước: Nhóm tác giả tiến hành tìm hiểu và tập hợp từ các nghiên cứu đi trước trong nước và nước ngoài về các khái niệm, các mối quan hệ giữa các khái niệm trong ý định khởi nghiệp của sinh viên. Đồng thời tìm hiểu về các nhân tố khác ảnh hưởng đến ý định khởi nghiệp, cụ thể là thái độ đối với khởi nghiệp, chuẩn mực niềm tin, nhận thức kiểm soát hành vi.

Bước 3: Thiết kế nghiên cứu: Dựa vào những dữ liệu thu thập được ở bước 2, nhóm tác giả xem xét thiết lập mô hình nghiên cứu chứa những giả thiết nghiên cứu và xây dựng bộ thang đo nháp cho từng khái niệm nghiên cứu trong mô hình. Ngoài ra nhóm tác giả cũng tham khảo thêm một số nghiên cứu trước đó để thiết kế các biến phân loại bằng câu hỏi phụ. 
Bước 4: Nhóm tác giả đã thực hiện một cuộc khảo sát trên một mẫu gồm 210 sinh viên đại học tại Hà Nội với tỉ lệ xấp xỉ 1 nam tương ứng với 2 nữ. Theo sau Krueger et al. (2000) và Liñán và Chen (2009), nhóm tác giả đã lựa chọn những sinh viên quan tâm đến kinh doanh và đang đứng trước ngưỡng cửa quyết định tương lai nghề nghiệp của bản thân. Vì theo Shinnar et al. (2012) thì một số sinh viên sẽ bị thu hút bởi việc khởi nghiệp trong khi những người khác thì không nên cần mở rộng mẫu điều tra nên nhóm tác giả khảo sát phần lớn dựa trên nhóm sinh viên kinh tế. Dự kiến nhóm tác giả sẽ sử dụng hai phương pháp đánh giá là kiểm định Cronbach Alpha và phân tích khám phá nhân tố EFA. Kết quả đánh giá sơ bộ thang đo sẽ giúp nhóm tác giả loại đi những biến quan sát không phù hợp để hình thành thang đo cho nghiên cứu định lượng chính thức. Sau khi có thang đo chính thức, dữ liệu thu thập sẽ được tiến hành tổng hợp, làm sạch và phân tích bằng các kỹ thuật gồm: thống kê mô tả, phân tích khẳng định nhân tố, thông qua việc sử dụng các phần mềm phân tích dữ liệu Excel và SPSS.

Bước 5: Hoàn thiện chính thức: Sau khi tiến hành phân tích dữ liệu nhóm tác giả sẽ đưa ra các kết luận và viết báo cáo để trả lời các vấn đề nghiên cứu đặt ra. Ngoài ra, nhóm tác giả cũng xác định ý nghĩa, những đóng góp, những hạn chế của nghiên cứu và hướng nghiên cứu tiếp theo trong tương lai cho đề tài và lĩnh vực nghiên cứu.

\subsection{Mô hình và giả thuyết nghiên cứu}

\subsubsection{Mô hình nghiên cứu}


Sơ đồ 5 . Mô hình thể hiện mối quan giữa giới tính và các nhân tố ảnh hưởng đến ý định khởi nghiệp

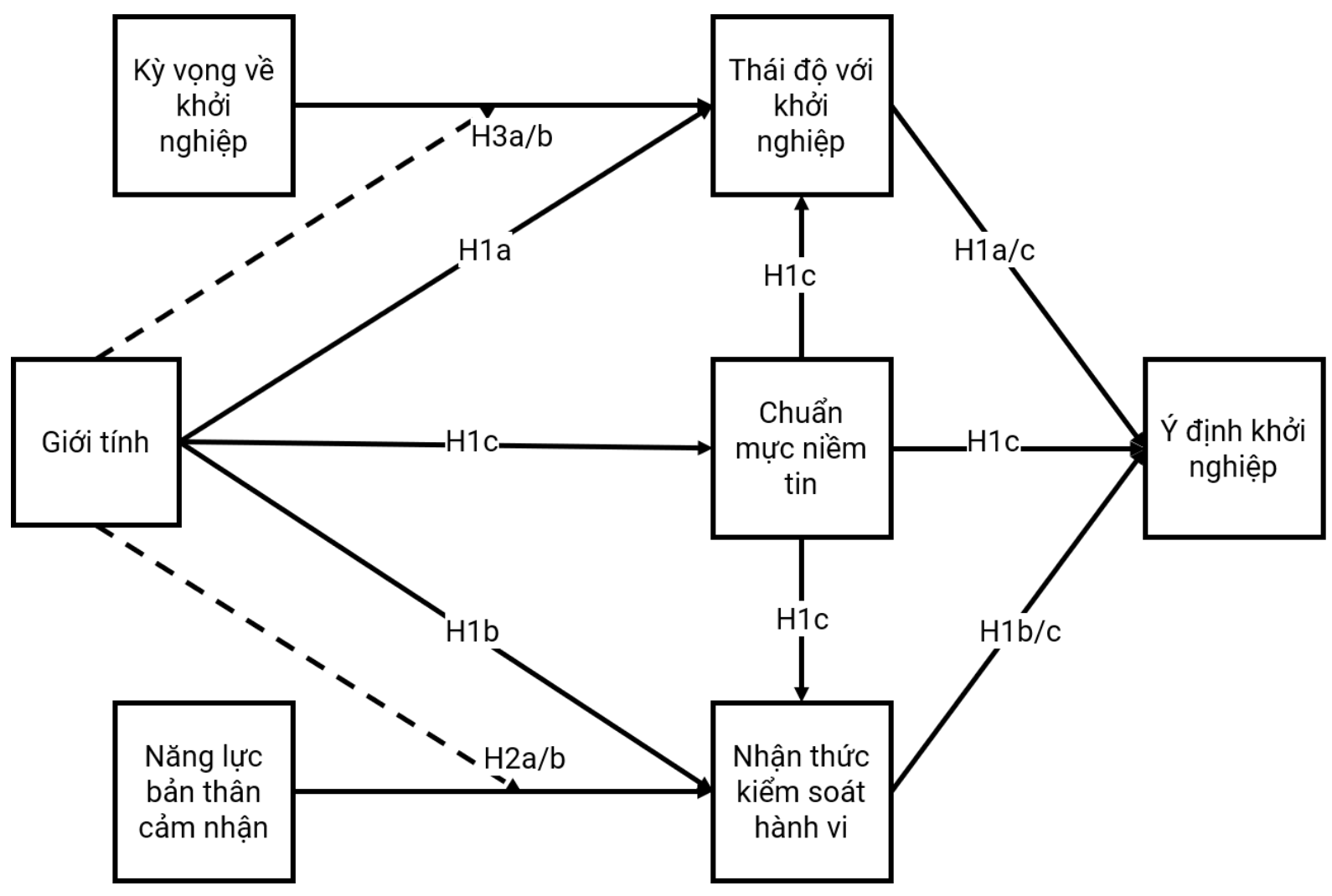

Nguồn: Nhóm nghiên cứu tụ tổng hợp

\subsubsection{Các giả thuyết nghiên cưu}

Liñán và Chen (2009) cho rằng thái độ đối với khởi nghiệp và nhận thức kiểm soát hành vi có ảnh hưởng tích cực đến ý định khởi nghiệp, còn yếu tố chuẩn mực niềm tin lại không ảnh hưởng rõ rệt đến ý định khởi nghiệp. Điều này còn được khẳng định hơn nữa trong các nghiên cứu của Conner và Armitage (1998), về việc thực hiện tổng quan về nghiên cứu trước đây về TPB và thấy rằng vai trò của các chuẩn mực niềm tin là không thuyết phục. Nhìn chung, nhận định này cũng đã được chỉ ra ở nhiều nghiên cứu trước đó (Carsrud \& Brännback, 2011). Ngoại lệ duy nhất là nghiên cứu của Kolvereid và Isaksen (2006). Tuy nhiên, trong bài nghiên cứu này, nhóm tác giả sẽ đưa ra giả thiết về việc chuẩn mực niềm tin có ảnh hưởng nổi bật tới ý định khởi nghiệp và kiểm chứng. Bên cạnh đó, Liñán và Chen (2009) đã đề xuất việc đưa chuẩn mực niềm tin nghiên cứu thông qua thái độ với khởi nghiệp và nhận thức kiểm soát hành vi. Điều này cũng được nhóm tác giả đưa trong các giả thuyết.

Bên cạnh xem xét nhân tố ảnh hưởng của lý thuyết hành vi định trước, nhóm tác giả còn xem xét mối liên hệ của các nhân tố này với giới tính. Liñán và Chen (2009) đã phát hiện ra ảnh hưởng tích cực của giới tính tới thái độ đối với khởi nghiệp và nhận thức kiểm soát hành 
vi. Cụ thể, nam giới bị thu hút nhiều hơn bởi việc kinh doanh và cho rằng bản thân họ có khả năng thực hiện nó hơn so với nữ giới. Ngoài ra, Verheul et al. (2009) cho rằng nam giới bị ảnh hưởng nhiều hơn bởi chuẩn mực niềm tin so với nữ giới. Thêm vào đó, nữ giới cho rằng bản thân họ ít có khả năng kinh doanh (Barnir et al., 2011; Langowitz \& Triniti, 2007) và rằng một khuôn mẫu giới tính doanh nhân nam giới đã thiết lập các chuẩn mực niềm tin rằng kinh doanh ít phù hợp với nữ giới (ví dụ Mueller \& Conway Dato-on, 2013; Shinnar, Giacomin, \& Janssen, 2012). Dựa trên những nghiên cứu này, chúng tôi đề xuất các giả thuyết sau ở cấp độ yếu tố của mô hình lý thuyết hành vi định trước

Hla: Thái độ đối với khởi nghiệp đóng vai trò nhu 1 nhân tố trung gian trục tiếp giải thích ý định khởi nghiệp mạnh hơn của nam so với nũ

H1b: Nhận thức kiểm soát hành vi đóng vai trò nhu 1 nhân tố trung gian trục tiếp giải thích ý định khởi nghiệp mạnh hơn của nam so với nũ.

Hlc: Chuẩn mưc niềm tin vì̀a đóng vai trò nhu 1 nhân tố trung gian trục tiếp giải thích $y$ định khởi nghiệp mạnh hơn của nam so với nũu, vùa đóng vai trò nhu 1 nhân tố trung gian gián tiếp khi ảnh hưởng thông qua thái độ đối với khởi nghiệp và nhận thức kiểm soát hành vi. kết quả của Yang (2013) đối với sinh viên Trung Quốc cũng cho ra kết quả như vậy. Cụ thể, nữ giới ảnh hưởng tiêu cực đến thái độ đối với khởi nghiệp, nhận thức kiểm soát hành vi và chuẩn mực niềm tin hơn nam giới.

Theo các nghiên cứu trước đây, có rất nhiều yếu tố ảnh hưởng đến kỳ vọng về khởi nghiệp như sự tự chủ, thách thức, tài chính (Kolvereid \& Isaksen, 2006; Krueger et al., 2000; Souitaris, Zerbinati, \& Al-Laham, 2007; Van Gelderen et al., 2008). Carter và cộng sự. (2003) đã liệt kê sáu thuộc tính mà cả nam giới và phụ nữ đều có thể coi trọng trong tinh thần kinh doanh như sự tự chủ, tài chính dư giả, vai trò, tính đổi mới, công nhận và sự độc lập. Trong đó yếu tố tài chính và đổi mới sáng tạo được ưu tiên hơn cả. Cromie (1987) cho rằng phụ nữ ít quan tâm đến việc kiếm tiền và thường chọn khởi nghiệp như là một phương tiện để con cái và gia đình của họ. Các nghiên cứu khác cũng đã đưa ra kết luận này. Budig (2006) phát hiện ra rằng nữ giới làm các công việc tự do để cân bằng công việc và gia đình. Georgellis và Wall (2005) chỉ ra rằng phụ nữ coi khởi nghiệp như một sự thay thế cho công việc bán thời gian.

Kirk và Belovics (2006) đã chỉ ra rằng nam giới và nữ giới khác nhau về động lực trở thành doanh nhân: nữ giới chọn kinh doanh để cân bằng giữa công việc và gia đình, trong khi nam giới tìm kiếm sự giàu có. Nhìn chung, dường như cả nam giới và phụ nữ đều coi kinh doanh là một phương tiện để 'tiến lên' (tuy nhiên, đàn ông mạnh mẽ hơn phụ nữ). Nhóm tác giả 
quy các thuộc tính như tiền, thách thức... là yếu tố "thành tích" trong khi các thuộc tính như tự chủ, cân bằng cuộc sống công việc... như yếu tố "cân bằng”.

\section{H2a: Nũ giới giá trị tính cân bằng trong khởi nghiệp nhiều hơn nam giới.}

H2b: Nũ giới giá trị tính cạnh tranh trong khởi nghiệp it hơn nam giới.

Năng lực bản thân cảm nhân từ bên trong có liên quan đến khả năng cá nhân, trong khi Năng lực bản thân cảm nhân từ bên ngoài có liên quan đến tính cách trong các tình huống. Langowitz và Triniti (2007) và Noguera, Alvarez và Urbano (2013) đã kết luận rằng việc phụ nữ khởi nghiệp bị ảnh hưởng tích cực bởi khả năng phát hiện cơ hội có và việc tự đánh giá có đủ kỹ năng và kiến thức hay không. Kỹ năng bao gồm khả năng giải quyết vấn đề, đưa ra quyết định, quản lý tiền bạc, sáng tạo, thuyết phục mọi người, truyền cảm hứng. Theo Ajzen (2002), tuy nhiên, trọng tâm được mở rộng để bao gồm các thuộc tính kiểm soát bên ngoài. Verheul et al. (2009) đã chứng minh rằng nữ giới nhận thức được nhiều rào cản bên ngoài hơn để trở thành một doanh nhân. Các tác giả này liệt kê các rào cản như văn hóa khác nhau trong quản lý, luật pháp và thiếu sự hỗ trợ kinh tế. Heilman, Martell và Simon (1988) phát hiện ra rằng những người cho vay, khách hàng, nhà cung cấp ... thường chịu sự ảnh hưởng của định kiến về giới tính (hình ảnh doanh nhân thường là nam giới) bởi vì họ đưa ra quyết định dựa trên thông tin không đầy đủ. Điều này tất nhiên làm tăng những thách thức mà nữ giới phải đối mặt để trở thành doanh nhân. Do đó, nhóm tác giả cho rằng năng lực bản thân cảm nhân từ bên trong (so với bên ngoài) sẽ chiếm ưu thế hơn trong việc dự đoán kiểm soát hành vi nhận thức. Theo quan điểm của lý do này, nhóm tác giả đưa ra giả thuyết.

H3a: Năng lục bản thân cảm nhân tù bên trong là quan trọng đối với nũu giới hơn nam giới trong khởi nghiệp

H3b: Năng lục bản thân cảm nhân tù̀ bên ngoài là quan trọng đối với nũ giới hơn nam giới trong khởi nghiệp

\subsection{Thiết kế nghiên cứu}

\subsubsection{Phát triển bảng hỏi và lựa chọn thang đo nghiên cúu}

Mô hình nghiên cứu gồm 6 khái niệm nghiên cứu. Các khái niệm - các nhân tố tiềm ẩn được đo lường thông qua 2-5 biến quan sát. Các biến quan sát được tham khảo, kế thừa từ các nghiên cứu nước ngoài đi trước và hiệu chỉnh cho phù hợp với bối cảnh và môi trường nghiên cứu. Đầu tiên các bộ câu hỏi được dịch từ tiếng Anh sang tiếng Việt và sau đó dịch ngược để đảm bảo tính chính xác và ý nghĩa của các câu hỏi gốc. Bước thứ hai, nhóm tác giả đánh giá thử bộ câu hỏi với 20 người và ghi nhận các phản hồi, từ đó điều chỉnh để đảm bảo sự rõ ràng, 
phù hợp về ngữ nghĩa, lối diễn đạt. Kết quả cuối cùng sử dụng cho điều tra thực nghiệm thu được như sau:

Bảng 1. Câu hỏi khảo sát

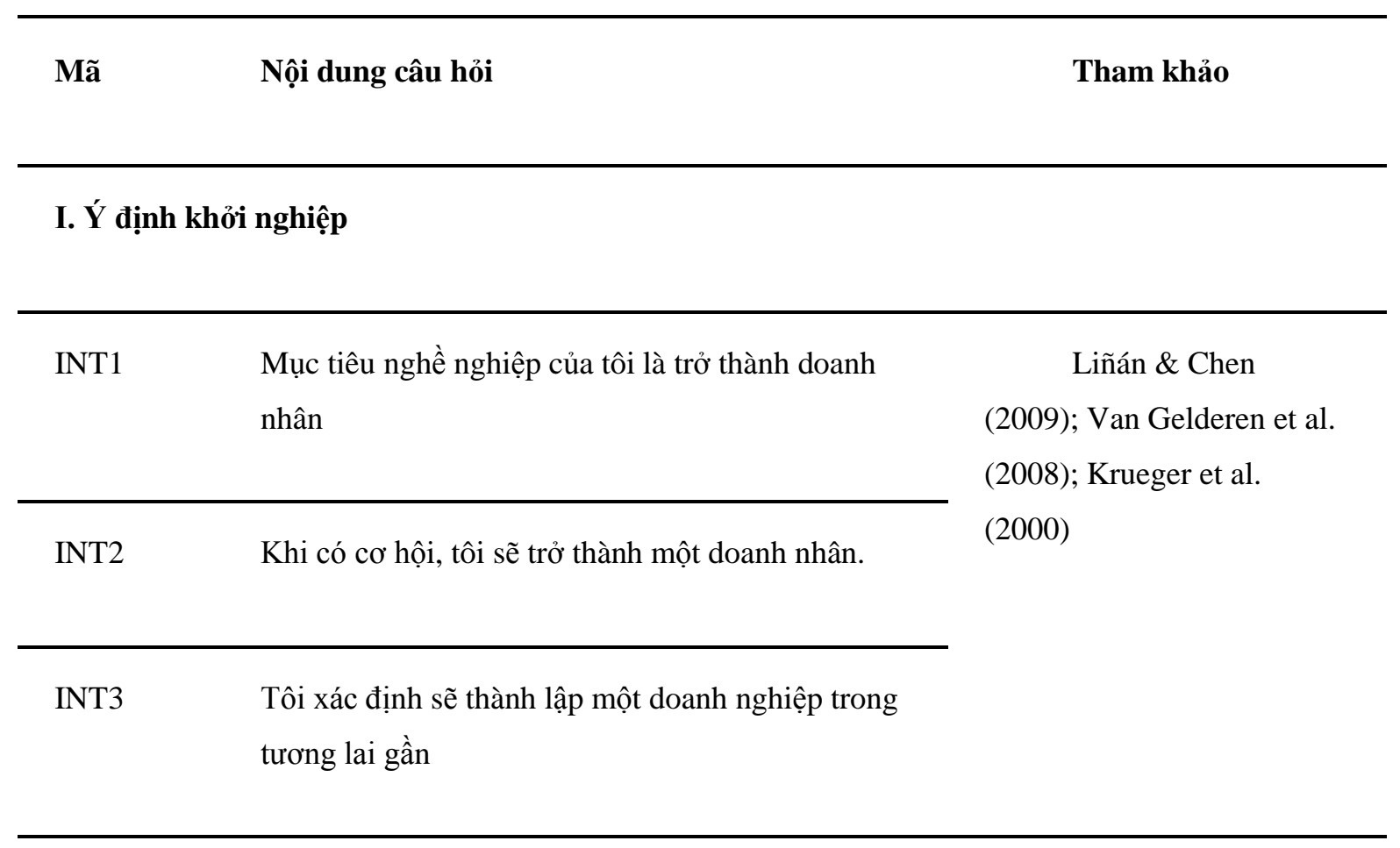

\section{Thái độ với khởi nghiệp}

\begin{tabular}{lll}
\hline ATT1 & Tôi thấy việc khởi nghiệp là hấp dẫn & $\begin{array}{c}\text { Krueger et al. (2000); } \\
\text { Autio và cộng sự (2001); } \\
\text { ATT2 }\end{array}$ \\
$\begin{array}{lll}\text { Tônán \& Chen (2009) } \\
\text { lợi ích cho tồi hơn là bất lợi }\end{array}$ & \\
\hline
\end{tabular}

\section{Kỳ vọng về khởi nghiệp}

\begin{tabular}{ll}
\hline BBE1 & $\begin{array}{l}\text { Tôi muốn đối mặt với nhiều thử thách mới trong } \\
\text { sự nghiệp của mình. }\end{array}$ \\
\hline BBE2 & $\begin{array}{l}\text { Tôi coi trọng sự tự chủ trong nghề nghiệp tương et al. (2000) } \\
\text { lai của tôi. }\end{array}$ \\
\hline
\end{tabular}

\section{Chuẩn mực niềm tin}


NBL1 Bố me luôn định hướng tôi trở thành một doanh

Kolvereid và Isaksen nhân

(2006); Krueger et al.

(2000); Liñán \& Chen

NBL2 Bạn bè nghĩ khởi nghiệp là một sự lựa chọn hợp

lý với tôi

NBL3 Người thân của tôi luôn mong muốn tôi trở thành

một doanh nhân

\section{Nhận thức kiểm soát hành vi}

\begin{tabular}{lll}
\hline PBC1 & $\begin{array}{l}\text { Tôi tự tin sẽ thành lập công ty riêng của mình } \\
\text { trong tương lai }\end{array}$ & $\begin{array}{c}\text { Krueger et al. (2000); } \\
\text { Kraft, Rise, Sutton và } \\
\text { Roysamb (2005) }\end{array}$ \\
\cline { 1 - 2 } PBC2 & $\begin{array}{l}\text { Tôi tự tin sẽ vượt qua các trở ngại để trở thành } \\
\text { doanh nhân }\end{array}$ & \\
\hline PBC3 & $\begin{array}{l}\text { Tôi tin rằng mình có đủ năng lực để trở thành một } \\
\text { doanh nhân }\end{array}$ \\
\hline PBC4 & $\begin{array}{l}\text { Trở thành doanh nhân là một lựa chọn phù hợp } \\
\text { dối với tôi. }\end{array}$ \\
\hline
\end{tabular}

VI. Năng lực bản thân cảm nhận

CBP1 Tôi nghĩ rằng mình có đủ kiến thức cần thiết để

Krueger et al. (2000);

trở thành doanh nhân.

Autio và cộng sự (2001);

Liñán \& Chen (2009)

CBP2 Tôi thấy mình có đủ khả năng nhạy bén để phát

hiện ra những cơ hội kinh doanh tốt.

CBP3 Thiếu nguồn lực tài chính không ngăn tôi khởi

nghiệp 
CBP4 Sự hỗ trợ của chính phủ không ảnh hưởng đến

quyết định trở thành doanh nhân.

CBP5

Tôi nghĩ rằng mình có đủ sự sáng tạo để trở thành

doanh nhân

Nguồn: Tổng hợp của nhóm tác giả

Thang đo được sử dụng để đo lường các khía cạnh trong các nhân tố (đo lường các biến quan sát) là thang đo Likert 5 điểm. Mặc dù về nguyên tắc sử dụng thang đo càng nhiều điểm càng chính xác, tuy nhiên để tránh nhầm lẫn cho người trả lời khảo sát, nhóm tác giả sử dụng thang đo Likert 5 điểm với điểm 1 là "hoàn toàn không đồng ý" và điểm 5 là "hoàn toàn đồng ý”. Bên cạnh nhóm câu hỏi phục vụ cho mô hình nghiên cứu, bảng khảo sát còn bao gồm 1 phần câu hỏi mang tính chất sàng lọc và phân loại đối tượng điều tra, đó là câu hỏi về các thông tin nhân khẩu học đặc biệt là về giới tính hay câu hỏi về việc sinh viên đã từng khởi nghiệp hoặc có ý khởi nghiệp trong tương lai hay không.

\subsubsection{Tổng thể, mẫu nghiên cưu và phuơng pháp thu thập dũ liệu}

Việc điều tra mẫu nghiên cứu tổng thể là không khả thi và rất khó có thể xác định chính xác tổng thể là bao nhiêu, do đó nhóm tác giả tiến hành điều tra chọn mẫu ngẫu nhiên. Hiện tại có rất nhiều quan điểm không thực sự thống nhất về kích cỡ mẫu phù hợp để đại diện cho tổng thể. Nếu cỡ mẫu lựa chọn dựa theo các quy tắc và yêu cầu của phân tích khám phá nhân tố EFA (Exploratory Factor Analysis) thì kích cỡ tối thiểu gấp 5 lần biến quan sát $\left(\mathrm{n}=5^{*} \mathrm{~m}\right)$ (Hair và cộng sự, 2010). Trong khi đó đối với phân tích hồi quy đa biến, cỡ mẫu tối thiểu cần đạt được tính theo công thức $\mathrm{n}=50+8 * \mathrm{p}$ trong đó $\mathrm{p}$ là số nhân tố tiềm ẩn (Tabachnick \& Fidell, 2006). Ngoài ra, quy tắc lấy mẫu có thể được dựa theo sai số biến dựa trên tổng thể nghiên cứu (Suanders et al., 2007). Trong phạm vi nghiên cứu, nhóm tác giả áp dụng cỡ mẫu trên 210 là phù hợp với mô hình và khả năng tiếp cận điều tra, đồng thời đạt mức tốt theo quy tắc Comrey \& Lee (1992). Phương pháp thu thập dữ liệu là điều tra online thông qua google forms. Nhóm tác giả gửi email, chia sẻ link khảo sát trên mạng xã hội Facebook và các diễn đàn với các ứng viên tiềm năng thuộc các trường kinh tế như Đại học Ngoại thương, Học viện tài chính hay Đại học Bách Khoa, .... Kết quả sau 2 tháng khảo sát (từ tháng cuối 02 đến tháng 04 năm 2018) thu về 270 phiếu điều tra online, như vậy mẫu chính thức phục vụ cho phân tích là 210 mẫu hợp lệ. 


\subsection{Phương pháp phân tích dữ liệu}

Sau khi thu thập, dữ liệu nghiên cứu được mã hóa và xử lý làm sạch, nhóm tác giả tiến hành phân tích đánh giá với sự hỗ trợ của phần mềm SPSS. Trong tương lai, nhóm nghiên cứu dự kiến sẽ sử dụng phương pháp thống kê Bayesian với phần mềm bayesvl trên môi trường $\mathrm{R}$ (Vuong \& La, 2019; La \& Vuong, 2019).

\subsubsection{Thống kê mô tả mẫu}

Các biến phân loại như: đã từng hoặc có ý định khởi nghiệp trong tương lai không và các biến nhân khẩu học (giới tính, trường đại học, năm đại học...) được phân loại bằng tần suất và tỷ lệ được sinh viên lựa chọn.

\subsection{2. Đánh giá so bộ thang đo}

Quá trình đánh giá sơ bộ thang đo được thực hiện bằng việc (1) xem xét độ tin cậy và (2) giá trị hội tụ của các nhân tố trong mô hình (tính đơn hướng).

Đầu tiên, nhóm tác giả sử dụng kiểm định độ tin cậy thang đo, được đánh giá thông qua hệ số Cronbach Alpha và hệ số tương quan biến tổng. Hệ số Cronbach Alpha giúp đo lường tính nhất quán nội tại của nhân tố (Suanders et al., 2007). Trong phạm vi phân tích bài, nhóm tác giả sử dụng giá trị 0.5 (Peterson, 1994) để xem xét độ tin cậy của 6 nhân tố trong quá trình điều tra sơ bộ với kích cỡ 210 mẫu nghiên cứu. Tiếp theo, để xem xét sự đóng góp mức đóng góp ý nghĩa giải thích khái niệm nghiên cứu, hệ số tương quan biến tổng của mỗi biến quan sát phải trên 0.3 (Nunally \& Bernstein, 1994).

Sau đó, nhóm tác giả sử dụng phân tích khám phá nhân tố để đánh giá giá trị hội tụ (tính đơn hướng) của các nhân tố tiềm ẩn. Phương pháp này được sử dụng chủ yếu để thu gọn từ nhóm nhiều biến quan sát thành biến tiềm ẩn mà vẫn giải thích được dữ liệu (Hair et al., 2010). Các tham số thống kê quan trọng và tiêu chí chấp nhận trong phân tích nhân tố (Hoàng Trọng và Chu Nguyễn Mộng Ngọc, 2008) gồm có: (1) hệ số tải nhân tố lớn 0.5; (2) chỉ số Eigenvalue lớn hơn 1; (3) chỉ số Kaiser-Meyer- Olkin (KMO) lớn 0.5; (4) kiểm định Bartlett có p-value nhỏ hơn 0.05 và (5) phương sai giải thích lớn hơn 50\%. Phương pháp phân tích nhân tố được sử dụng đánh giá sơ bộ này là phân tích thành phần chính (Principal component analysis) với phép quay vuông góc (varimax). 


\subsection{3. Đánh giá chính thức thang đo}

Các thang đo trong mô hình được tham khảo và thiết lập từ những nghiên cứu đi trước, việc sử dụng phân tích khẳng định nhân tố được xem là phù hợp với mẫu điều tra chính thức. Phương pháp phân tích khẳng định nhân tố được sử dụng nhằm kiểm chứng tính thích hợp của mô hình với dữ liệu thực tế và sự tồn tại của các khái niệm nghiên cứu (Hair và cộng sự, 2010). Mô hình tới hạn tiến hành phân tích với tất cả các khái niệm, được xây dựng để xem xét tính tương thích với dữ liệu thị trường, đánh giá các cấu trúc khái niệm trong mô hình với nhau, các khái niệm có đạt giá trị phân biệt, giá trị hội tụ hay không. Phương pháp ước lượng sử dụng là ước lượng bằng hàm hợp lý cực đại (maximum likelihood estimation).

Để đánh giá giá trị phân biệt giữa các khái niệm nghiên cứu với nhau, sử dụng kiểm định hệ số tương quan giữa các biến trong mô hình khác đơn vị (1). Nghiên cứu sử dụng phân tích bằng bootstrap với khoảng tin cậy $95 \%$. Nếu khoảng tin cậy $95 \%$ của các hệ số tương quan không chứa giá trị 1 thì các khái niệm được xem là đạt giá trị phân biệt (Anderson và Gerbing, 1988; Torkzadeh et al., 2003).

\subsection{4. Đánh giá của sinh viên về các nhân tố.}

Nghiên cứu sử dụng điểm trung bình, độ lệch chuẩn và khoảng tin cậy $95 \%$ để xem xét các đánh giá của khách hàng đối với 6 nhân tố.

\subsection{5. Đánh giá sụ khác biệt giữa các biến phân loại với ý định chuyển đổi}

Nghiên cứu sử dụng phương pháp so sánh trung bình t-test, phân tích phương sai (ANOVA) cho từng nhóm khách hàng phân loại theo nhân khẩu học và hoạt động sử dụng dịch vụ chia sẻ nhà ở với độ tin cậy 95\%. 


\section{CHƯONG 4. KẾT QUẢ NGHIÊN CÚU}

\subsection{Kết quả thống kê mô tả mẫu}

Nghiên cứu xem xét phân loại sinh viên tham gia khảo sát theo các tiêu chí về giới tính, trường đại học, năm đại học và ngành học. Trong số 210 phiếu khảo sát hợp lệ thu về, một số thông tin cá nhân bị khuyết do khách hàng từ chối cung cấp cũng đã được xử lý và mô phỏng (tỉ lệ khuyết dưới 5\%). Kết quả thống kê nhân khẩu học được thể hiện trong bảng:

Bảng 2. Đặc điểm sinh viên điều tra

\begin{tabular}{|c|c|c|c|}
\hline Nhóm & Thành phần & Số người & Tỷ lệ (\%) \\
\hline \multirow[t]{2}{*}{ Giới tính } & Nữ & 136 & $62.76 \%$ \\
\hline & Nam & 74 & $35.24 \%$ \\
\hline \multirow[t]{2}{*}{ Trường Đại học } & Đại học Ngoại thương & 157 & $74.76 \%$ \\
\hline & Các trường Đại học khác & 53 & $25.24 \%$ \\
\hline \multirow[t]{3}{*}{ Năm Đại học } & Năm 3 & 136 & $64.76 \%$ \\
\hline & Năm 4,5,6 & 39 & $18.57 \%$ \\
\hline & Năm 1,2 & 35 & $16.67 \%$ \\
\hline \multirow[t]{2}{*}{ Chuyên ngành } & Kinh tế & 167 & $79.52 \%$ \\
\hline & Khác & 43 & $20.48 \%$ \\
\hline \multirow{2}{*}{$\begin{array}{l}\text { Bạn đã từng khởi } \\
\text { nghiệp hoặc có ý định } \\
\text { khởi nghiệp }\end{array}$} & Có & 119 & $56.67 \%$ \\
\hline & Không & 91 & $43.33 \%$ \\
\hline
\end{tabular}

\section{Nguồn: Kết quả phân tích dũ liệu với sự hỗ trợ của phần mềm Excel}

Giải thích số liệu trong bảng: Từ kết quả bảng khảo sát có thể thấy, sinh viên tham gia trả lời phần lớn là năm 3 khối ngành kinh tế (cụ thể là trường Đại học Ngoại thương), chiếm gần $70 \%$ tổng số sinh viên thực hiện khảo sát. Về giới tính, số sinh viên nữ tham gia khảo sát nhiều gần gấp 2 lần so với sinh viên nam với tỷ lệ lần lượt là $62.86 \%$ và $37.11 \%$. 


\subsection{Kết quả đánh giá so bộ thang đo}

Nghiên cứu sử dụng hệ số Cronbach Alpha và hệ số tương quan biến tổng để đánh giá sơ bộ về độ tin cậy của thang đo đối với từng nhân tố. Bên cạnh đó, nghiên cứu cũng thực hiện phương pháp phân tích khám phá nhân tố EFA để kiểm tra tính hội tụ của các biến quan sát trong việc đo lường 6 biến tiềm ẩn với hệ số KMO, p-value của kiểm định Bartlett, phương sai giải thích và hệ số tải nhân tố. Việc đánh giá sơ bộ thang đo được tiến hành với 70 mẫu khảo sát và kết quả được thể hiện như trong bảng dưới đây:

Bảng 3. Kết quả đánh giá sơ bộ thang đo

\begin{tabular}{|l|l|l|l|l|l|}
\hline $\begin{array}{l}\text { Nhân tố (số biến } \\
\text { quan sát) }\end{array}$ & $\begin{array}{l}\text { Hệ } \\
\text { Cronbach } \\
\text { Alpha }\end{array}$ & $\begin{array}{l}\text { Tương quan } \\
\text { biến tổng bé } \\
\text { nhất }\end{array}$ & KMO & p-value & $\begin{array}{l}\text { Phương sai } \\
\text { trích }\end{array}$ \\
\hline $\begin{array}{l}\text { Ý định khởi nghiệp } \\
\text { (3) }\end{array}$ & 0,763 & 0,545 & 0,685 & 0,000 & $68,516 \%$ \\
\hline $\begin{array}{c}\text { Thái độ với khởi } \\
\text { nghiệp (2) }\end{array}$ & 0,637 & 0,467 & 0,5 & 0,000 & $73,363 \%$ \\
\hline $\begin{array}{l}\text { Kỳ vọng về khởi } \\
\text { nghiệp (2) }\end{array}$ & 0,522 & 0,354 & 0,5 & 0,000 & $67,712 \%$ \\
\hline $\begin{array}{l}\text { Chuẩn mực niềm tin } \\
\text { (3) }\end{array}$ & 0,825 & 0,601 & 0,679 & 0,000 & $74,039 \%$ \\
\hline $\begin{array}{l}\text { Nhận thức kiểm soát } \\
\text { hành vi (4) }\end{array}$ & 0,906 & 0,784 & 0,797 & 0,000 & $78,087 \%$ \\
\hline $\begin{array}{l}\text { Năng lực bản thân } \\
\text { (5) }\end{array}$ & 0,808 & 0,487 & 0,773 & 0,000 & $57,845 \%$ \\
\hline
\end{tabular}

Nguồn: Tổng hợp của nhóm tác giả

Nhân tố ý định khởi nghiệp:

Thang đo nhân tố ý định khởi nghiệp bao gồm 3 biến quan sát từ INT1 đến INT3, đạt tin cậy với hệ số Cronbach Alpha là 0.763 lớn hơn 0.6 và các hệ số tương quan biến tổng đều lớn hơn 0.3 (nhỏ nhất đạt 0.545). Từ kết quả phân tích khám phá nhân tố (bảng 3), các chỉ số cần thiết đều đạt yêu cầu trong đó, hệ số KMO lớn hơn 0.5 (0.685), p-value $=0.000$ nhỏ hơn 0.05 
và phương sai giải thích lớn hơn $50 \%$ (68.516\%), các hệ số tải đều lớn hơn 0.5 và hội tụ thành một nhân tố. Do đó, thang đo nhân tố ý định khởi nghiệp với ba biến quan sát đã đạt tính tin cậy cần thiết và là một thang đo đơn hướng.

\section{Nhân tố thái độ với khởi nghiệp:}

Thang đo nhân tố thái độ với khởi nghiệp khởi nghiệp bao gồm 2 biến quan sát từ ATT1 đến ATT2, đạt tin cậy với hệ số Cronbach Alpha là 0.637 lớn hơn 0.6 và các hệ số tương quan biến tổng đều lớn hơn 0.3 (nhỏ nhất đạt 0.467 ). Từ kết quả phân tích khám phá nhân tố (bảng 3 ), các chỉ số cần thiết đều đạt yêu cầu trong đó, hệ số KMO là $0.5, p$-value $=0,000$ nhỏ hơn 0.05 và phương sai giải thích lớn hơn $50 \%$ (73.363\%), các hệ số tải đều lớn hơn 0.5 và hội tụ thành một nhân tố. Do đó, thang đo nhân tố thái độ với khởi nghiệp với hai biến quan sát đã đạt tính tin cậy cần thiết và là một thang đo đơn hướng.

Nhân tố kỳ vọng về khởi nghiệp:

Thang đo nhân tố kỳ vọng về khởi nghiệp bao gồm 2 biến quan sát từ BBE1 đến BBE2, đạt tin cậy với hệ số Cronbach Alpha là 0.522 lớn hơn 0.5 và các hệ số tương quan biến tổng đều lớn hơn 0.3 (nhỏ nhất đạt 0.354 ). Từ kết quả phân tích khám phá nhân tố (bảng 3 ), các chỉ số cần thiết đều đạt yêu cầu trong đó, hệ số KMO là 0.5 , p-value $=0.000$ nhỏ hơn 0.05 và phương sai giải thích lớn hơn $50 \%$ (67.712\%), các hệ số tải đều lớn hơn 0.5 và hội tụ thành một nhân tố. Do đó, thang đo nhân tố kỳ vọng về khởi nghiệp với hai biến quan sát đã đạt tính tin cậy cần thiết và là một thang đo đơn hướng.

\section{Nhân tố chuẩn mưc niềm tin:}

Thang đo nhân tố chuẩn mực niềm tin bao gồm 3 biến quan sát từ NBL1 đến NBL3, đạt tin cậy với hệ số Cronbach Alpha là 0.825 lớn hơn 0.6 và các hệ số tương quan biến tổng đều lớn hơn 0.3 (nhỏ nhất đạt 0.601). Từ kết quả phân tích khám phá nhân tố (bảng 3), các chỉ số cần thiết đều đạt yêu cầu trong đó, hệ số KMO lớn hơn 0.5 (0.679), p-value $=0.000$ nhỏ hơn 0.05 và phương sai giải thích lớn hơn $50 \%$ (74.039\%), các hệ số tải đều lớn hơn 0.5 và hội tụ thành một nhân tố. Do đó, thang đo nhân tố chuẩn mực niềm tin với ba biến quan sát đã đạt tính tin cậy cần thiết và là một thang đo đơn hướng.

\section{Nhân tố nhận thức kiểm soát hành vi:}

Thang đo nhân tố nhận thức kiểm soát hành vi bao gồm 4 biến quan sát từ $\mathrm{PBC} 1$ đến PBC4, đạt tin cậy với hệ số Cronbach Alpha là 0.906 lớn hơn 0.6 và các hệ số tương quan biến tổng đều lớn hơn 0.3 (nhỏ nhất đạt 0.784 ). Từ kết quả phân tích khám phá nhân tố (bảng 3), các chỉ số cần thiết đều đạt yêu cầu trong đó, hệ số KMO lớn hơn 0.5 (0.797), p-value $=0.000$ nhỏ 
hơn 0.05 và phương sai giả i thích lớn hơn $50 \%$ (78,087\%), các hệ số tải đều lớn hơn 0,5 và hội tụ thành một nhân tố. Do đó, thang đo nhân tố nhận thức kiểm soát hành vi với bốn biến quan sát đã đạt tính tin cậy cần thiết và là một thang đo đơn hướng.

Nhân tố năng lực bản thân:

Thang đo nhân tố năng lực bản thân bao gồm 5 biến quan sát từ CBP1 đến CBP5, đạt tin cậy với hệ số Cronbach Alpha là 0,808 lớn hơn 0,6 và các hệ số tương quan biến tổng đều lớn hơn 0,3 (nhỏ nhất đạt 0,487 ). Từ kết quả phân tích khám phá nhân tố (bảng 3), các chỉ số cần thiết đều đạt yêu cầu trong đó, hệ số KMO lớn hơn $0,5(0,773)$, p-value $=0,000$ nhỏ hơn 0,05 và phương sai giải thích lớn hơn $50 \%$ (57,845\%), các hệ số tải đều lớn hơn 0,5 và hội tụ thành một nhân tố. Do đó, thang đo nhân tố năng lực bản thân với năm biến quan sát đã đạt tính tin cậy cần thiết và là một thang đo đơn hướng.

\subsection{Kết quả đánh giá chính thức thang đo}

Kết quả đánh giá sơ bộ thang đo với cỡ mẫu 70 cho thấy các khái niệm nghiên cứu đạt tính tin cậy cần thiết và phù hợp với dữ liệu nghiên cứu. Tiếp tục, nghiên cứu sử dụng phương pháp phân tích khẳng định nhân tố với mô hình tới hạn nhằm đánh giá thang đo với cơ mẫu chính thức $(\mathrm{n}=210)$.

\subsubsection{Kết quả đánh giá giá trị phân biệt}

Bảng 4. Kết quả đánh giá giá trị phân biệt

\begin{tabular}{|c|c|c|c|c|c|c|}
\hline & Mean (SD) & Giới tính & INT & ATT & NBL & PBC \\
\hline \multirow[t]{2}{*}{ Giới tính } & 0.35 & 1 & & & & \\
\hline & $(0.479)$ & & & & & \\
\hline \multirow[t]{2}{*}{ INT } & 3.5952 & 0,080 & 1 & & & \\
\hline & $(0.8234)$ & & & & & \\
\hline \multirow[t]{2}{*}{ ATT } & 3.7500 & $-0,013$ & $0,354 * *$ & 1 & & \\
\hline & $(0.7783)$ & & & & & \\
\hline \multirow[t]{2}{*}{ NBL } & 2.6413 & 0,070 & $0,381 * *$ & $0,266 * *$ & 1 & \\
\hline & $(0.8866)$ & & & & & \\
\hline PBC & 3.2702 & 0,070 & $0,682 * *$ & $0,417 * *$ & $0,401 * *$ & 1 \\
\hline
\end{tabular}


$(0.8513)$

**. Tương quan có ý nghĩa ở mức 0.05 (tương quan 2 phía).

Nguồn: Nhóm nghiên cứu tụ tổng hợp

Ghi chú: INT: Ý định khởi nghiệp; ATT: Thái độ với khởi nghiệp: BBE: Kỳ vọng về khởi nghiệp; NBL: Chuẩn mục niềm tin; PBC: Nhận thức kiểm soát hành vi; CBP: Năng lục bản thân

4.3.2. Kết quả phân tích bằng hồi quy đa biến và kiểm định giả thuyết nghiên cứu 
Bảng 5. Mô hình thể hiện mối quan giữa giới tính và các nhân tố ảnh hưởng đến ý định khởi nghiệp

\begin{tabular}{|c|c|c|c|c|c|c|}
\hline \multirow[t]{2}{*}{ Biến độc lập } & \multicolumn{2}{|c|}{ Hệ số chưa chuẩn hóa } & \multirow{2}{*}{$\begin{array}{l}\begin{array}{l}\text { Hệ } \quad \text { số } \\
\text { chuẩn hóa }\end{array} \\
\text { Beta }\end{array}$} & \multirow[t]{2}{*}{$\mathbf{t}$} & \multirow[t]{2}{*}{ Sig. } & \multirow{2}{*}{$\begin{array}{l}\text { Đa cộng } \\
\text { tuyến (VIF) }\end{array}$} \\
\hline & Beta & Sai số chuẩn & & & & \\
\hline \multicolumn{7}{|c|}{ Hồi quy với biến phụ thuộc INT } \\
\hline (Constant) & 1,111 & 0,224 & & 4,949 & 0,000 & \\
\hline ATT & 0,073 & 0,059 & 0,069 & 1,250 & 0,013 & 0,814 \\
\hline NBL & 0,112 & 0,051 & 0,120 & 2,188 & 0,030 & 0,828 \\
\hline $\mathrm{PBC}$ & 0,585 & 0,056 & 0,605 & 10,364 & 0,000 & 0,735 \\
\hline \multicolumn{7}{|c|}{$\mathrm{p}$-value $(\mathrm{F})=0,000, \mathrm{R}$ square $=0,476$} \\
\hline \multicolumn{7}{|c|}{ Hồi quy với biến phụ thuộc ATT } \\
\hline (Constant) & 1,709 & 0,282 & & 6,069 & 0,000 & \\
\hline NBL & 0,175 & 0,055 & 0,199 & 3,166 & 0,002 & 0,969 \\
\hline BBE & 0,404 & 0,067 & 0,377 & 5,999 & 0,000 & 0,969 \\
\hline \multicolumn{7}{|c|}{$\mathrm{p}$-value $(\mathrm{F})=0,000, \mathrm{R}$ square $=0,201$} \\
\hline \multicolumn{7}{|c|}{ Hồi quy với biến phụ thuộc PBC } \\
\hline (Constant) & 0,947 & 0,209 & & 4,534 & 0,000 & \\
\hline NBL & 0,198 & 0,056 & 0,206 & 3,510 & 0,001 & 0,857 \\
\hline $\mathrm{CBP}$ & 0,574 & 0,066 & 0,514 & 8,736 & 0,000 & 0,857 \\
\hline
\end{tabular}

Nguồn: Nhóm nghiên cứu tụ tổng hợp 


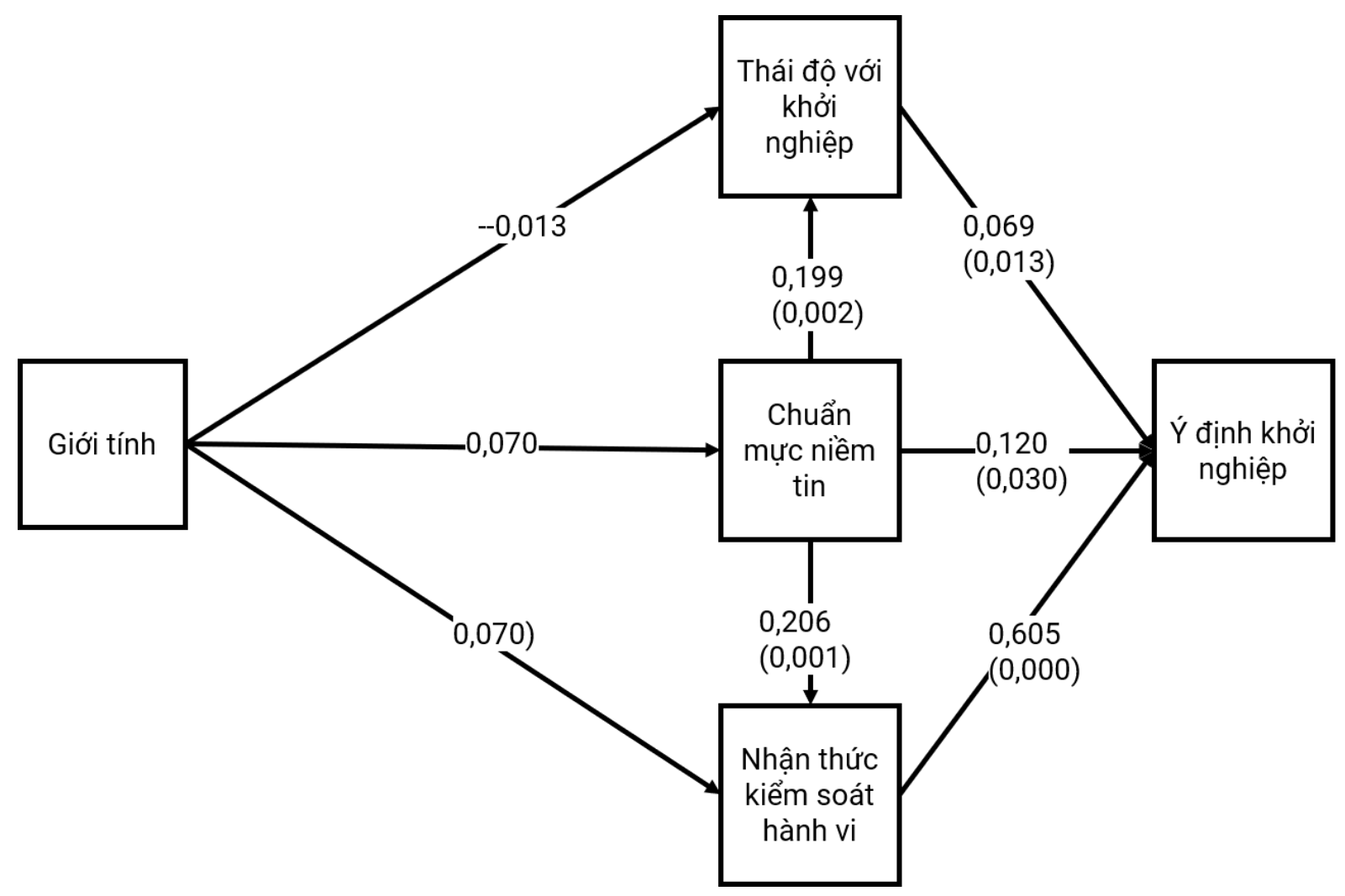

Nguồn: Nhóm nghiên cưu tụ tổng hợp

\subsubsection{Kiểm định t-test}

Bảng 6. Kết quả kiểm định T-test ảnh hưởng của giới tính tới ý định khởi nghiệp

\begin{tabular}{|ll|l|l|l|l|}
\hline \multicolumn{2}{|l|}{ Giới tính } & N & Mean & SD & Std. Error Mean \\
\hline INT & 1 & 74 & 3.6847 & .86693 & .10078 \\
& 2 & $0 \mathrm{a}$ & & & \\
\hline
\end{tabular}

Nguồn: Nhóm nghiên cưu tự tổng hợp

Từ kiểm định trên ta thấy với việc mã hóa (nam:1, nữ: 2) nên khi mean (3.6847) ta có thể rút ra kết luận ý định khởi nghiệp của nam giới lớn hơn nữ giới. 


\subsection{Kiểm định giả thuyết}

Nhóm khảo sát đã phát hiện ra những kết quả nổi bật với giả thuyết đề ra ban đầu. Đối với các biến nhân tố như thái độ với khởi nghiệp, chuẩn mực niềm tin, nhận thức kiểm soát hành vi, nhóm khảo sát đã kiểm tra xem ảnh hưởng của giới tính đến ý định khởi nghiệp có qua trung gian bởi các yếu tố trên (giả thuyết H1a, H1b và H1c). Mặc dù thái độ đối với khởi nghiệp đóng vai trò như 1 nhân tố trung gian trực tiếp giải thích mối quan hệ giữa giới tính và ý định khởi nghiệp nhưng một kết quả bất ngờ là thái độ đối với khởi nghiệp lại ảnh hưởng theo hướng ý định khởi nghiệp của nữ giới hơn nam giới. Điều này khá thú vị vì phần lớn đối tượng khảo sát là sinh viên nữ khối ngành kinh tế, những người năng động và có xu hướng sẽ kinh doanh trong tương lai gần. Mặc dù điều này khác với các học thuyết trước đây nhưng lại phù hợp trong bối cảnh khảo sát. Giả thuyết H1b nhận được sự hỗ trợ đầy đủ, cho thấy vai trò trung gian của nhận thức kiểm soát hành vi trong việc giải thích ảnh hưởng của giới tính tới ý định kinh doanh thấp hơn của nữ giới so với nam giới. Giả thuyết $1 \mathrm{c}$ chỉ đúng về việc chuẩn mực niềm tin đóng vai trò trung gian gián tiếp thông quan thái độ đối với khởi nghiệp và nhận thức kiểm soát hành vi.

Đối với các yếu tố thái độ cá nhân và kiểm soát hành vi nhận thức, chúng tôi đã phân tích cách giới tính kiểm duyệt tác động của các chỉ số đối với các yếu tố (giả thuyết $2 \mathrm{a}$ đến $3 \mathrm{c}$ ). Bảng 7 tóm tắt kết quả của các phân tích này bằng cách sử dụng thái độ cá nhân và nhận thức kiểm soát hành vi như các biến phụ thuộc tương ứng. Nó liệt kê các hệ số beta được tiêu chuẩn hóa cho mỗi chỉ số về yếu tố liên quan và lượng phương sai được giải thích trong yếu tố đó. Các sinh viên tiếp theo tái hiện các thông số beta được tiêu chuẩn hóa khác nhau cho nhóm nam và nữ. 
Bảng 7. Ảnh hưởng của giới tính tới yếu tố cấu thành kỳ vọng về khởi nghiệp và năng lực bản thân cảm nhận (thông qua hệ số Beta chuẩn hóa)

\begin{tabular}{|c|c|c|c|c|}
\hline & \multicolumn{4}{|c|}{ Sự khác biệt giới tính } \\
\hline & $\begin{array}{l}\text { Beta chuẩn hóa } \\
\text { cho nam giới }\end{array}$ & $\begin{array}{l}\text { Beta chuẩn hóa } \\
\text { cho nữ giới }\end{array}$ & F-value & sig \\
\hline \multicolumn{5}{|l|}{$\begin{array}{l}\text { Thái độ đối với } \\
\text { khởi nghiệp }\end{array}$} \\
\hline Thách thức (A) & $0.24 * *$ & 0.12 & 7.12 & 0.00 \\
\hline Tự chủ (B) & 0.11 & 0.14 & 3.37 & 0.04 \\
\hline \multicolumn{5}{|l|}{$\begin{array}{l}\text { Nhận thức kiểm } \\
\text { soát hành vi }\end{array}$} \\
\hline Pháp luật (E) & 0,09 & 0,13 & 3,61 & 0,03 \\
\hline $\begin{array}{l}\text { Môi trường kinh } \\
\text { doanh }(\mathrm{E})\end{array}$ & 0,12 & $-0,03$ & 2,77 & 0,06 \\
\hline Kiến thức (I) & $0,18^{*}$ & $0,23 * *$ & 8,58 & 0,00 \\
\hline Cơ hội (I) & $0,29 * *$ & $0,38^{* *}$ & 23,92 & 0,00 \\
\hline
\end{tabular}

Nguồn: Nhóm nghiên cứu tụe tổng hợp

A: Thành tích; B: Cân bằng; E: Bên ngoài; I: Bên trong.

* Tương quan có ý nghĩa ở múc 0.01

** Tưong quan có ý nghĩa ở múc 0.05

Các sinh viên được hỏi cho rằng tầm quan trọng của một số thuộc tính hành vi: thử thách (thành tích), tự chủ (cân bằng). Trong đó các chỉ số thành tích là yếu tố dự báo quan trọng hơn đối với nam giới so với nữ giới, chỉ số cân bằng là yếu tố dự báo quan trọng hơn đối với nữ giới, giả thuyết chắc chắn $2 \mathrm{a}$ và $2 \mathrm{~b}$. Ngoài ra, đối với nam giới chỉ số thành tích là yếu tố dự báo quan trọng hơn cho thái độ cá nhân so với các chỉ số cân bằng.

Đối với phụ nữ, mô hình ít rõ ràng hơn và đặc biệt phụ thuộc vào quan điểm được thực hiện: số lượng chỉ số so với kích thước hiệu ứng. Những người được hỏi cho rằng tầm quan trọng của năng lực tự cảm nhận từ bên ngoài (luật pháp và môi trường kinh doanh) và năng lực 
tự cảm nhận từ bên trong (bí quyết và nhận biết cơ hội). Năng lực bản thân cảm nhận từ bên trong là một yếu tố dự báo quan trọng hơn đối với phụ nữ so với nam giới, giả thuyết chắc chắn 3a. Vì vậy, so với nam giới, ý định khởi nghiệp của phụ nữ phụ thuộc mạnh mẽ hơn vào việc họ tự đánh giá khả năng kinh doanh của bản thân. Đối với năng lực bản thân cảm nhận từ bên ngoài, các rào cản lập pháp nhưng không phải là môi trường kinh doanh quan trọng hơn đối với nữ giới. Do đó, giả thuyết $3 b$ cũng được xác định, mặc dù chỉ có một trong hai thuộc tính năng lực bản thân cảm nhận từ bên ngoài được nghiên cứu. Những kết quả này giúp nhóm khảo sát hiểu rõ hơn về các tác động đã được thảo luận trước đó của giới tính tới ý định khởi nghiệp thông qua các chuẩn mực niềm tin. 


\section{CHƯƠNG 5. THẢO LUẬN VÀ ĐỀ XUÂT GIẢI PHÁP}

\subsection{Thảo luận kết quả nghiên cứu}

Mục đích nghiên cứu của nhóm là đánh giá sự khác biệt về giới tính trong việc hình thành ý định khởi nghiệp. Nhóm đã xem xét cả mô hình cấu trúc nghiên cứu (Ajzen, 1991) và nghiên cứu sâu hơn của mô hình TPB (Ajzen, 2006) và đưa ra giả thuyết về vai trò của giới tính trong tài liệu này. Kết quả của nghiên cứu khảo sát với sinh viên trên địa bàn Hà Nội chứng minh rằng sự khác biệt giới tính trong ý định khởi nghiệp có thể được giải thích bởi các yếu tố nhận thức kiểm soát hành vi, thái độ cá nhân và chuẩn mực niềm tin. Nhóm sẽ giải thích những giả thuyết trên chi tiết hơn trong các đoạn tiếp theo.

Nhóm tác giả tìm thấy sự khác biệt về giới tính ảnh hưởng đến động cơ khởi nghiệp của sinh viên. Nữ giới tương đối ưu tiên hơn việc giữ quyền tự chủ và cân bằng nhu cầu công việc và gia đình. Nam giới coi trọng sự nghiệp kinh doanh nhiều hơn như một phương tiện để đạt được sự giàu có và mong muốn có một công việc đầy thách thức. Những phát hiện này có thể giải thích bởi các khuôn mẫu giới tính của nam giới (Eagly \& Carli, 2003) giúp hình thành các sở thích nghề nghiệp và coi tinh thần kinh doanh như một phương tiện để đạt được thành công trong tương lai. Những khác biệt này giúp chúng ta hiểu rõ hơn sự khác biệt về giới trong thái độ cá nhân đối với tinh thần kinh doanh và, mở rộng hơn là ý định khởi nghiệp.

Về tác động của yếu tố kiểm soát nhận thức hành vi, nhóm nghiên cứu thấy rằng nữ giới có thuộc tính quan trọng hơn để tiếp thu kiến thức đầy đủ và khả năng so với nam giới. Hơn nữa, nhóm đã phát hiện ra rằng cảm giác bên trong của sự kiểm soát chi phối sự kiểm soát từ ngoại cảnh (ví dụ luật pháp) trong việc hình thành ý định khởi nghiệp. Trong khi cả nam và nữ đều có thể thiếu kiểm soát để trở thành một doanh nhân, những kết quả này cho thấy nữ giới thể hiện cảm giác kiểm soát nội bộ thấp hơn nam giới.

Cuối cùng, chuẩn mực niềm tin cũng là một trong ba nhân tố quan trọng ảnh hưởng đến sự khác nhau trong ý định khởi nghiệp của nam và nữ. Nghiên cứu này rất quan trọng đối với những nghiên cứu sau này khi đánh giá ảnh hưởng của giới tính đến ý định khởi nghiệp.

\section{2. Đề xuất giải pháp}

Từ kết quả nghiên cứu của chương 4 , phần này sẽ trình bày các giải pháp và đề xuất để nhằm nâng cao cũng như thúc đẩy sự cân bằng về giới tính trong ý định khởi nghiệp của sinh viên Hà Nội. Cụ thể, phần 5.2 gồm các giải pháp và đề xuất liên quan đến: nhóm giải pháp từ hoạt động giáo dục của nhà trường và nhóm giải pháp từ xã hội. 


\subsubsection{Nhóm giải pháp tù hoạt động giáo dục của nhà truờng}

Để phát triển trở thành một trường học hoặc chí ít một ngành khởi nghiệp kinh doanh chuyên nghiệp có hai chiến lược có thể được áp dụng:

- Thay đồi chuoong trình giảng dạy:

Một trong những yếu tố quan trọng nhất của hệ thống giáo dục là chương trinh đào tạo. Nó đóng vai trò cốt yếu trong quá trình đạt được các mục tiêu và chính sách giáo dục theo chất lượng lẫn số lượng. Các trường học truyền thống về kinh doanh mới chỉ đơn thuần là "giảng dạy" mà không tập trung vào "giáo dục". Vì vậy, quá trình thay đổi chương trình đào tạo theo hướng nghề nghiệp và hướng tiếp cận khởi nghiệp là thực sự cần thiết và cấp bách. Những nhà hoạch định và nhà quản lý trong lĩnh vực giáo dục nên thực hiện các phương pháp tương ứng với các điều kiện ứng dụng vào thực tế. Các kiến nghị cụ thể:

- Mở ra ngôi trường hoặc ngành chuyên đào tạo về khởi nghiệp với các chuyên gia giàu kinh nghiệm về lĩnh vực này.

- Học tập, trao đổi chương trình đào tạo khởi nghiệp với các quốc gia phát triển.

- Thiết kế chương trình và cuộc thi với định hướng khởi nghiệp kinh doanh trong trường học.

- Gia tăng các học bổng giáo dục ý tưởng khởi nghiệp nhằm khuyến khích tinh thần sinh viên.

- Tập trung vào những nhu cầu cụ thể thực tiễn của xã hội khi xây dựng nội dung chương trình đào tạo.

- Cung cấp bằng chứng về khởi nghiệp thành công trong trường học...

- Thiết kế những môn học về kĩ năng mềm như tư duy sáng tạo, quản lý thời gian, phương pháp học tập.

- Thay đổi chương trình nghiên cứu:

Để tạo ra các trường học khởi nghiệp hiện đại, các nhà nghiên cứu nên xây dựng các chương trình theo định hướng chủ động trong đào tạo. Liên quan tới vấn đề này, chúng ta có thể:

- Khuyến khích tính linh động trong chương trình học và nghiên cứu khoa học của sinh viên.

- Tạo ra môi trường cho sinh viên thể hiện các ý tưởng của mình bằng những cuộc thi, hội thảo các cấp.

- Trang bị và phát triển phòng thí nghiệm ứng dụng. 
- Bồi dưỡng tinh thần, tư duy không ngừng sáng tạo của sinh viên.

- Tạo ra nền tảng cho quá trình thực hành thực tiễn.

- Tham quan thực tế các nhà máy, phân xưởng, doanh nghiệp kinh doanh.

- Tiếp xúc và học hỏi kinh nghiệm từ tổ chức nghiên cứu bên ngoài.

- Liên hệ giữa lý thuyết và thực tế với hiệu quả cao

\subsubsection{Nhóm giải pháp tù xã hội}

\subsubsection{Tạo ra nhiều co hội kinh doanh tại thị truờng trong nước}

Đa dạng hóa hình thức truyền thông, tuyên truyền đối với các doanh nghiệp và người tiêu dùng về cuộc vận động "Người Việt Nam dùng hàng Việt Nam”, "Ngày hàng Việt", "Tháng hàng Việt".

\subsubsection{Xây dựng khung pháp lý ưu đãi khuyến khích khởi nghiệp}

\section{Một là đơn giản hóa quy trình thủ tục hành chính}

Trong thời gian tới, giải pháp hàng đầu cho Hà Nội là đẩy mạnh công tác cải cách hành chính một cách đồng bộ, theo đó chú trọng lấy việc tăng cường kỷ luật kỷ cương, công khai minh bạch các quy định của Nhà nước về thủ tục hành chính doanh nghiệp và bố trí cán bộ, công chức, viên chức đủ phẩm chất, năng lực theo yêu cầu công việc làm khâu đột phá trong cải cách hành chính. Đồng thời, gắn với kiểm soát thủ tục hành chính và ứng dụng công nghệ thông tin trong công tác quản lý nhà nước.

\section{Hai là giảm thiểu rủi ro khi phá sản doanh nghiệp}

Những nhóm điều khoản cần phải sửa đổi trong Luật Phá sản: một là mở rộng đối tượng nộp đơn yêu cầu phá sản: hộ gia đình, cá nhân... hai là cho phép chủ nợ có tài sản bảo đảm nộp đơn, bổ sung quyền nộp đơn cho một số chủ thể đặc biệt như ngân hàng, tổ chức tín dụng và cho phép doanh nghiệp lâm vào tình trạng phá sản được lựa chọn thủ tục giải quyết phá sản, đặc biệt là việc phục hồi khả năng sản xuất, kinh doanh. Đặc biệt, nên sửa đổi điều khoản về chủ doanh nghiệp bị tuyên bố phá sản không được quyền thành lập doanh nghiệp, hợp tác xã, không được làm người quản lý doanh nghiệp, hợp tác xã trong thời hạn 1 - 3 năm kể từ ngày doanh nghiệp, hợp tác xã bị tuyên bố phá sản.

\subsubsection{Quan niệm tích cục của xã hội về khởi nghiệp và khát khao làm chủ doanh nghiệp}

Để làm nổi bật giá trị của kinh doanh và chỉ ra những định kiến về khởi nghiệp và người khởi nghiệp, chúng ta nên:

Đưa vào môn học Đạo đức và Giáo dục công dân giúp các em hiểu thất bại không có gì đáng xấu hổ, đáng xấu hổ là khi bỏ cuộc giữa chừng. 
Sử dụng truyền thông đại chúng, phương tiện truyền thông gắn với Internet (Youtube, các mạng xã hội) với cấp quốc gia để nâng cao tinh thần khởi nghiệp, khai thác câu chuyện thất bại của những doanh nhân thành đạt ngày nay hơn là chỉ khai thác vẻ ngoài hào nhoáng. Đối tượng không dừng lại ở các bạn trẻ, mà là toàn xã hội để thay đổi nhận thức của họ về thất bại. Ở Singapore, chiến dịch "Hành động vì một Cộng đồng Khởi nghiệp" (AEC) thực hiện vào tháng 5 năm 2013 là một nỗ lực của cả quốc gia để xây dựng Singapore thành một quốc gia khởi nghiệp. AEC hợp tác với các khối công và tư nhân để nâng cao môi trường chuyên nghiệp cho khởi nghiệp, nuôi dưỡng văn hóa và tư duy kinh doanh thông qua giáo dục và truyền thông, tạo điều kiện học tập, giao lưu giữa các doanh nghiệp khởi nghiệp thông qua các Vườn ươm. Chương trình được điều hành bởi các Doanh nhân và những quan chức của Bộ Thương mại và Công nghiệp.

Phổ biến các thông tin về doanh nghiệp nói chung, doanh nghiệp khởi nghiệp nói riêng tác động tích cực đến nền kinh tế và xã hội.

Trao các giải thưởng, chứng nhận cho những nhà khởi nghiệp trẻ. 


\section{KẾT LUẬN}

Sau quá trình thực hiện, đề tài rút ra một số kết luận như sau:

Thứ nhất, các nhân tố chính ảnh hưởng đến hoạt động khởi nghiệp kinh doanh bao gồm 6 nhóm chính, đó là nhóm yếu tố nhân khẩu học, nhóm yếu tố năng lực cá nhân, nhóm yếu tố đặc điểm tính cách, nhóm yếu tố xã hội, nhóm yếu tố văn hóa và nhóm các yếu tố môi trường.

Thứ hai, trong hệ sinh thái khởi nghiệp tại Việt Nam nói chung cũng như tại Hà Nội nói riêng, hiện nay làn sóng khởi nghiệp vẫn chưa thực sự bền vững và khởi sắc. Từ năm 2012 khái niệm hệ sinh thái khởi nghiệp đổi mới sáng tạo ở Việt Nam ít người biết đến, nay vươn lên thứ ba trong các nước ASEAN, chỉ sau Singapore cả về tốc độ phát triển doanh nghiệp cũng như hình thành hệ sinh thái khởi nghiệp sáng tạo. Chính phủ cam kết sẽ tạo mọi điều kiện thuận lợi nhất để doanh nghiệp khởi nghiệp thành công, chính phủ luôn quan tâm và đặt khởi nghiệp sáng tạo là một trong những giải pháp đột phá cho đổi mới mô hình tăng trưởng. Tuy nhiên, có nhiều khó khăn về vốn, đầu tư, hiện chưa có chính sách ưu đãi thuế và các chính sách đầu tư tài chính để các nhà đầu tư thiên thần (người bỏ vốn mồi đầu tiên) sẵn sàng bỏ vốn. Trong khi giai đoạn vốn mồi rất quan trọng với các doanh nghiệp khởi nghiệp. Trung tâm Đổi mới sáng tạo trực thuộc Bộ Khoa học và Công nghệ tại Hà Nội sẽ kết nối các nhu cầu đổi mới sáng tạo của các tập đoàn, công ty trong nước với mạng lưới hơn 12 nghìn nhà khoa học, nhà sáng tạo toàn cầu, tạo điều kiện cho các nhà khoa học, các kỹ sư Việt Nam tham gia mạng lưới, cũng như đào tạo đội ngũ cán bộ làm quản lý công nghệ và đổi mới sáng tạo tiếp cận với những phương thức thúc đẩy đổi mới sáng tạo mới của thế giới.

Thứ ba, mô hình ảnh hưởng của giới tính đến ý định khởi nghiệp của sinh viên được xây dựng đã giải thích được sự khác biệt về giới tính trong ý định khởi nghiệp đến trực tiếp từ yếu tố nhận thức kiểm soát hành vi và thái độ đối với khởi nghiệp. Ngoài ra, mặc dù đi ngược lại với nhiều nghiên cứu trước nhưng đối với bối cảnh nghiên cứu của bài viết thì sự khác biệt về giới tính trong ý định khởi nghiệp cũng đến trực tiếp từ các chuẩn mực niềm tin. Tiếp đến, sự cân bằng là yếu tố được nữ giới coi trọng hơn khi quyết định khởi nghiệp trong khi nam giới là việc đạt được thành tựu như vượt qua được những khó khăn, thách thức. Thêm vào đó, dù ảnh hưởng của yếu tố năng lực bản thân tự cảm nhận từ bên ngoài đến nam giới và nữ giới có sự chênh lệch nhưng ảnh hưởng của yếu tố năng lực bản thân tự cảm nhận từ bên trong đến nam giới và nữ giới vẫn đóng vai trò quan trọng hơn trong việc giải thích sự khác biệt về giới tính tới ý định khởi nghiệp. Ngoài ra, yếu tố này của nữ giới yếu hơn nam giới khiến nữ giới dễ cảm thấy tự ti hơn khi quyết định khởi nghiệp. Do vậy, để kích thích tinh thần khởi nghiệp của nữ giới rất cần nhấn mạnh việc củng cố cảm xúc cá nhân của bản thân. 
Thứ tư, các hoạt động nhằm thúc đẩy và hỗ trợ thanh niên khởi nghiệp cần phải đóng một vai trò thiết yếu và phải có được sự quan tâm kịp thời, đầu tư lâu dài, đúng mức và đồng bộ từ phía các cơ quan chức năng và các tổ chức - đoàn thể xã hội. Nhóm xin phép được nhấn mạnh một số giải pháp như tăng cường đào tạo và các chương trình học, xây dựng khung pháp lý chính sách khuyến khích khởi nghiệp, tạo cơ hội kinh doanh trong nước.

Tóm lại, do những điều kiện khách quan và nguồn lực hạn chế, đề tài nghiên cứu mới chỉ tập trung vào các nhân tố tác động đến ý định khởi nghiệp của sinh viên Hà Nội, trong đó quan trọng nhất là nhân tố ảnh hưởng của giới tính và đề xuất nhóm giải pháp hướng đến việc thúc đẩy, hỗ trợ khởi nghiệp. Nhóm nghiên cứu hy vọng những giải pháp, kiến nghị đề ra, dù chưa thật sự hoàn thiện, sẽ góp phần định hướng xây dựng các chương trình hỗ trợ, thúc đẩy sinh viên tìm hiểu và tạo lập ý định khởi nghiệp. 


\section{PHỤ LỤC}

\section{PHỤ LỤC I: BẢNG KHẢO SÁT MỨC Độ ẢNH HƯởNG CỦA GIỚI TÍNH TớI Ý ĐỊNH KHỞI NGHIỆP CỦA SINH VIÊN HÀ NỘI}

Chào các bạn, chúng mình là nhóm sinh viên đến từ Trường Đại học Ngoại thương. Hiện tại chúng mình đang nghiên cứu về mức độ ảnh hưởng của giới tính tới ý định khởi nghiệp của sinh viên. Chúng mình rất mong sẽ nhận được sự ủng hộ của các bạn bằng cách điền form khảo sát này.

Lưu ý: Thông tin của các bạn trong phiếu khảo sát này sẽ không bị tiết lộ và chỉ được sử dụng cho mục đích học thuật. Cảm ơn các bạn!

\section{NỘI DUNG BẢNG KHẢO SÁT}

Anh/chị vui lòng khoanh tròn vào các ô điểm tương ứng với mức độ đồng ý của anh/chị đối với những phát biểu dưới đây. Trong đó:

1. Hoàn toàn không đồng ý

2. Không đồng ý

3. Bình thường (trung lập)

4. Đồng ý

5. Hoàn toàn đồng ý

\begin{tabular}{|l|l|l|l|l|l|l|}
\hline STT & Nội dung câu hỏi & \multicolumn{4}{|l|}{ Mức độ đồng ý } \\
\hline I. Ý định khởi nghiệp & 1 & 2 & 3 & 4 & 5 \\
\hline INT1 & Mục tiêu nghề nghiệp của tôi là trở thành doanh nhân & 1 & 2 & 3 & 4 & 5 \\
\hline INT2 & Khi có cơ hội, tôi sẽ trở thành một doanh nhân. & 1 & 2 & 3 & 4 & 5 \\
\hline INT3 & Tôi xác định sẽ thành lập một doanh nghiệp trong tương lai gần &
\end{tabular}

II. Thái độ với khởi nghiệp

\begin{tabular}{|l|l|l|l|l|l|l|}
\hline ATT1 & Tôi thấy việc khởi nghiệp là hấp dẫn & 1 & 2 & 3 & 4 & 5 \\
\hline ATT2 & $\begin{array}{l}\text { Tôi nghĩ rằng việc khởi nghiệp sẽ mang lại nhiều lợi ích cho tôi hơn là bất } \\
\text { lợi }\end{array}$ & 1 & 2 & 3 & 4 & 5 \\
\hline
\end{tabular}

\begin{tabular}{|l|l|l|l|l|l|l|}
\hline III. Kỳ vọng về khởi nghiệp & \multicolumn{3}{|l|}{} \\
\hline BBE1 & Tôi muốn đối mặt với nhiều thử thách mới trong sự nghiệp của mình. & 1 & 2 & 3 & 4 & 5 \\
\hline BBE2 & Tôi coi trọng sự tự chủ trong nghề nghiệp tương lai của tôi. & 1 & 2 & 3 & 4 & 5 \\
\hline IV. Chuân
\end{tabular}

IV. Chuẩn mực niềm tin

\begin{tabular}{|l|l|l|l|l|l|l|}
\hline NBL1 & Bố mẹ luôn định hướng tôi trở thành một doanh nhân & 1 & 2 & 3 & 4 & 5 \\
\hline NBL2 & Bạn bè nghĩ khởi nghiệp là một sự lựa chọn hợp lý với tôi & 1 & 2 & 3 & 4 & 5 \\
\hline NBL3 & Người thân của tôi luôn mong muốn tôi trở thành một doanh nhân & 1 & 2 & 3 & 4 & 5 \\
\hline
\end{tabular}

V. Nhận thức kiểm soát hành vi

\begin{tabular}{|l|l|l|l|l|l|l|}
\hline PBC1 & Tôi tự tin sẽ thành lập công ty riêng của mình trong tương lai & 1 & 2 & 3 & 4 & 5 \\
\hline PBC2 & Tôi tự tin sẽ vượt qua các trở ngại để trở thành doanh nhân & 1 & 2 & 3 & 4 & 5 \\
\hline
\end{tabular}




\begin{tabular}{|l|l|l|l|l|l|l|}
\hline PBC3 & Tôi tin rằng mình có đủ năng lực để trở thành một doanh nhân & 1 & 2 & 3 & 4 & 5 \\
\hline PBC4 & Trở thành doanh nhân là một lựa chọn phù hợp đối với tôi. & 1 & 2 & 3 & 4 & 5 \\
\hline
\end{tabular}

\section{Năng lực bản thân cảm nhận}

\begin{tabular}{|l|l|l|l|l|l|l|}
\hline CBP1 & Tôi nghĩ rằng mình có đủ kiến thức cần thiết để trở thành doanh nhân. & 1 & 2 & 3 & 4 & 5 \\
\hline CBP2 & $\begin{array}{l}\text { Tôi thấy mình có đủ khả năng nhạy bén để phát hiện ra những cơ hội kinh } \\
\text { doanh tốt. }\end{array}$ & 1 & 2 & 3 & 4 & 5 \\
\hline CBP3 & Thiếu nguồn lực tài chính không ngăn tôi khởi nghiệp & 1 & 2 & 3 & 4 & 5 \\
\hline CBP4 & $\begin{array}{l}\text { Sự hỗ trợ của chính phủ không ảnh hưởng đến quyết định trở thành doanh } \\
\text { nhân. }\end{array}$ & 1 & 2 & 3 & 4 & 5 \\
\hline CBP5 & Tôi nghĩ rằng mình có đủ sự sáng tạo để trở thành doanh nhân & 1 & 2 & 3 & 4 & 5 \\
\hline
\end{tabular}




\section{PHỤ LỤC II: KẾT QUẢ PHẦN MỀM SPSS}

I. Kết quả kiểm định độ tin cậy thang đo: hệ số Cronbach's Alpha, hệ số tương quan biến tổng

1. Ý định khởi nghiệp

Case Processing Summary

\begin{tabular}{|ll|l|l|}
\hline & & $\mathbf{N}$ & $\%$ \\
\hline \multirow{4}{*}{ Cases } & Valid $^{*}$ & 210 & 100,0 \\
& Excluded $^{\mathrm{a}}$ & 0 & 0,0 \\
& Total & 210 & 100,0 \\
\hline
\end{tabular}

a. Listwise deletion based on all variables in the procedure.

Reliability Statistics

\begin{tabular}{|l|l|}
\hline Cronbach's Alpha & $\mathrm{N}$ of Items \\
\hline, 763 & 3 \\
\hline
\end{tabular}

Item-Total Statistics

\begin{tabular}{|l|l|l|l|l|}
\hline & $\begin{array}{l}\text { Scale Mean if } \\
\text { Item Deleted }\end{array}$ & $\begin{array}{l}\text { Scale Variance } \\
\text { if Item Deleted }\end{array}$ & $\begin{array}{l}\text { Corrected Item- } \\
\text { Total } \\
\text { Correlation }\end{array}$ & $\begin{array}{l}\text { Cronbach's } \\
\text { Alpha if Item } \\
\text { Deleted }\end{array}$ \\
\hline INT1 & 7,09 & 2,944 & 0,636 & 0,636 \\
INT2 & 6,71 & 3,279 & 0,619 & 0,665 \\
INT3 & 7,77 & 2,876 & 0,545 & 0,751 \\
\hline
\end{tabular}

2. Thái độ với khởi nghiệp

Case Processing Summary

\begin{tabular}{|ll|l|l|}
\hline & $\mathbf{N}$ & $\mathbf{\%}$ \\
\hline \multirow{4}{*}{ Cases } & Valid & 210 & 100,0 \\
& Excluded $^{\mathrm{a}}$ & 0 & 0,0 \\
& Total & 210 & 100,0 \\
\hline
\end{tabular}

a. Listwise deletion based on all variables in the procedure.

Reliability Statistics

\begin{tabular}{|l|l|}
\hline Cronbach's Alpha & N of Items \\
\hline, 637 & 2 \\
\hline
\end{tabular}

Item-Total Statistics

\begin{tabular}{|l|l|l|l|l|}
\hline & $\begin{array}{l}\text { Scale Mean if } \\
\text { Item Deleted }\end{array}$ & $\begin{array}{l}\text { Scale } \\
\text { Variance if } \\
\text { Item Deleted }\end{array}$ & $\begin{array}{l}\text { Corrected Item- } \\
\text { Total } \\
\text { Correlation }\end{array}$ & $\begin{array}{l}\text { Cronbach's } \\
\text { Alpha if Item } \\
\text { Deleted }\end{array}$ \\
\hline ATT1 & 3,52 & 0,853 & 0,467 &. \\
ATT2 & 3,98 & 0,798 & 0,467 &. \\
\hline
\end{tabular}

3. Kỳ vọng về khởi nghiệp

Case Processing Summary

\begin{tabular}{|ll|l|l|}
\hline & N & \% \\
\hline \multirow{2}{*}{ Cases } & Valid & 210 & 100,0 \\
& Excluded $^{\mathrm{a}}$ & 0 & 0,0
\end{tabular}




\begin{tabular}{|l|l|l|}
\hline Total & 210 & 100,0 \\
\hline
\end{tabular}

a. Listwise deletion based on all variables in the procedure.

Reliability Statistics

\begin{tabular}{|l|l|}
\hline Cronbach's Alpha & N of Items \\
\hline 0,522 & 2 \\
\hline
\end{tabular}

Item-Total Statistics

\begin{tabular}{|l|l|l|l|l|}
\hline & $\begin{array}{l}\text { Scale Mean if } \\
\text { Item Deleted }\end{array}$ & $\begin{array}{l}\text { Scale } \\
\text { Variance if } \\
\text { Item Deleted }\end{array}$ & $\begin{array}{l}\text { Corrected Item- } \\
\text { Total } \\
\text { Correlation }\end{array}$ & $\begin{array}{l}\text { Cronbach's } \\
\text { Alpha if Item } \\
\text { Deleted }\end{array}$ \\
\hline BBE1 & 4,07 & 0,717 & 0,354 &. \\
BBE2 & 3,76 & 0,845 & 0,354 &. \\
\hline
\end{tabular}

4. Chuẩn mực niềm tin

Case Processing Summary

\begin{tabular}{|ll|l|l|}
\hline & $\mathbf{N}$ & $\%$ \\
\hline \multirow{3}{*}{ Cases } & Valid & 210 & 100,0 \\
& Excluded $^{\mathrm{a}}$ & 0 & 0,0 \\
& Total & 210 & 100,0 \\
\hline
\end{tabular}

a. Listwise deletion based on all variables in the procedure.

Reliability Statistics

\begin{tabular}{|l|l|}
\hline Cronbach's Alpha & N of Items \\
\hline, 825 & 3 \\
\hline
\end{tabular}

Item-Total Statistics

\begin{tabular}{|l|l|l|l|l|}
\hline & $\begin{array}{l}\text { Scale Mean if } \\
\text { Item Deleted }\end{array}$ & $\begin{array}{l}\text { Scale } \\
\text { Variance if } \\
\text { Item Deleted }\end{array}$ & $\begin{array}{l}\text { Corrected Item- } \\
\text { Total } \\
\text { Correlation }\end{array}$ & $\begin{array}{l}\text { Cronbach's } \\
\text { Alpha if Item } \\
\text { Deleted }\end{array}$ \\
\hline NBL1 & 5,49 & 3,313 &, 687 &, 752 \\
NBL2 & 5,19 & 3,913 &, 601 &, 833 \\
NBL3 & 5,18 & 3,036 &, 764 &, 669 \\
\hline
\end{tabular}

5. Nhận thức kiểm soát hành vi

Case Processing Summary

\begin{tabular}{|ll|l|l|}
\hline & & N & \% \\
\hline \multirow{4}{*}{ Cases } & Valid & 210 & 100,0 \\
& Excluded $^{\text {a }}$ & 0 & 0,0 \\
& Total & 210 & 100,0 \\
\hline
\end{tabular}

a. Listwise deletion based on all variables in the procedure.

Reliability Statistics

\begin{tabular}{|l|l|}
\hline Cronbach's Alpha & N of Items \\
\hline, 906 & 4 \\
\hline
\end{tabular}

Item-Total Statistics 


\begin{tabular}{|l|l|l|l|l|}
\hline & $\begin{array}{l}\text { Scale Mean if } \\
\text { Item Deleted }\end{array}$ & $\begin{array}{l}\text { Scale } \\
\text { Variance if } \\
\text { Item Deleted }\end{array}$ & $\begin{array}{l}\text { Corrected Item- } \\
\text { Total } \\
\text { Correlation }\end{array}$ & $\begin{array}{l}\text { Cronbach's } \\
\text { Alpha if Item } \\
\text { Deleted }\end{array}$ \\
\hline PBC1 & 9,98 & 6,569 & 0,784 & 0,880 \\
PBC2 & 9,72 & 6,545 & 0,794 & 0,876 \\
PBC3 & 9,63 & 6,818 & 0,789 & 0,878 \\
PBC4 & 9,91 & 6,978 & 0,788 & 0,879 \\
\hline
\end{tabular}

6. Năng lực bản thân cảm nhận

Case Processing Summary

\begin{tabular}{|ll|l|l|}
\hline & & $\mathbf{N}$ & $\%$ \\
\hline \multirow{3}{*}{ Cases } & Valid & 210 & 100,0 \\
& Excluded $^{\mathrm{a}}$ & 0 & 0,0 \\
& Total & 210 & 100,0 \\
\hline
\end{tabular}

a. Listwise deletion based on all variables in the procedure.

Reliability Statistics

\begin{tabular}{|l|l|}
\hline Cronbach's Alpha & N of Items \\
\hline, 808 & 5 \\
\hline
\end{tabular}

Item-Total Statistics

\begin{tabular}{|l|l|l|l|l|}
\hline & $\begin{array}{l}\text { Scale Mean if } \\
\text { Item Deleted }\end{array}$ & $\begin{array}{l}\text { Scale } \\
\text { Variance if } \\
\text { Item Deleted }\end{array}$ & $\begin{array}{l}\text { Corrected Item- } \\
\text { Total } \\
\text { Correlation }\end{array}$ & $\begin{array}{l}\text { Cronbach's } \\
\text { Alpha if Item } \\
\text { Deleted }\end{array}$ \\
\hline CBP1 & 12,73 & 9,498 & 0,650 & 0,753 \\
CBP2 & 12,57 & 9,529 & 0,715 & 0,736 \\
CBP3 & 12,60 & 10,098 & 0,487 & 0,804 \\
CBP4 & 12,59 & 10,004 & 0,490 & 0,804 \\
CBP5 & 12,27 & 9,605 & 0,657 & 0,752 \\
\hline
\end{tabular}

II. Kết quả phân tích khám phá nhân tố EFA: hệ số KMO, p-value của kiểm định Bartlett, phương sai giải thích và hệ số tải nhân tố

1. Ý định khởi nghiệp

KMO and Bartlett's Test

\begin{tabular}{|c|c|c|}
\hline \multicolumn{2}{|c|}{$\begin{array}{l}\text { Kaiser-Meyer-Olkin Measure of Sampling } \\
\text { Adequacy. }\end{array}$} & 0,685 \\
\hline \multirow{3}{*}{$\begin{array}{l}\text { Bartlett's Test of } \\
\text { Sphericity }\end{array}$} & Approx. Chi-Square & 167,364 \\
\hline & $\mathrm{df}$ & \\
\hline & Sig. & 0,000 \\
\hline
\end{tabular}

\begin{tabular}{|l|r|r|}
\hline \multicolumn{3}{|c|}{ Communalities } \\
\hline & \multicolumn{1}{|c|}{ Initial } & Extraction \\
\hline INT1 & 1,000 & 0,730 \\
INT2 & 1,000 & 0,710 \\
INT3 & 1,000 & 0,615 \\
\hline
\end{tabular}


Extraction Method: Principal

Component Analysis.

Total Variance Explained

\begin{tabular}{|l|r|r|r|r|r|c|}
\hline Component & \multicolumn{3}{|c|}{ Initial Eigenvalues } & \multicolumn{3}{c|}{$\begin{array}{c}\text { Extraction Sums of Squared } \\
\text { Loadings }\end{array}$} \\
\cline { 2 - 7 } & \multicolumn{1}{|c|}{ Total } & $\begin{array}{c}\text { \% of } \\
\text { Variance }\end{array}$ & $\begin{array}{c}\text { Cumulative } \\
\text { \% }\end{array}$ & Total & $\begin{array}{c}\text { \% of } \\
\text { Variance }\end{array}$ & Cumulative \\
& & 68,516 & 68,516 & 2,055 & 68,516 & 68,516 \\
\hline 1 & 2,055 & 18,355 & 86,871 & & & \\
2 &, 551 & 13,129 & 100,000 & & & \\
3 & 394 & & & & \\
\hline
\end{tabular}

Extraction Method: Principal Component Analysis.

\section{Component}

\begin{tabular}{|l|r|}
\hline \multicolumn{2}{|c}{ Matrix $^{\mathbf{a}}$} \\
\cline { 2 - 2 } & Component $^{1}$ \\
\hline INT1 & 0,855 \\
INT2 & 0,843 \\
INT3 & 0,784 \\
\hline
\end{tabular}

Extraction Method:

Principal Component

Analysis.

a. 1 components

extracted.

2. Thái độ đối với khởi nghiệp

KMO and Bartlett's Test

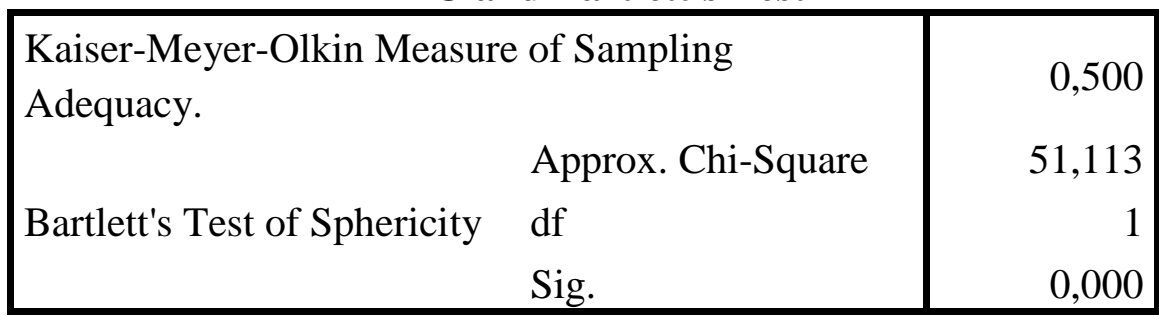

\begin{tabular}{|l|r|r|}
\hline \multicolumn{3}{|c|}{ Communalities } \\
\hline ATT1 & \multicolumn{1}{|c|}{ Initial } & Extraction \\
ATT2 & 1,000 & 0,734 \\
& 1,000 & 0,734 \\
\hline
\end{tabular}

Extraction Method: Principal Component Analysis.

Total Variance Explained

\begin{tabular}{|l|c|c|c|c|c|c|}
\hline \multirow{2}{*}{ Component } & \multicolumn{3}{|c|}{ Initial Eigenvalues } & \multicolumn{2}{c|}{ Extraction Sums of Squared } \\
& \multicolumn{3}{|c|}{ Loadings } \\
\cline { 2 - 7 } & Total & $\begin{array}{c}\text { \% of } \\
\text { Variance }\end{array}$ & $\begin{array}{c}\text { Cumulative } \\
\text { \% }\end{array}$ & Total & $\begin{array}{c}\text { \% of } \\
\text { Variance }\end{array}$ & $\begin{array}{c}\text { Cumulative } \\
\%\end{array}$ \\
\hline 1 & 1,467 & 73,363 & 73,363 & 1,467 & 73,363 & 73,363
\end{tabular}




\begin{tabular}{l|r|}
2 & 0,533 \\
Extraction Method: Principal \\
Component Matrix
\end{tabular}
\begin{tabular}{|l|c|}
\hline & Component $^{\mathbf{a}}$ \\
\cline { 2 - 2 } & 1 \\
\hline ATT2 & 0,857 \\
ATT1 & 0,857 \\
\hline
\end{tabular}

Extraction Method: Principal

Component Analysis.

a. 1 components extracted.

3. Kỳ vọng về khởi nghiệp

KMO and Bartlett's Test

\begin{tabular}{|c|c|c|}
\hline \multicolumn{2}{|c|}{$\begin{array}{l}\text { Kaiser-Meyer-Olkin Measure of Sampling } \\
\text { Adequacy. }\end{array}$} & 0,500 \\
\hline & Approx. Chi-Square & 27,822 \\
\hline Bartlett's Test of Sphericity & $\begin{array}{l}\text { df } \\
\text { Sig. }\end{array}$ & $\begin{array}{r}1 \\
0,000\end{array}$ \\
\hline
\end{tabular}

\begin{tabular}{|l|r|r|}
\hline \multicolumn{3}{|c|}{ Communalities } \\
\hline BBE1 & \multicolumn{1}{|c|}{ Initial } & Extraction \\
BBE2 & 1,000 & 0,677 \\
& 1,000 & 0,677 \\
\hline
\end{tabular}

Extraction Method: Principal Component

Analysis.

Total Variance Explained

\begin{tabular}{|l|r|r|r|r|r|r|}
\hline \multirow{2}{*}{ Component } & \multicolumn{3}{|c|}{ Initial Eigenvalues } & \multicolumn{2}{c|}{$\begin{array}{c}\text { Extraction Sums of Squared } \\
\text { Loadings }\end{array}$} \\
\cline { 2 - 7 } & Total & $\begin{array}{c}\text { \% of } \\
\text { Variance }\end{array}$ & $\begin{array}{c}\text { Cumulative } \\
\text { \% }\end{array}$ & Total & $\begin{array}{c}\text { \% of } \\
\text { Variance }\end{array}$ & $\begin{array}{c}\text { Cumulative } \\
\%\end{array}$ \\
\hline 1 & 1,354 & 67,712 & 67,712 & 1,354 & 67,712 & 67,712 \\
2 & 0,646 & 32,288 & 100,000 & & & \\
\hline
\end{tabular}

Extraction Method: Principal Component Analysis.

Component Matrix ${ }^{\mathrm{a}}$

\begin{tabular}{|l|r|}
\hline \multirow{2}{*}{} & Component \\
\cline { 2 - 2 } & 1 \\
\hline BBE1 & 0,823 \\
BBE2 & 0,823 \\
\hline
\end{tabular}

Extraction Method: Principal

Component Analysis.

a. 1 components extracted.

4. Chuẩn mực niềm tin

KMO and Bartlett's Test 


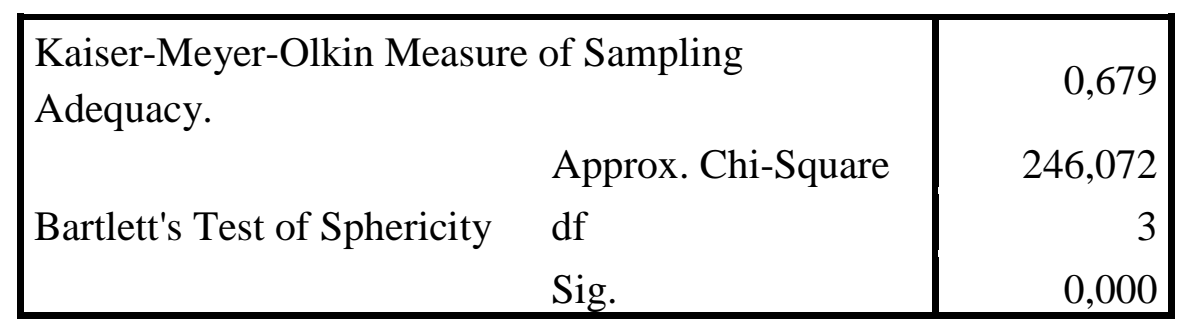

\begin{tabular}{|l|r|r|}
\hline \multicolumn{3}{|c|}{ Communalities } \\
\hline & \multicolumn{1}{|c|}{ Initial } & Extraction \\
\hline NBL1 & 1,000 & 0,746 \\
NBL2 & 1,000 & 0,653 \\
NBL3 & 1,000 & 0,822 \\
\hline
\end{tabular}

Extraction Method: Principal Component Analysis.

Total Variance Explained

\begin{tabular}{|l|r|r|r|r|r|r|}
\hline \multirow{2}{*}{ Component } & \multicolumn{3}{|c|}{ Initial Eigenvalues } & \multicolumn{2}{|c|}{$\begin{array}{c}\text { Extraction Sums of Squared } \\
\text { Loadings }\end{array}$} \\
\cline { 2 - 7 } & Total & $\begin{array}{c}\text { \% of } \\
\text { Variance }\end{array}$ & $\begin{array}{c}\text { Cumulative } \\
\text { \% }\end{array}$ & Total & $\begin{array}{c}\text { \% of } \\
\text { Variance }\end{array}$ & Cumulative \\
& & 74,039 & 74,039 & 2,221 & 74,039 & 74,039 \\
\hline 1 & 2,221 & 16,978 & 91,017 & & & \\
2 & 0,509 & 8,983 & 100,000 & & & \\
\hline 3 & 0,270 & & & & \\
\hline
\end{tabular}

Extraction Method: Principal Component Analysis.

Component Matrix ${ }^{\mathrm{a}}$

\begin{tabular}{|l|r|}
\hline & Component \\
\cline { 2 - 2 } & 1 \\
\hline NBL3 & 0,906 \\
NBL1 & 0,864 \\
NBL2 & 0,808 \\
\hline
\end{tabular}

Extraction Method: Principal

Component Analysis.

a. 1 components extracted.

5. Nhận thức kiểm soát hành vi

KMO and Bartlett's Test

\begin{tabular}{|c|c|c|}
\hline \multicolumn{2}{|c|}{$\begin{array}{l}\text { Kaiser-Meyer-Olkin Measure of Sampling } \\
\text { Adequacy. }\end{array}$} & 0,797 \\
\hline \multirow{3}{*}{ Bartlett's Test of Sphericity } & Approx. Chi-Square & 560,302 \\
\hline & df & 6 \\
\hline & Sig. & 0,000 \\
\hline
\end{tabular}

\begin{tabular}{|l|r|r|}
\hline \multicolumn{3}{|c|}{ Communalities } \\
\hline & \multicolumn{1}{|c|}{ Initial } & Extraction \\
\hline PBC1 & 1,000 & 0,773 \\
PBC2 & 1,000 & 0,784 \\
PBC3 & 1,000 & 0,785
\end{tabular}


\begin{tabular}{|l|r|r|} 
PBC4 & 1,000 & 0,782 \\
\hline
\end{tabular}

Extraction Method: Principal Component

Analysis.

Total Variance Explained

\begin{tabular}{|l|r|r|r|r|r|r|}
\hline \multirow{2}{*}{ Component } & \multicolumn{3}{|c|}{ Initial Eigenvalues } & \multicolumn{2}{c|}{$\begin{array}{c}\text { Extraction Sums of Squared } \\
\text { Loadings }\end{array}$} \\
\cline { 2 - 7 } & Total & $\begin{array}{c}\text { \% of } \\
\text { Variance }\end{array}$ & $\begin{array}{c}\text { Cumulative } \\
\text { \% }\end{array}$ & Total & $\begin{array}{c}\text { \% of } \\
\text { Variance }\end{array}$ & $\begin{array}{c}\text { Cumulative } \\
\text { \% }\end{array}$ \\
\hline 1 & 3,123 & 78,087 & 78,087 & 3,123 & 78,087 & 78,087 \\
2 & 0,419 & 10,465 & 88,552 & & & \\
3 & 0,267 & 6,687 & 95,239 & & & \\
4 & 0,190 & 4,761 & 100,000 & & & \\
\hline
\end{tabular}

Extraction Method: Principal Component Analysis.

Component Matrix ${ }^{a}$

\begin{tabular}{|l|r|}
\hline & Component \\
\cline { 2 - 2 } & 1 \\
\hline PBC3 & 0,886 \\
PBC2 & 0,885 \\
PBC4 & 0,884 \\
PBC1 & 0,879 \\
\hline
\end{tabular}

Extraction Method: Principal

Component Analysis.

a. 1 components extracted.

6. Năng lực bản thân cảm nhận

KMO and Bartlett's Test

\begin{tabular}{|c|c|c|}
\hline $\begin{array}{l}\text { Kaiser-Meyer-Olkin Measu } \\
\text { Adequacy. }\end{array}$ & of Sampling & 0,773 \\
\hline & Approx. Chi-Square & 394,688 \\
\hline Bartlett's Test of Sphericity & df & 10 \\
\hline & Sig. & 0,000 \\
\hline
\end{tabular}

\begin{tabular}{|l|r|r|}
\hline \multicolumn{3}{|c}{ Communalities } \\
\hline & \multicolumn{1}{|c|}{ Initial } & Extraction \\
\hline CBP1 & 1,000 & 0,662 \\
CBP2 & 1,000 & 0,746 \\
CBP3 & 1,000 & 0,405 \\
CBP4 & 1,000 & 0,408 \\
CBP5 & 1,000 & 0,671 \\
\hline
\end{tabular}

Extraction Method: Principal Component

Analysis.

Total Variance Explained

\begin{tabular}{|l|c|c|}
\hline Component & Initial Eigenvalues & $\begin{array}{c}\text { Extraction Sums of Squared } \\
\text { Loadings }\end{array}$ \\
\hline
\end{tabular}




\begin{tabular}{|l|r|r|r|r|r|r|}
\hline & Total & $\begin{array}{c}\text { \% of } \\
\text { Variance }\end{array}$ & $\begin{array}{c}\text { Cumulative } \\
\text { \% }\end{array}$ & Total & $\begin{array}{c}\text { \% of } \\
\text { Variance }\end{array}$ & $\begin{array}{c}\text { Cumulative } \\
\text { \% }\end{array}$ \\
\hline 1 & 2,892 & 57,845 & 57,845 & 2,892 & 57,845 & 57,845 \\
2 & 0,851 & 17,015 & 74,860 & & & \\
4 & 0,580 & 11,592 & 86,452 & & & \\
5 & 0,444 & 8,874 & 95,326 & & & \\
\hline
\end{tabular}

Extraction Method: Principal Component Analysis.

Component Matrix ${ }^{\mathrm{a}}$

\begin{tabular}{|l|r|}
\hline & Component \\
\cline { 2 - 2 } & 1 \\
\hline CBP2 & 0,864 \\
CBP5 & 0,819 \\
CBP1 & 0,813 \\
CBP4 & 0,639 \\
CBP3 & 0,636 \\
\hline
\end{tabular}

Extraction Method: Principal

Component Analysis.

a. 1 components extracted.

III. Kết quả đánh giá khác biệt giữa giới tính với ý định khởi nghiệp: kiểm định t, phân tích phương sai, kiểm định hậu định

Nhóm giới tính

Group Statistics

\begin{tabular}{|r|l|r|r|r|r|}
\hline & Giới tính & N & Mean & Std. Deviation & Std. Error Mean \\
\hline \multirow{2}{*}{ INT } & 1 & 74 & 3,6847 & 0,86693 & 0,10078 \\
& 2 & 0 & & & \\
\hline
\end{tabular}

a. $t$ cannot be computed because at least one of the groups is empty.

IV. Kết quả đánh giá giá trị phân biệt

\section{Descriptive Statistics}

\begin{tabular}{|l|r|r|r|}
\hline & Mean & Std. Deviation & \multicolumn{1}{|c|}{ N } \\
\hline INT & 3,5952 & 0,82342 & 210 \\
ATT & 3,7500 & 0,77837 & 210 \\
NBL & 2,6413 & 0,88666 & 210 \\
PBC & 3,2702 & 0,85133 & 210 \\
BBE & 3,9143 & 0,72698 & 210 \\
CBP & 3,1381 & 0,76238 & 210 \\
\hline
\end{tabular}

Correlations

\begin{tabular}{|ll|r|r|r|r|r|r|}
\hline & \multicolumn{1}{|c|}{ INT } & ATT & NBL & PBC & \multicolumn{1}{c|}{ BBE } & \multicolumn{1}{c|}{ CBP } \\
\hline \multirow{4}{*}{ INT } & Pearson Correlation & 1 & $0,354^{* *}$ & $0,381^{* *}$ & $0,682^{* *}$ & $0,396^{* *}$ & $0,435^{* *}$ \\
& Sig. (2-tailed) & & 0,000 & 0,000 & 0,000 & 0,000 & 0,000 \\
& N & 210 & 210 & 210 & 210 & 210 & 210
\end{tabular}




\begin{tabular}{|ll|r|r|r|r|r|r|} 
& Pearson Correlation & $0,354^{* *}$ & 1 & $0,266^{* *}$ &, $417^{* *}$ & $0,412^{* *}$ & $0,274^{* *}$ \\
ATT & Sig. (2-tailed) & 0,000 & & 0,000 &, 000 & 0,000 & 0,000 \\
& N & 210 & 210 & 210 & 210 & 210 & 210 \\
& Pearson Correlation & $0,381^{* * *}$ & $0,266^{* *}$ & 1 & $0,401^{* *}$ & $0,177^{*}$ & $0,378^{* *}$ \\
NBL & Sig. (2-tailed) & 0,000 & 0,000 & & 0,000 & 0,010 & 0,000 \\
& N & 210 & 210 & 210 & 210 & 210 & 210 \\
& Pearson Correlation & $0,682^{* *}$ & $0,417^{* *}$ & $0,401^{* *}$ & 1 & $0,416^{* *}$ & $0,592^{* *}$ \\
PBC & Sig. (2-tailed) & 0,000 & 0,000 & 0,000 & & 0,000 & 0,000 \\
& N & 210 & 210 & 210 & 210 & 210 & 210 \\
& Pearson Correlation & $0,396^{* *}$ & $0,412^{* *}$ & $0,177^{*}$ & $0,416^{* *}$ & 1 & $0,286^{* *}$ \\
BBE & Sig. (2-tailed) &, 000 & 0,000 & 0,010 & 0,000 & & 0,000 \\
& N & 210 & 210 & 210 & 210 & 210 & 210 \\
& Pearson Correlation & $0,435^{* *}$ & $0,274^{* *}$ & $0,378^{* *}$ & $0,592^{* *}$ & $0,286^{* *}$ & 1 \\
CBP & Sig. (2-tailed) & 0,000 & 0,000 & 0,000 & 0,000 & 0,000 & \\
& N & 210 & 210 & 210 & 210 & 210 & 210 \\
\hline
\end{tabular}

**. Correlation is significant at the 0.01 level (2-tailed).

*. Correlation is significant at the 0.05 level (2-tailed).

V. Kết quả đánh giá hồi quy

1. Biến phụ thuộc: Ý định khởi nghiệp

Variables Entered/Removed $^{\text {a }}$

\begin{tabular}{|l|l|l|l|}
\hline $\begin{array}{l}\text { Mode } \\
\mathbf{l}\end{array}$ & \multicolumn{1}{|c|}{$\begin{array}{c}\text { Variables } \\
\text { Entered }\end{array}$} & $\begin{array}{c}\text { Variables } \\
\text { Removed }\end{array}$ & \multicolumn{1}{|c|}{ Method } \\
\hline 1 & $\begin{array}{l}\text { PBC, NBL, } \\
\text { ATT }^{\mathrm{b}}\end{array}$ & & Enter \\
\hline
\end{tabular}

a. Dependent Variable: INT

b. All requested variables entered.

Model Summary

\begin{tabular}{|l|c|r|r|r|}
\hline $\begin{array}{l}\text { Mode } \\
\mathbf{l}\end{array}$ & $\mathbf{R}$ & R Square & $\begin{array}{r}\text { Adjuste } \\
\mathbf{d} \text { R } \\
\text { Square }\end{array}$ & $\begin{array}{r}\text { Std. Error of } \\
\text { the Estimate }\end{array}$ \\
\hline 1 & 0,695 & 0,483 & 0,476 & 0,59613 \\
\hline
\end{tabular}

a. Predictors: (Constant), PBC, NBL, ATT

ANOVA $^{\mathrm{a}}$

\begin{tabular}{|c|c|c|c|c|c|c|}
\hline \multicolumn{2}{|c|}{ Model } & $\begin{array}{l}\text { Sum of } \\
\text { Squares }\end{array}$ & df & Mean Square & $\mathbf{F}$ & Sig. \\
\hline \multirow{3}{*}{1} & Regression & 68,499 & 3 & \multirow[t]{3}{*}{22,833} & 64,25 & \multirow[t]{3}{*}{$0,000^{\mathrm{b}}$} \\
\hline & Residual & 73,207 & $\begin{array}{r}20 \\
6\end{array}$ & & & \\
\hline & Total & 141,706 & $\begin{array}{r}20 \\
9\end{array}$ & & & \\
\hline
\end{tabular}


a. Dependent Variable: INT

b. Predictors: (Constant), PBC, NBL, ATT

Coefficients $^{\mathbf{a}}$

\begin{tabular}{|c|c|c|c|c|c|c|c|}
\hline \multirow[t]{2}{*}{ Model } & \multicolumn{2}{|c|}{$\begin{array}{c}\text { Unstandardized } \\
\text { Coefficients } \\
\end{array}$} & \multirow{2}{*}{$\begin{array}{c}\text { Standardized } \\
\text { Coefficients }\end{array}$} & \multirow[t]{2}{*}{$\mathbf{t}$} & \multirow[t]{2}{*}{ Sig. } & \multicolumn{2}{|c|}{$\begin{array}{c}\text { Collinearity } \\
\text { Statistics } \\
\end{array}$} \\
\hline & B & $\begin{array}{l}\text { Std. } \\
\text { Error }\end{array}$ & & & & $\begin{array}{c}\text { Toleran } \\
\text { ce }\end{array}$ & VIF \\
\hline $\begin{array}{l}\text { (Constant } \\
\text { ) }\end{array}$ & 1,111 & 0,224 & & 4,949 & $\begin{array}{r}0,00 \\
0\end{array}$ & & \\
\hline ATT & 0,073 & 0,059 & 0,069 & 1,250 & & 0,814 & $\begin{array}{r}1,22 \\
8\end{array}$ \\
\hline NBL & 0,112 & 0,051 & 0,120 & 2,188 & $\begin{array}{r}0,03 \\
0\end{array}$ & 0,828 & $\begin{array}{r}1,20 \\
8\end{array}$ \\
\hline PBC & 0,585 & 0,056 & 0,605 & $\begin{array}{r}10,36 \\
4\end{array}$ & $\begin{array}{r}0,00 \\
0\end{array}$ & 0,735 & $\begin{array}{r}1,36 \\
0\end{array}$ \\
\hline
\end{tabular}

a. Dependent Variable: INT

Collinearity Diagnostics ${ }^{a}$

\begin{tabular}{|c|c|c|c|c|c|c|c|}
\hline \multirow[t]{2}{*}{ Model } & \multirow{2}{*}{$\begin{array}{l}\text { Dimensio } \\
\text { n }\end{array}$} & \multirow{2}{*}{$\begin{array}{c}\text { Eigenval } \\
\text { ue }\end{array}$} & \multirow{2}{*}{$\begin{array}{c}\text { Condition } \\
\text { Index }\end{array}$} & \multicolumn{4}{|c|}{ Variance Proportions } \\
\hline & & & & $\begin{array}{c}\text { (Constan } \\
\text { t) }\end{array}$ & ATT & NBL & $\begin{array}{c}\text { PB } \\
\text { C }\end{array}$ \\
\hline \multirow{4}{*}{1} & 1 & 3,880 & 1,000 & 0,00 & 0,00 & 0,01 & 0,00 \\
\hline & 2 & 0,065 & 7,736 & 0,05 & 0,07 & 0,95 & 0,02 \\
\hline & 3 & 0,034 & 10,608 & 0,16 & 0,09 & 0,04 & 0,97 \\
\hline & 4 & 0,021 & 13,710 & 0,78 & 0,83 & 0,01 & 0,01 \\
\hline
\end{tabular}

a. Dependent Variable: INT

2. Biến phụ thuộc: Thái độ với khởi nghiệp

Variables Entered/Removed ${ }^{\text {a }}$

\begin{tabular}{|l|l|l|l|}
\hline $\begin{array}{l}\text { Mode } \\
1\end{array}$ & $\begin{array}{c}\text { Variables } \\
\text { Entered }\end{array}$ & $\begin{array}{c}\text { Variables } \\
\text { Removed }\end{array}$ & Method \\
\hline 1 & BBE, NBL & & \\
\hline
\end{tabular}

a. Dependent Variable: ATT

b. All requested variables entered.

Model Summary

\begin{tabular}{|l|c|r|r|r|}
\hline $\begin{array}{l}\text { Mode } \\
\mathbf{l}\end{array}$ & $\mathbf{R}$ & R Square & \multicolumn{1}{|c|}{$\begin{array}{c}\text { Adjuste } \\
\mathbf{d} \text { R } \\
\text { Square }\end{array}$} & $\begin{array}{r}\text { Std. Error of } \\
\text { the Estimate }\end{array}$ \\
\hline 1 & 0,456 \\
$\mathrm{a}$ & 0,208 & 0,201 & 0,69593 \\
\hline
\end{tabular}

a. Predictors: (Constant), BVV, NBL

ANOVA $^{\mathrm{a}}$

\begin{tabular}{|l|c|c|c|c|c|}
\hline Model & $\begin{array}{c}\text { Sum of } \\
\text { Squares }\end{array}$ & df & Mean Square & F & Sig. \\
\hline
\end{tabular}




\begin{tabular}{|c|c|c|c|c|c|c|}
\hline & Regression & 26,370 & 2 & 13,185 & $\begin{array}{r}27,22 \\
4\end{array}$ & $0,000^{\mathrm{b}}$ \\
\hline 1 & Residual & 100,255 & $\begin{array}{r}20 \\
7\end{array}$ & 0,484 & & \\
\hline & Total & 126,625 & $\begin{array}{r}20 \\
9\end{array}$ & & & \\
\hline
\end{tabular}

a. Dependent Variable: ATT

b. Predictors: (Constant), BVV, NBL

Coefficients $^{\mathbf{a}}$

\begin{tabular}{|c|c|c|c|c|c|c|c|}
\hline \multirow[t]{2}{*}{ Model } & \multicolumn{2}{|c|}{$\begin{array}{c}\text { Unstandardized } \\
\text { Coefficients } \\
\end{array}$} & \multirow{2}{*}{$\begin{array}{c}\text { Standardized } \\
\text { Coefficients }\end{array}$} & \multirow[t]{2}{*}{$\mathbf{t}$} & \multirow[t]{2}{*}{ Sig. } & \multicolumn{2}{|c|}{$\begin{array}{c}\text { Collinearity } \\
\text { Statistics } \\
\end{array}$} \\
\hline & B & $\begin{array}{l}\text { Std. } \\
\text { Error }\end{array}$ & & & & $\begin{array}{c}\text { Toleran } \\
\text { ce }\end{array}$ & VIF \\
\hline (Constant & 1,709 & 0,282 & & $\begin{array}{r}6,06 \\
9\end{array}$ & $\begin{array}{r}0,00 \\
0\end{array}$ & & \\
\hline NBL & 0,175 & 0,055 & 0,199 & $\begin{array}{r}3,16 \\
6\end{array}$ & $\begin{array}{r}0,00 \\
2\end{array}$ & 0,969 & $\begin{array}{r}1,03 \\
2\end{array}$ \\
\hline $\mathrm{BBE}$ & 0,404 & 0,067 & 0,377 & $\begin{array}{r}5,99 \\
9\end{array}$ & $\begin{array}{r}0,00 \\
0\end{array}$ & 0,969 & $\begin{array}{r}1,03 \\
2\end{array}$ \\
\hline
\end{tabular}

a. Dependent Variable: ATT

Collinearity Diagnostics ${ }^{\mathrm{a}}$

\begin{tabular}{|c|c|c|c|c|c|c|}
\hline \multirow[t]{2}{*}{ Model } & \multirow{2}{*}{$\begin{array}{l}\text { Dimensio } \\
\text { n }\end{array}$} & \multirow{2}{*}{$\begin{array}{c}\text { Eigenval } \\
\text { ue }\end{array}$} & \multirow{2}{*}{$\begin{array}{l}\text { Condition } \\
\text { Index }\end{array}$} & \multicolumn{3}{|c|}{ Variance Proportions } \\
\hline & & & & $\begin{array}{c}\text { (Constan } \\
\text { t) }\end{array}$ & NBL & BVV \\
\hline \multirow{3}{*}{1} & 1 & 2,916 & 1,000 & 0,00 & 0,01 & 0,00 \\
\hline & 2 & 0,067 & 6,584 & 0,06 & 0,97 & 0,10 \\
\hline & 3 & 0,017 & 13,285 & 0,94 & 0,02 & 0,90 \\
\hline
\end{tabular}

a. Dependent Variable: ATT

3. Biến phụ thuộc: Nhận thức kiểm soát hành vi

\begin{tabular}{|l|c|c|c|}
\hline \multicolumn{4}{|c|}{ Variables Entered/Removed $^{\mathrm{a}}$} \\
\hline $\begin{array}{l}\text { Mode } \\
\mathbf{l}\end{array}$ & $\begin{array}{c}\text { Variables } \\
\text { Entered }\end{array}$ & $\begin{array}{c}\text { Variables } \\
\text { Removed }\end{array}$ & \multicolumn{1}{|c|}{ Method } \\
\hline 1 & $\mathrm{CBP}, \mathrm{NBL}^{\mathrm{b}}$ & & Enter \\
\hline
\end{tabular}

a. Dependent Variable: PBC

b. All requested variables entered.

Model Summary

\begin{tabular}{|l|c|r|r|r|}
\hline $\begin{array}{l}\text { Mode } \\
\mathbf{l}\end{array}$ & $\mathbf{R}$ & \multicolumn{1}{|c|}{ R Square } & $\begin{array}{r}\text { Adjuste } \\
\mathbf{d} \text { R } \\
\text { Square }\end{array}$ & $\begin{array}{r}\text { Std. Error of } \\
\text { the Estimate }\end{array}$ \\
\hline 1 & 0,622 \\
$\mathrm{a}$ & 0,387 & 0,381 & 0,66997 \\
\hline
\end{tabular}

a. Predictors: (Constant), CBP, NBL 
ANOVA ${ }^{\mathrm{a}}$

\begin{tabular}{|c|c|c|c|c|c|}
\hline Model & $\begin{array}{c}\text { Sum of } \\
\text { Squares }\end{array}$ & df & Mean Square & $\mathbf{F}$ & Sig. \\
\hline Regression & 58,562 & 2 & 29,281 & $\begin{array}{r}65,23 \\
4\end{array}$ & $0,000^{b}$ \\
\hline Residual & 92,914 & $\begin{array}{r}20 \\
7\end{array}$ & 0,449 & & \\
\hline Total & 151,476 & $\begin{array}{r}20 \\
9\end{array}$ & & & \\
\hline
\end{tabular}

a. Dependent Variable: PBC

b. Predictors: (Constant), CBP, NBL

Coefficients $^{\mathbf{a}}$

\begin{tabular}{|c|c|c|c|c|c|c|c|}
\hline \multirow[t]{2}{*}{ Model } & \multicolumn{2}{|c|}{$\begin{array}{c}\text { Unstandardized } \\
\text { Coefficients }\end{array}$} & \multirow{2}{*}{$\begin{array}{c}\begin{array}{c}\text { Standardized } \\
\text { Coefficients }\end{array} \\
\text { Beta }\end{array}$} & \multirow[t]{2}{*}{$\mathbf{t}$} & \multirow[t]{2}{*}{ Sig. } & \multicolumn{2}{|c|}{$\begin{array}{c}\text { Collinearity } \\
\text { Statistics } \\
\end{array}$} \\
\hline & B & $\begin{array}{l}\text { Std. } \\
\text { Error }\end{array}$ & & & & $\begin{array}{c}\text { Toleran } \\
\text { ce }\end{array}$ & VIF \\
\hline (Constant & 0,947 & 0,209 & & $\begin{array}{r}4,53 \\
4\end{array}$ & $\begin{array}{r}0,00 \\
0\end{array}$ & & \\
\hline NBL & 0,198 & 0,056 & 0,206 & $\begin{array}{r}3,51 \\
0\end{array}$ & $\begin{array}{r}0,00 \\
1\end{array}$ & 0,857 & $\begin{array}{r}1,16 \\
7\end{array}$ \\
\hline CBP & 0,574 & 0,066 & 0,514 & $\begin{array}{r}8,73 \\
6\end{array}$ & $\begin{array}{r}0,00 \\
0\end{array}$ & 0,857 & $\begin{array}{r}1,16 \\
7\end{array}$ \\
\hline
\end{tabular}

a. Dependent Variable: PBC

Collinearity Diagnostics ${ }^{\mathrm{a}}$

\begin{tabular}{|ll|r|r|r|r|r|}
\hline Model & Dimensio & \multirow{2}{*}{$\begin{array}{c}\text { Eigenval } \\
\text { ue }\end{array}$} & \multirow{2}{*}{$\begin{array}{c}\text { Condition } \\
\text { Index }\end{array}$} & & \multicolumn{3}{|c|}{ Variance Proportions } \\
\cline { 5 - 7 } & & & & $\begin{array}{c}\text { (Constan } \\
\mathbf{t})\end{array}$ & NBL & CBP \\
\hline \multirow{3}{*}{1} & 1 & 2,913 & 1,000 & 0,01 & 0,01 & 0,01 \\
& 2 & 0,059 & 7,053 & 0,15 & 0,99 & 0,12 \\
& 3 & 0,028 & 10,181 & 0,84 & 0,00 & 0,87 \\
\hline
\end{tabular}

a. Dependent Variable: PBC

\section{REFERENCES}

Ahl, H. (2006). Why research on women entrepreneurs needs new directions?. Entrepreneurship Theory Practice, 3(5), 595-621.

Ajzen, I. (1987). Attitudes, traits, and actions: Dispositional prediction of behavior in personality and social psychology. Advances in Experimental Social Psychology, 20, 163, DOI: 10.1016/S0065-2601(08)60411-6. 
Ajzen, I. (1991). The theory of planned behavior. Organizational Behavior and Human Decision Processes, 50(2), 179-211, DOI: 10.1016/0749-5978(91)90020-T.

Ajzen, I. (2002). Perceived behavioral control, self-efficacy, locus of control, and the theory of planned behavior. Journal of Applied Social Psychology, 32(4), 665-683, DOI: 10.1111/j.1559-1816.2002.tb00236.x.

Armitage, C. J., \& Conner, M. (2001). Efficacy of the theory of planned behaviour: A metaanalytic review. British Journal of Social Psychology, 40(4), 471-499.

Bandura, A. (1986). The social foundations of thought and action. Englewood Cliffs, NJ: Prentice-Hall.

Bird, B. (1988). Implementing entrepreneurial ideas: The case for intention. Academy of Management Review, 13(3), 442-453.

Bosma, N., \& Levie, J. (2009). Global Entrepreneurship Monitor 2009 Global Report. London, U.K.: Global Entrepreneurship Research Association.

Bosma, N., Acs, Z. J., Autio, E., Coduras, A., \& Levie, J. (2008). Global Entrepreneurship Monitor 2008 Global Report. London, U.K.: Global Entrepreneurship Research Association.

Bosma, N., Jones, K., Autio, E., \& Levie, J. (2007). Global Entrepreneurship Monitor 2007 Global Report. London, U.K.: Global Entrepreneurship Research Association.

Brockhaus, R., \& Horwitz, P. (1986). Psychology of the entrepreneur. In D. Sexton and R. Smilor (eds.), The Art and Science of Entrepreneurship (pp.25-48). Cambridge, MA: Ballinger.

Crant, M. (1996). The proactive personality scale as a predictor of entrepreneurial intentions. Journal of Small Business Management, 34(3), 42-49.

Davidsson, P. (1995). Culture, structure and regional levels of entrepreneurship. Entrepreneurship \& Regional Development, 7(1), 41-62.

Duy, B. H. T., Lin, L. T., Duyên, Đ. T. X., \& Hiền, N. T. (2011). Nghiên cứu ảnh hưởng của các yếu tố tính cách cá nhân lên tiềm năng khởi nghiệp của sinh viên. Tạp chí phát triển khoa học và công nghệ, 14(Q3), 68-82.

Fisbein, M. \& Ajzen, I. (2011). Predicting and changing behavior the reasoned action approach. New York, NY: Psychology Press.

Hackett, G., Betz, N., Casas, J., and Rocha-Singh, I. (1992). Gender, ethnicity, and social cognitive factors predicting achievement. Journal of Counseling Psychology, 39(4), 527-538, DOI:10.1037/0022-0167.39.4.527.

Hisrich, R. D., Peters, M. P., \& Shepherd, D. A. (2013). Entrepreneurship (9th ed.). New Yor, NY: McGraw Hill. 
Hoang, V. Q., \& Dung, T. T. (2009). The cultural dimensions of the Vietnamese private entrepreneurship. IUP Journal of Entrepreneurship Development, VI(3-4), 54-78.

Jack, S. L., \& Anderson, A. R. (2002). The effects of embeddedness on the entrepreneurial process. Journal of business Venturing, 17(5), 467-487, DOI: 10.1016/S08839026(01)00076-3.

Kelly, D. J., Bosma, N., \& Amóros, J. E. (2010). Global Entrepreneurship Monitor 2010 Global Report. London, U.K.: Global Entrepreneurship Research Association.

Kibler, E., Kautonen, T., \& Fink, M. (2014). Regional social legitimacy of entrepreneurship: Implications for entrepreneurial intention and start-up behaviour. Regional Studies, 48(6), 995-1015.

Kolvereid, L. (1996). Prediction of employment status choice intentions. Entrepreneurship Theory and practice, 21(1), 47-58.

Kolvereid, L., \& Isaksen, E. (2006). New business start-up and subsequent entry into selfemployment. Journal of Business Venturing, 21(6), 866-885.

Kolvereid, L., \& Moen, O. (1997). Entrepreneurship among business graduates: does a major in entrepreneurship make a difference?. Journal of European Industrial Training, 21(4), 154-160.

Kourilsky, M., \& Walstad, M. (1998). Entrepreneurship and female youth: Knowledge, attitudes, gender differences and educational practices. Journal of Business Venturing, 13(1), 77-88.

Krueger, N. F., Reilly, M. D., \& Carsrud, A. L. (2000). Competing models of entrepreneurial intentions. Journal of Business Venturing, 15(5-6), 411-432, DOI: 10.1016/S08839026(98)00033-0.

Kwong, C., Evans, D. J., \& Brooksbank, D. (2006). The state of graduate entrepreneurship in the UK-Preliminary Policy Paper Based on GEM 2005 data (GEM Wales Working Paper Series). United Kingdom.

La, V. P., \& Vuong, Q. H. (2019). bayesvl: Visually Learning the Graphical Structure of Bayesian Networks and Performing MCMC with 'Stan'. The Comprehensive R Archive Network (CRAN): <https://cran.r-project.org/web/packages/bayesvl/index.html>; version 0.8.5 (May 24, 2019).

Maes, J., Leroy, H., \& Sels, L. (2014). Gender differences in entrepreneurial intentions: A TPB multi-group analysis at factor and indicator level. European Management Journal, 32(5), 784-794, DOI: 10.1016/j.emj.2014.01.001.

Phạm, M. C., \& Vương, Q. H. (2009). Kinh tế Việt Nam - Thăng trầm và đột phá. Hà Nội, Việt Nam: NXB Chính trị Quốc gia. 
Raijman, R (2001). Determinants of entrepreneurial intentions: Mexican immigrants in Chicago. Journal of Socio-Economics, 30(5), 393-411.

Shapero A. (1982). Social Dimensions of Entrepreneurship. In C. Kent, D. Sexton and K. Vesper (eds.). The Encyclopedia of Entrepreneurship (pp.72-90). Englewood Cliffs, NJ: Prentice Hall.

Technovation, 24(2), 163-172.

VCCI. (2015). Báo cáo chỉ số khởi nghiệp Việt Nam 2014. Hà Nội, Việt Nam: NXB Thông tấn VCCI. (2016a). Báo cáo chỉ số khởi nghiệp Việt Nam 2015/16, chủ đề năm: Hoạt động kinh doanh xã hội. Hà Nội, Việt Nam: NXB Giao thông vận tải.

VCCI. (2016b). Nghịch lý doanh nghiệp vừa và nhỏ. Phòng Thuoong mại và Công nghiệp Việt Nam. Retrieved from http://m.vcci.com.vn/nghi\%CC\%A3ch-ly\%CC\%81-voi-doanhnghie\%CC\%A3p-vu\%CC\%80a-va\%CC\%80-nho\%CC\%89 (Truy cập 03-06-2019).

Veciana, J. M., Aponte, M., \& Urbano, D. (2005). University students' attitudes towards entrepreneurship: A two countries comparison. International Entrepreneurship and Management Journal, 1(2), 165-182.

Vương, Q. H. (2007). Văn minh làm giàu \& Nguồn gốc của cải. Hà Nội, Việt Nam: NXB Chính trị Quốc gia.

Vuong, Q. H. (2018). The (ir)rational consideration of the cost of science in transition economies. Nature Human Behaviour, 2(1), 5, DOI: 10.1038/s41562-017-0281-4.

Vuong, Q. H. (2019). Computational entrepreneurship: From economic complexities to interdisciplinary research. Problems and Perspectives in Management, 17(1), 117-129, DOI:10.21511/ppm.17(1).2019.11.

Vuong, Q. H., Ho, M. T., Nguyen, H. K. T., Vuong, T. T., Tran, K., \& Ho, M. T.. (2018). "Paintings can be forged, but not feeling": Vietnamese art-Market, fraud, and value. Arts, 7(4), 62, https://doi.org/10.3390/arts7040062.

Vuong, Q. H., La, V. P. (2019). BayesVL package for Bayesian statistical analyses in R. Github: <https://github.com/sshpa/bayesvl > v0.8.5; DOI:10.31219/osf.io/ya9u6.

Vuong, Q. H., La, V. P., Vuong, T. T., Nguyen, V. H., Ho, M. T., Nguyen, T. H. K., Bui, Q. K., \& Ho, M. T.. (2018). Cultural additivity: Behavioural insights from the interaction of Confucianism, Buddhism, and Taoism in folktales. Palgrave Communications, 4 , 143, DOI: $10.1057 / \mathrm{s} 41599-018-0189-2$.

Wang, C., \& Wong, P. (2004). Entrepreneurial interest of university students in Singapore.

Wilson, F., Kickul, J., \& Marlino, D. (2007). Gender, entrepreneurial self-efficacy, and entrepreneurial career intentions: Implications for entrepreneurship education. Entrepreneurship Theory and Practice, 31(3), 387-406. 
Xuân, A. (2018). Quý II-2018: Gần 127 nghìn cử nhân thất nghiệp. Nhân Dân. Retrieved from http://www.nhandan.com.vn/xahoi/item/37655102-quy-ii-2018-gan-127-nghin-cunhan-that-nghiep.html (Truy cập 04-06-2019). 